\title{
Variation in pancreatic cancer care in the Netherlands
}

Citation for published version (APA):

Bakens, M. J. A. M. (2019). Variation in pancreatic cancer care in the Netherlands. [Doctoral Thesis, Maastricht University]. Gildeprint Drukkerijen. https://doi.org/10.26481/dis.20190418mb

Document status and date:

Published: 01/01/2019

DOI:

10.26481/dis.20190418mb

Document Version:

Publisher's PDF, also known as Version of record

\section{Please check the document version of this publication:}

- A submitted manuscript is the version of the article upon submission and before peer-review. There can be important differences between the submitted version and the official published version of record.

People interested in the research are advised to contact the author for the final version of the publication, or visit the DOI to the publisher's website.

- The final author version and the galley proof are versions of the publication after peer review.

- The final published version features the final layout of the paper including the volume, issue and page numbers.

Link to publication

\footnotetext{
General rights rights.

- You may freely distribute the URL identifying the publication in the public portal. please follow below link for the End User Agreement:

www.umlib.nl/taverne-license

Take down policy

If you believe that this document breaches copyright please contact us at:

repository@maastrichtuniversity.nl

providing details and we will investigate your claim.
}

Copyright and moral rights for the publications made accessible in the public portal are retained by the authors and/or other copyright owners and it is a condition of accessing publications that users recognise and abide by the legal requirements associated with these

- Users may download and print one copy of any publication from the public portal for the purpose of private study or research.

- You may not further distribute the material or use it for any profit-making activity or commercial gain

If the publication is distributed under the terms of Article $25 \mathrm{fa}$ of the Dutch Copyright Act, indicated by the "Taverne" license above, 


\section{VARIATION IN PANCREATIC CANCER CARE IN THE NETHERLANDS}


The studies described in this thesis were supported by the Dutch Cancer Society [grant nr 2013-649]

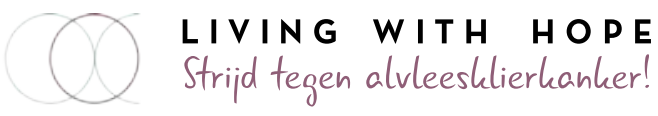

This thesis was accomplished with financial support from the department of Surgery (Catharina ziekenhuis Eindhoven), stichting wetenschappelijk onderzoek chirurgie (Catharina ziekenhuis Eindhoven), Stockx Oncology Stipendium (S.O.S.), Catharina ziekenhuis Eindhoven, Integraal Kankercentrum Nederland (IKNL), department of Surgery (Zuyderland Medisch centrum Heerlen/Sittard-Geleen), Maastricht University, Living with Hope foundation, Ipsen and Mylan Healthcare B.V.

\section{COLOFON}

Author:

M.J.A.M. Bakens

Cover design en lay-out: Miranda Dood, Mirakels Ontwerp

Printing:

Gildeprint - The Netherlands

ISBN:

978-90-9031596-6

Copyright @ M.J.A.M. Bakens, Maastricht 2019

All rights reserved. No part of this thesis may be reproduced or transmitted in any form or by any means without prior permission of the author, or when appropriate, of the publisher of the publications. 


\title{
VARIATION IN PANCREATIC CANCER CARE IN THE NETHERLANDS
}

\author{
Proefschrift \\ ter verkrijging van de graad van doctor aan de \\ Universiteit Maastricht, \\ op gezag van de Rector Magnificus,
}

Prof. dr. Rianne M. Letschert

volgens het besluit van het College van Decanen, in het openbaar te verdedigen op 18 april 2019

om 12.00 uur

door

Maikel Johannes Anna Maria Bakens

geboren op 16 november 1989

te Weert 


\section{PROMOTORES}

Prof. dr. I.H.J.T. de Hingh

Prof. dr. C.H.C. Dejong

Prof. dr. V.E.P.P. Lemmens

Erasmus Universiteit, Rotterdam

\section{BEOORDELINGSCOMMISSIE}

Prof. Dr. N.D. Bouvy (voorzitter)

Prof. Dr. N.L.U. van Meeteren

Prof. Dr. S. Siesling

Universiteit Twente, Enschede

Dr. J.H.M.B. Stoot

Zuyderland ziekenhuis, Heerlen - Sittard 



\section{TABLE OF CONTENTS}

CHAPTER $1 \quad$ General introduction 08

CHAPTER 2 Hospital of diagnosis and likelihood of surgical treatment for pancreatic cancer Br J Surg. 2015 Dec;102(13):1670-5.

CHAPTER 3 Evaluation of preoperative biliairy drainage in patients undergoing pancreatoduodenectomy for suspected pancreatic or periampullary cancer J Pancreas 2018 Jan 29; 19(1):1-6.

CHAPTER 4 The use of adjuvant chemotherapy for pancreatic cancer varies widely between hospitals: a nationwide populationbased analysis

Cancer Med. 2016 Oct;5(10):2825-2831

CHAPTER 5 Socio-economic status influences the likelihood of 66 undergoing surgical treatment for pancreatic cancer in the Netherlands HPB. 2017 May;19(5):443-448.

CHAPTER 6 Implementing an enhanced recovery program after pancreaticoduodenectomy in elderly patients: Is it feasible? World J Surg. 2015 Jan;39(1):251-8. 
CHAPTER 7 Low skeletal muscle radiation attenuation and visceral

adiposity are associated with overall survival and surgical

site infections in patients with pancreatic cancer

J Cachexia Sarcopenia Muscle. 2017 Apr;8(2):317-326.

CHAPTER 8 Summary and General Discussion

CHAPTER 9 Valorization

140

CHAPTER 10

Nederlandse samenvatting

CHAPTER 11 Appendices

Publications

154

Curriculum Vitae

157

Dankwoord

158 
Q 810

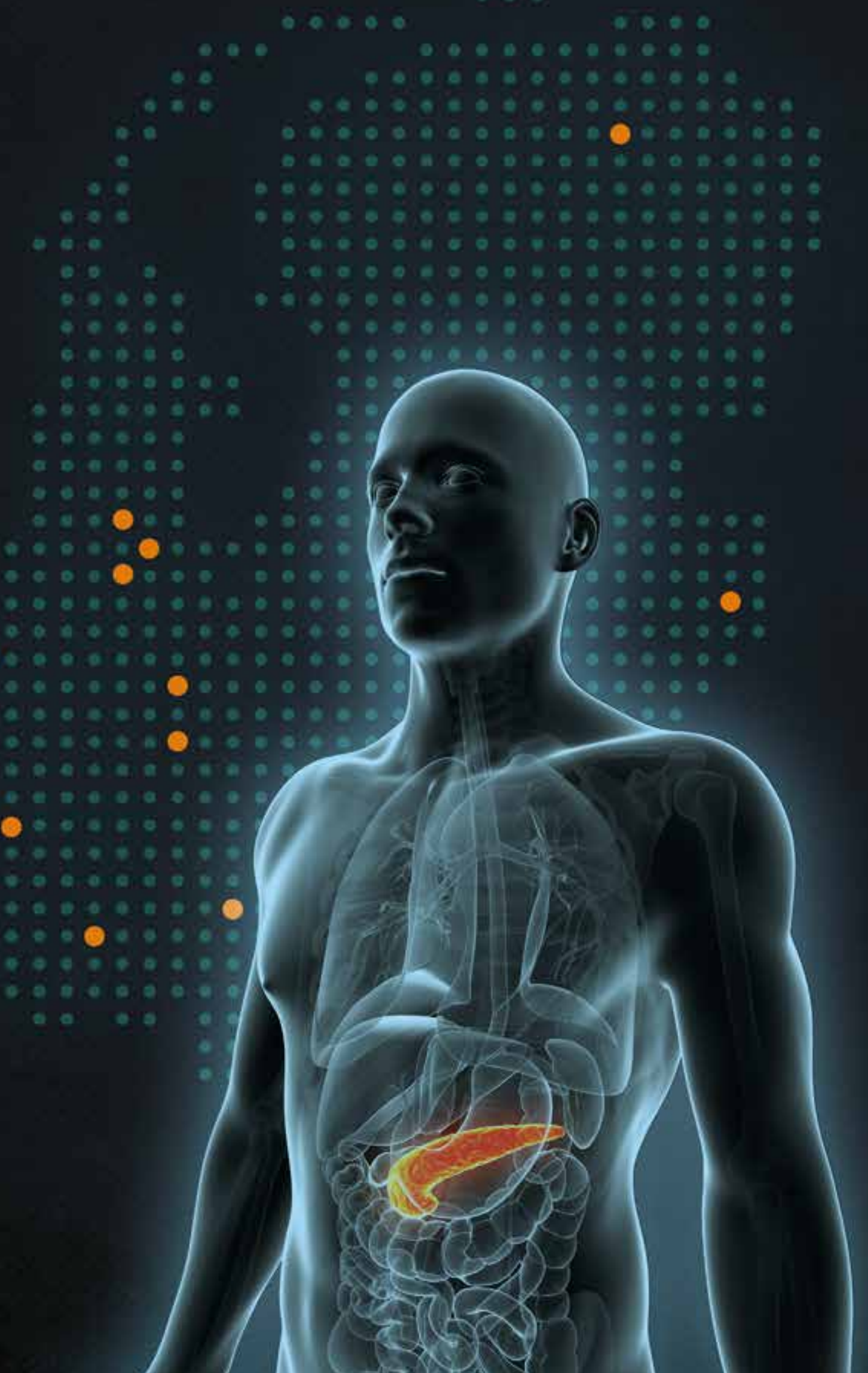

00080000000000000

0.00000000000000

0.000 .00 .0

0.0000000

$\ldots$

0000000000

Q

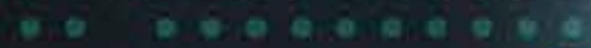

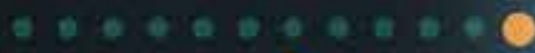

0.0000000008

0.000 .0 .00

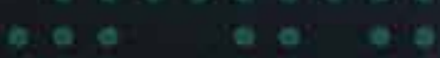

$\ldots$

a: 


\section{GENERAL INTRODUCTION}




\section{GENERAL INTRODUCTION}

The pancreas has a digestive and hormonal function and is named after the Greek words

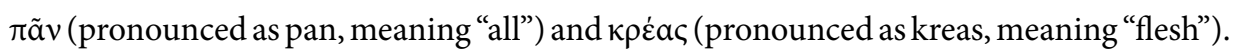
The pancreas is positioned retroperitoneally behind the stomach with the pancreatic head in the duodenal loop in front of the vena cava inferior. The uncinate process lies between the aorta and superior mesenteric artery and vein. The pancreatic neck has an anatomic position on top of the portal vein at the junction of the superior mesenteric and splenic vein. The pancreatic tail lies in front of the splenic vein. ${ }^{1}$

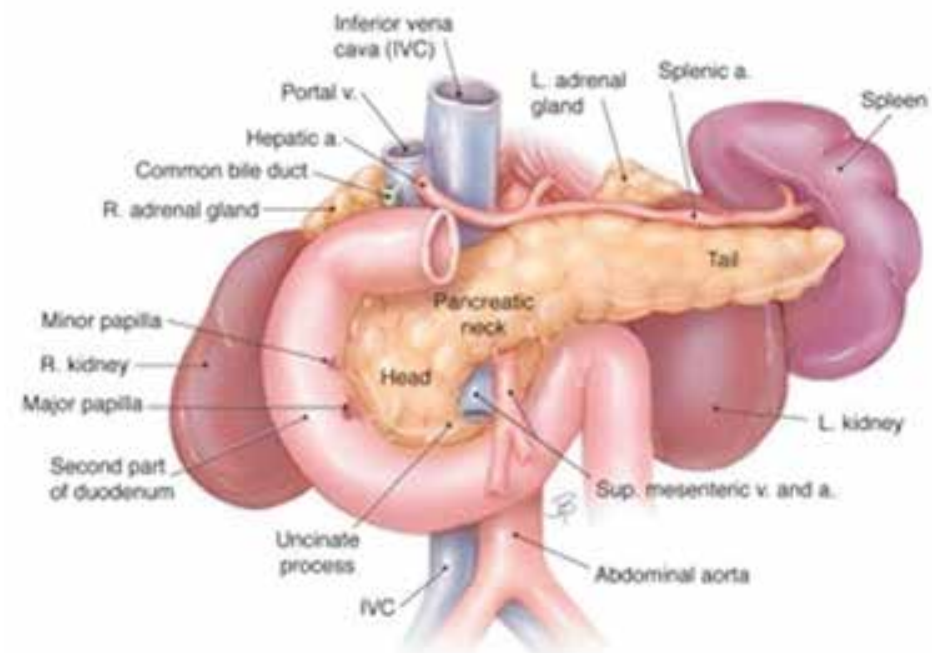

FIGURE 1. Anatomy of the pancreas. ${ }^{2}$

\section{PANCREATIC CANCER}

Pancreatic cancer represents about $2 \%$ of all cancer types in the Netherlands. ${ }^{3}$ Although this is not the most common type of cancer, pancreatic cancer is known as the fourth leading cause of cancer related death in Europe and the USA. One and five year survival 
rates are $24 \%$ and $7 \%$ respectively. ${ }^{4}$ About $94 \%$ of pancreatic cancers are exocrine tumors (mostly adenocarcinoma). The other $6 \%$ of pancreatic tumors are neuroendocrine tumors. $^{5}$

The incidence of pancreatic cancer increases with age. Most patients are between 60 and 80 years old when pancreatic cancer is diagnosed. The most frequent symptoms of pancreatic cancer are weight loss, jaundice and pain. Patients describe pain localized epigastrically typically radiating to the back. The pain often gets worse during nighttime. Jaundice in pancreatic cancer is the result of bile duct obstruction by the tumor.

The poor prognosis of pancreatic cancer is caused by the early occurrence of metastatic disease. This is present in $40 \%$ of the patients at the time of diagnosis and generally affects the liver, peritoneum and lungs. ${ }^{6-9}$

\section{STAGING}

Pancreatic cancer is staged using the Tumor Node Metastasis (TNM) classification. In the most recent edition, $\mathrm{T}$ stage is classified as $\mathrm{T} 1$ for tumors within the pancreas with a diameter not more than 2 centimeters. $\mathrm{T}$ stage is classified as T2 if the diameter is over 2 centimeters. T3 tumors are extending out of the pancreas without involvement of the coeliac trunc or superior mesenteric artery. If tumor involvement of these arteries is present, T-stage is classified as T4. If there are metastases in regional lymph nodes, tumors are staged as N1. In case of distant metastasis, tumors are classified as M1. ${ }^{10}$

\section{TREATMENT OF PANCREATIC CANCER}

Patients diagnosed with pancreatic cancer can undergo treatment with curative intent if they are diagnosed without systemic metastatic disease and without advanced vascular involvement of the celiac trunk or superior mesenteric artery (T1-3, N0-1, M0). Pancreatic tumors classified as T4 or M1 can not be treated with curative intent at this moment. ${ }^{10}$ The only potentially curative treatment is radical surgical resection, ideally followed by adjuvant chemotherapy. ${ }^{4,10}$

The surgical resection of a pancreatic head tumor is mostly done by a pancreatoduodenectomy (classical Whipple procedure) or a pylorus preserving pancreatoduodenectomy (PPPD). These are major surgical procedures with relatively high morbidity and mortality rates compared to other gastrointestinal procedures. ${ }^{4}$ 
Traditionally, preoperative biliary drainage was performed when patients presented with jaundice, because it was thought that elevated bilirubin levels resulted in more postoperative complications. ${ }^{11-13}$ However, a randomized controlled trial in the Netherlands showed that patients presenting with obstructive jaundice and bilirubin levels $<250 \mu \mathrm{mol} / \mathrm{l}$ had higher complication rates after preoperative biliary drainage compared to the early surgery group without biliary drainage (74\% versus $39 \%$ respectively).${ }^{14}$ Since the publication of these results, early surgery is the preferred treatment instead of preoperative biliary drainage in pancreatic cancer patients with preoperative jaundice. ${ }^{10}$

Unfortunately, patients who undergo a pancreatoduodenectomy still have a poor 5-year survival rate of only $10-20 \% .{ }^{4,10}$ To further improve 5-year survival in patients who underwent a pancreatoduodenectomy, adjuvant chemotherapy is currently standard of care since a randomized controlled trial showed a benefit in disease free and overall survival. ${ }^{10,15}$

Thus, in most patients with pancreatic cancer and resectable disease, the current optimal treatment consists of early surgery without preoperative biliary drainage followed by adjuvant chemotherapy treatment.

In the Netherlands, pancreatic surgery was not centralized before 2005. Surgical procedures were performed in almost all Dutch hospitals resulting in low numbers of procedures per year per center. Since 2005 pancreatic surgery was gradually centralized in high volume centers performing 20 or more procedures a year. Centralization of pancreatic surgery reduced postoperative morbidity and mortality considerably. ${ }^{16-20}$ As a result, centers not performing pancreatic surgery now refer patients for surgical treatment to high volume, specialized centers.

In contrast to the surgical procedure, staging and diagnostic processes in pancreatic cancer have not been centralized yet and are currently performed in most hospitals in the Netherlands. This means that decisions on resectable or non-resectable disease are made in both specialized and non-specialized centers. In fact, most patients are diagnosed, staged and discussed in non-specialized centers in the Netherlands. This is not only the case in patients with non-metastatic disease but also in patients with metastatic disease. Palliative chemotherapy is administered in specialized as well as non-specialized centers. ${ }^{21}$ 
In summary, specialized and non-specialized centers in the Netherlands perform diagnostic procedures and decide on resectability in patients with pancreatic cancer. Moreover, preoperative treatment such as biliary drainage and postoperative treatment with chemotherapy is provided in specialized as well as non-specialized centers. The surgical procedure is currently the only centralized care in pancreatic cancer.

\section{AIMS AND OUTLINES OF THE THESIS}

As a consequence of centralization, surgical treatment in pancreatic cancer care has been improved in recent years with currently low morbidity and mortality rates in specialized centers. ${ }^{16,18}$ The treatment of these patients typically requires a multi-disciplinary effort and also involves care in non-specialized centers, especially during the diagnostic phase and in the adjuvant setting.

This thesis focuses on variation in care for pancreatic cancer patients with resectable disease in the Netherlands. The main objectives of this thesis are to identify variation in preoperative, operative and postoperative treatment for potentially resectable disease in pancreatic cancer. In addition, possible reasons for variation in pancreatic cancer care were investigated.

As mentioned before, only surgical treatment is currently centralized in high-volume pancreatic centers in the Netherlands, defined as those centers performing over 20 procedures annually. Diagnosing and staging of pancreatic cancer is not centralized and is performed in all hospitals. This might cause a variation in the likelihood for referral and subsequent surgical treatment between centers of diagnosis. Furthermore, patient characteristics such as age might influence the likelihood for surgical treatment. In Chapter 2, the likelihood to undergo surgical treatment for pancreatic cancer in the Netherlands is investigated.

If a patient with pancreatic cancer and jaundice is selected for surgical treatment, early surgery without preoperative biliary drainage is preferred. ${ }^{14}$ Currently, the decision on the use of preoperative biliary drainage is made in both specialized as well as nonspecialized centers. In Chapter 3, the usage of preoperative biliary drainage is evaluated, mainly to identify a possible variation in preoperative biliary drainage between centers. 
The Dutch guidelines advise adjuvant chemotherapy after recovery from a pancreatoduodenectomy to prolong survival. ${ }^{10}$ In Chapter 4, the variation in adjuvant chemotherapy between pancreatic centers is studied. Furthermore, patient and tumor characteristics influencing the likelihood to be treated with adjuvant chemotherapy are investigated.

It is known that the accessibility of a health care system can influence the likelihood of surgical treatment and thereby cause a variation in treatment. In countries with a non-equally accessible health care system, patients with low socio-economic status were less likely to undergo complex oncological procedures compared to patients with a high socio-economic status. ${ }^{22,23}$ The Netherlands has an equally accessible health care system. To identify possible reasons for a variation in surgical treatment of pancreatic cancer, the effect of socio-economic status is studied in Chapter 5.

Furthermore, age might cause a variation in pancreatic cancer treatment. This might be explained by a more nihilistic approach to surgery in elderly patients. Postoperative outcomes might improve by optimizing perioperative care for elderly patients. A less nihilistic approach of surgeons for the elderly patient might be achieved by improving postoperative outcomes. In postoperative care, an Enhanced Recovery After Surgery (ERAS) program has already been proven to accelerate recovery and reduce hospital costs without compromising postoperative morbidity and mortality in young populations. ${ }^{24-26}$ In Chapter 6, the feasibility and safety of an ERAS program in elderly patients ( $\geq 70$ years) undergoing pancreatoduodenectomy is studied.

In deciding whether or not to refer a patient to a specialized center for surgery, prediction of postoperative outcomes based on patient characteristics might be helpful. Patient-related conditions such as cachexia are known to affect postoperative outcomes negatively. ${ }^{27}$ By performing calculations on computed tomography scans resulting in the muscle radiation attenuation, cachexia can be objectively determined. In Chapter 7 , the association of low muscle radiation attenuation with postoperative outcomes is studied to determine if the muscle radiation attenuation can be used as a tool in defining cachexia preoperatively. If cachexia can be defined preoperatively, patients more prone to postoperative complications can be recognized in a more early stage. Assessing the degree of cachexia before surgery might be an important tool to select patients fit enough for pancreatic surgery. 


\section{REFERENCES}

1. Kampoor VK. Medscape, Pancreas Anatomy 2015 [Available from: http://emedicine. medscape.com/article/1948885-overview - a2.

2. Longnecker DS. In: Pancreas AaHot, editor. 2014. p. Figure 3.

3. Nederlandse Kankerregistratie I. 2017 [Available from: http://www.cijfersoverkanker.nl.

4. Vincent A, Herman J, Schulick R, Hruban RH, Goggins M. Pancreatic cancer. Lancet. 2011;378(9791):607-20.

5. [Available from: https://www.pancan.org/facing-pancreatic-cancer/about-pancreatic-cancer/ types-of-pancreatic-cancer/.

6. Ferlay J, Steliarova-Foucher E, Lortet-Tieulent J, Rosso S, Coebergh JW, Comber H, et al. Cancer incidence and mortality patterns in Europe: estimates for 40 countries in 2012. Eur J Cancer. 2013;49(6):1374-403.

7. Hartwig W, Werner J, Jager D, Debus J, Buchler MW. Improvement of surgical results for pancreatic cancer. Lancet Oncol. 2013;14(11):e476-85.

8. Dewys WD, Begg C, Lavin PT, Band PR, Bennett JM, Bertino JR, et al. Prognostic effect of weight loss prior to chemotherapy in cancer patients. Eastern Cooperative Oncology Group. Am J Med. 1980;69(4):491-7.

9. Fearon K, Strasser F, Anker SD, Bosaeus I, Bruera E, Fainsinger RL, et al. Definition and classification of cancer cachexia: an international consensus. Lancet Oncol. 2011;12(5):489-95.

10. Oncoline. Pancreascarcinoom: Netherlands Comprehensive Cancer Organisation (IKNL); 2011 [updated 2011-08-22. Available from: http://www.oncoline.nl/pancreascarcinoom.

11. Katz SC, Ryan K, Ahmed N, Plitas G, Chaudhry UI, Kingham TP, et al. Obstructive jaundice expands intrahepatic regulatory $\mathrm{T}$ cells, which impair liver $\mathrm{T}$ lymphocyte function but modulate liver cholestasis and fibrosis. J Immunol. 2011;187(3):1150-6.

12. Kawarabayashi N, Seki S, Hatsuse $K$, Kinoshita M, Takigawa T, Tsujimoto H, et al. Immunosuppression in the livers of mice with obstructive jaundice participates in their susceptibility to bacterial infection and tumor metastasis. Shock. 2010;33(5):500-6.

13. Chowdhury AH, Camara M, Martinez-Pomares L, Zaitoun AM, Eremin O, Aithal GP, et al. Immune dysfunction in patients with obstructive jaundice before and after endoscopic retrograde cholangiopancreatography. Clin Sci (Lond). 2016;130(17):1535-44. 
14. van der Gaag NA, Rauws EA, van Eijck CH, Bruno MJ, van der Harst E, Kubben FJ, et al. Preoperative biliary drainage for cancer of the head of the pancreas. $N$ Engl J Med. 2010;362(2):129-37.

15. Oettle H, Neuhaus P, Hochhaus A, Hartmann JT, Gellert K, Ridwelski K, et al. Adjuvant chemotherapy with gemcitabine and long-term outcomes among patients with resected pancreatic cancer: the CONKO-001 randomized trial. JAMA. 2013;310(14):1473-81.

16. Lemmens VE, Bosscha K, van der Schelling G, Brenninkmeijer S, Coebergh JW, de Hingh $\mathrm{IH}$. Improving outcome for patients with pancreatic cancer through centralization. Br J Surg. 2011;98(10):1455-62.

17. de Wilde RF, Besselink MG, van der Tweel I, de Hingh IH, van Eijck CH, Dejong CH, et al. Impact of nationwide centralization of pancreaticoduodenectomy on hospital mortality. $\mathrm{Br} \mathrm{J}$ Surg. 2012;99(3):404-10.

18. Gooiker GA, Lemmens VE, Besselink MG, Busch OR, Bonsing BA, Molenaar IQ, et al. Impact of centralization of pancreatic cancer surgery on resection rates and survival. Br J Surg. 2014;101(8):1000-5.

19. van der Geest LG, Besselink MG, Busch OR, de Hingh IH, van Eijck CH, Dejong CH, et al. Elderly Patients Strongly Benefit from Centralization of Pancreatic Cancer Surgery: A Population-Based Study. Ann Surg Oncol. 2016;23(6):2002-9.

20. van der Geest LG, van Rijssen LB, Molenaar IQ, de Hingh IH, Groot Koerkamp B, Busch OR, et al. Volume-outcome relationships in pancreatoduodenectomy for cancer. HPB (Oxford). 2016;18(4):317-24.

21. Haj Mohammad N, Bernards N, Besselink MG, Busch OR, Wilmink JW, Creemers GJ, et al. Volume matters in the systemic treatment of metastatic pancreatic cancer: a population-based study in the Netherlands. J Cancer Res Clin Oncol. 2016;142(6):1353-60.

22. Sun $\mathrm{H}, \mathrm{Ma} H$, Hong G, Sun $\mathrm{H}$, Wang J. Survival improvement in patients with pancreatic cancer by decade: a period analysis of the SEER database, 1981-2010. Sci Rep. 2014;4:6747.

23. Seyedin S, Luu C, Stabile BE, Lee B. Effect of socioeconomic status on surgery for pancreatic adenocarcinoma. Am Surg. 2012;78(10):1128-31.

24. Balzano G, Zerbi A, Braga M, Rocchetti S, Beneduce AA, Di Carlo V. Fast-track recovery programme after pancreatico- duodenectomy reduces delayed gastric emptying. Br J Surg. 2008;95(11):1387-93. 
25. Porter GA, Pisters PW, Mansyur C, Bisanz A, Reyna K, Stanford P, et al. Cost and utilization impact of a clinical pathway for patients undergoing pancreaticoduodenectomy. Ann Surg Oncol. 2000;7(7):484-9.

26. Lassen K, Coolsen MM, Slim K, Carli F, de Aguilar-Nascimento JE, Schafer M, et al. Guidelines for perioperative care for pancreaticoduodenectomy: Enhanced Recovery After Surgery (ERAS(R)) Society recommendations. Clin Nutr. 2012;31(6):817-30.

27. Rollins KE, Tewari N, Ackner A, Awwad A, Madhusudan S, Macdonald IA, et al. The impact of sarcopenia and myosteatosis on outcomes of unresectable pancreatic cancer or distal cholangiocarcinoma. Clin Nutr. 2016;35(5):1103-9. 
Q 810

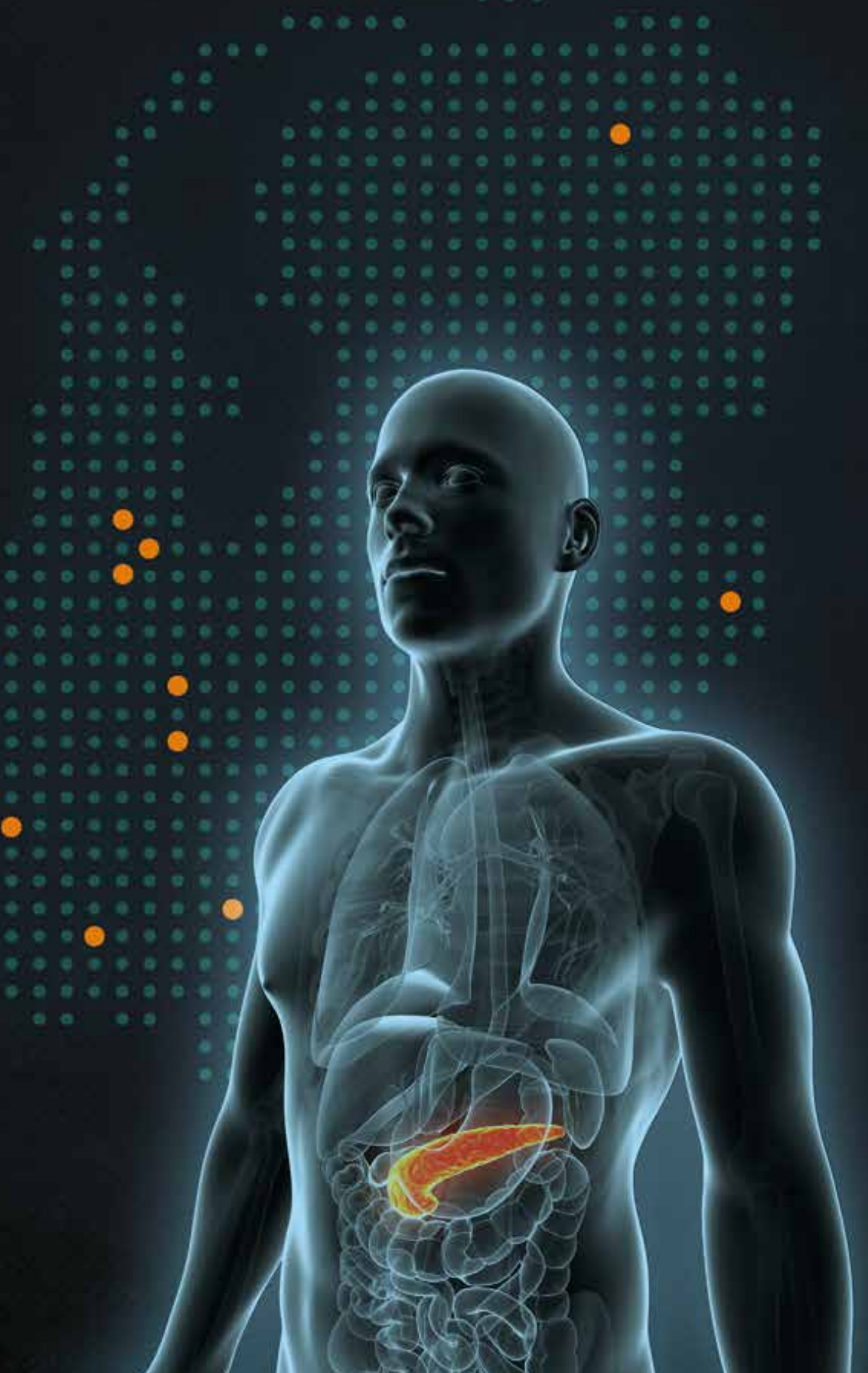

00080000000000000

0.00000000000000

0.000 .00 .0

0.0000000

$\ldots$

0000000000

Q

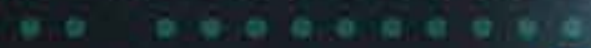

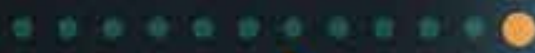

0.0000000008

0.000 .0 .00

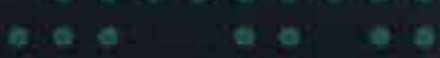

$\ldots$

a: 


\title{
HOSPITAL OF DIAGNOSIS AND LIKELIHOOD OF SURGICAL TREATMENT FOR PANCREATIC CANCER
}

\author{
M. J. A. M. Bakens ${ }^{1,2}$ | Y. R. B. M. van Gestel ${ }^{2} \mid$ M. Bongers ${ }^{1}$ \\ M. G. Besselink ${ }^{4}$ | C. H. C. Dejong ${ }^{5,6,7}$ | I. Q. Molenaar ${ }^{3}$ \\ \begin{tabular}{l|l|l} 
O. R. C. Busch & | V. E.P.P. Lemmens \\
& | I. H. J. T. de Hingh
\end{tabular}
}

On behalf of the Dutch Pancreatic Cancer Group

Br J Surg. 2015 Dec;102(13):1670-5.

${ }^{1}$ Department of Surgery, Catharina Hospital, Eindhoven

2 Department of Research, Netherlands Comprehensive Cancer Organization (IKNL)

${ }^{3}$ Department of Surgery, University Medical Centre Utrecht, Utrecht

${ }^{4}$ Department of Surgery, Academic Medical Centre, Amsterdam

${ }^{5}$ Department of Surgery, Maastricht University Medical Centre

${ }^{6}$ NUTRIM School of Nutrition and Translational Research in Metabolism

${ }^{7}$ GROWSchool for Oncology and Developmental Biology, Maastricht

${ }^{8}$ Department of Public Health, Erasmus Medical Centre, Rotterdam, The Netherlands 


\section{ABSTRACT}

Background Surgical resection for pancreatic cancer offers the only chance of cure. Assessment of the resectability of a pancreatic tumor is therefore of great importance. The aim of the study was to investigate whether center of diagnosis influences the likelihood of surgery and whether this affects long-term survival.

Methods Patients diagnosed with non-metastasized pancreatic cancer (M0) between 2005 and 2013 in the Netherlands were selected from the Netherlands Cancer Registry. Hospitals were classified as a pancreatic center (at least 20 resections/year) or a non-pancreatic center (fewer than 20 resections/year). The relationship between center of diagnosis and likelihood of surgery was analyzed by multivariable logistic regression. Influence of center on overall survival was assessed by means of multivariable Cox regression analysis.

Results Some 8141 patients were diagnosed with non-metastasized pancreatic cancer, of whom 3123 (38.4 percent) underwent surgery. Of the 2712 patients diagnosed in one of 19 pancreatic centers, 52.4 percent had exploratory laparotomy compared with 31.4 percent of 5429 patients diagnosed in one of 74 non-pancreatic centers $(\mathrm{P}<0.001)$. A pancreatectomy was performed in 42.8 and 24.6 percent of the patients respectively ( $P$ $<0.001)$. Multivariable analysis revealed that patients diagnosed in a pancreatic center had a higher chance of undergoing surgery (odds ratio 2.21, 95 percent c.i. 1.98 to 2.47). Center of diagnosis was not associated with improved long-term survival (hazard ratio $0.95,95$ percent c.i. 0.91 to 1.00$)$.

Conclusion Patients with non-metastasized pancreatic cancer had a greater likelihood of having surgical treatment when the diagnosis was established in a pancreatic center. 


\section{INTRODUCTION}

Pancreatic cancer is the fourth leading cause of cancer-related death in Europe and the USA, and is known for its poor long-term survival. ${ }^{1}$ Some 40 percent of patients present with metastatic disease at the time of diagnosis. ${ }^{2,3}$ Surgery offers the only chance of cure in patients presenting without distant metastases. Usually this involves a pancreatoduodenectomy, a procedure associated with a high morbidity rate. ${ }^{1}$

Centralization of pancreatoduodenectomy in high-volume centers (at least 20 resections/ year) has significantly reduced postoperative mortality and morbidity. ${ }^{4,5}$

However, the diagnostic and staging processes in patients with a pancreatic tumor have not yet been centralized.

According to the Dutch guidelines for pancreatic cancer ${ }^{6}$, all newly diagnosed patients with pancreatic cancer should be discussed in a multidisciplinary tumor board meeting in the hospital of diagnosis. Given that surgical and nonsurgical treatments are becoming increasingly complex and limited mainly to specialized centers, the treatment being offered might reflect the experience of the multidisciplinary tumor board with pancreatic cancer surgery. This could especially be true in the current era of portal vein resections and neoadjuvant treatment strategies. ${ }^{7}$ This study assessed whether the likelihood of surgical treatment is influenced by the presence of pancreatic cancer surgery in the center of diagnosis and whether this affects long-term survival.

\section{METHODS}

Patients with a clinical or histological diagnosis of pancreatic cancer (C25) ${ }^{8}$, between 1 January 2005 and 31 December 2013 in the Netherlands were selected from the Netherlands Cancer Registry (NCR). The NCR collects data for all newly diagnosed patients with cancer in 93 hospitals in the Netherlands, comprising approximately 16.7 million inhabitants in 2013. Specially trained registry administrators routinely extract diagnostic and treatment variables from the medical records (hospital of initial diagnosis, date of diagnosis, age, sex, histology, TNM stage, treatment, hospital of treatment and survival). Data essential for the present analysis were collected after 1 January 2005. Data on center of diagnosis and treatments were complete. 


\section{TUMOR STAGE AND HISTOLOGY}

The TNM sixth (2005-2009) ${ }^{9}$ and seventh (2010-2013) ${ }^{10}$ editions or Clinical Extent of Disease $(\mathrm{CEoD})$ were used for tumor staging. CEoD was established by combining clinical and radiological findings (abdominal ultrasonography or CT). ${ }^{11}$ Only patients without distant metastases were included in the study. Patients were grouped by TNM stage as TNM I, II, III, II/III or TN unknown. If T or N status was missing, CEoD was used for staging. CEoD classification 2 was categorized as TNM I, and CEoD 4 as TNM III. CEoD stages 3 and 5 represent tumors growing outside the pancreas but, as information on vascular involvement is missing in CEoD, these tumors were categorized as TNM II/III. Tumors with missing $\mathrm{T}$ or $\mathrm{N}$ status and missing CEoD were categorized as TN unknown. Tumors were analyzed in two groups based on tumor histology: neuroendocrine tumors (NETs) and all other pancreatic cancers (carcinoma group).

\section{TREATMENTS}

Patients were classified into three groups according to treatment: surgery with curative intent, including pancreatoduodenectomy, pancreatic body resection or distal pancreatectomy; palliative chemotherapy; and no surgery or chemotherapy.

\section{CENTERS}

Center of initial diagnosis was defined as the hospital in which the clinical diagnosis of pancreatic cancer was first made, even in the absence of pathological confirmation. Based on the number of pancreatic resections for cancer dictated by the Dutch inspectorate for healthcare, hospitals were classified as either a pancreatic center (20 or more resections/ year) or a non-pancreatic center (fewer than 20 resections/year).

\section{STATISTICAL ANALYSIS}

Patient and tumor characteristics were compared between pancreatic and non-pancreatic centers using $\chi^{2}$ tests. The relationship between center of diagnosis and the likelihood of surgery was investigated by multivariable logistic regression analysis. Other variables included in this analysis were: sex, age at diagnosis, interval of diagnosis, morphology and tumor stage. The results are reported as odds ratios (ORs) with 95 percent c.i. The influence of hospital of diagnosis on overall survival was assessed using Kaplan-Meier 
analysis and multivariable Cox regression. In the regression analysis, adjustments were made for sex, age at diagnosis, interval of diagnosis, tumor stage and treatment. Overall survival was calculated using data retrieved from the Municipal Personal Records Database. This database records all deaths or emigrations in the Netherlands. Survival time was defined as the interval between diagnosis and death, or until 1 January 2015 for patients who were still alive. Patients lost to follow-up or still alive on 1 January 2015 were censored. The results are reported as hazard ratios (HRs) with 95 percent c.i. NETs were excluded from the survival analysis because of their favorable survival compared with pancreatic carcinoma. All analyses were performed using SAS ${ }^{\varpi}$ version 9.4 (SAS Institute, Cary, North Carolina, USA). P <0.050 was considered statistically significant.

\section{RESULTS}

Between 2005 and 2013, 18733 patients were diagnosed with pancreatic cancer, including 9958 patients with metastatic disease and 634 patients for whom it was uncertain whether metastatic disease was present at the time of diagnosis. In total, 8141 patients (43.5 percent) had no signs of metastasis, and these were included in the present study. Pancreatic cancer was diagnosed in 89 (96 percent) of 93 hospitals in the Netherlands. Some 19 hospitals ( 21 percent) were classified as pancreatic centers and 70 (79 percent) as non-pancreatic centers. Patient characteristics differed between the centers (Table 1). Patients diagnosed in a pancreatic center were younger than those diagnosed in a non-pancreatic center: median (i.q.r.) 68 (60-76) versus 73 (64-80) years respectively (P $<0.001)$.

\section{SURGERY}

An exploratory laparotomy was performed in 3123 patients (38.4 percent). Resection with curative intent was undertaken in 2497 (80.0 percent) of these patients (Table 1). This represented 30.7 percent of patients diagnosed with non-metastasized pancreatic cancer and 13.3 percent of all patients diagnosed with pancreatic cancer in the study interval. 
Rates of surgery differed significantly between patients diagnosed in a pancreatic center versus a non-pancreatic center. Exploratory laparotomy was performed in 1421 (52.4 percent) and 1702 (31.4 percent) patients respectively $(\mathrm{P}<0.001)$, and surgery with curative intent in 1160 (42.8 percent) versus 1337 (24.6 percent) $(\mathrm{P}<0.001)$ (Table 1$)$. The resection rate increased with time for both types of center, but differences in resection rates remained throughout the study (Fig. 1).

TABLE 1. Characteristics of 8141 patients with M0 pancreatic cancer diagnosed between 2005 and 2013 in the Netherlands according to hospital of diagnosis

\begin{tabular}{|c|c|c|c|c|}
\hline & $\begin{array}{l}\text { All patients } \\
(n=8141)\end{array}$ & $\begin{array}{c}\text { Pancreatic } \\
\text { center } \\
(\mathbf{n = 2 7 1 2})\end{array}$ & $\begin{array}{c}\text { Non- } \\
\text { pancreatic } \\
\text { center } \\
(n=5429)\end{array}$ & $P^{*}$ \\
\hline Age (years) & & & & $<0.001$ \\
\hline$<60$ & $1517(18.6)$ & $663(24.5)$ & $854(15.7)$ & \\
\hline $60-69$ & $2149(26.4)$ & $801(29.5)$ & $1348(24.8)$ & \\
\hline $70-79$ & $2624(32.2)$ & $820(30.2)$ & $1804(33.2)$ & \\
\hline$\geq 80$ & $1851(22.7)$ & $428(15.8)$ & $1423(26.2)$ & \\
\hline Sex ratio $(M: F)$ & $3938: 4203$ & $1367: 1345$ & $2571: 2858$ & 0.010 \\
\hline Interval of diagnosis & & & & 0.046 \\
\hline $2005-2007$ & $2387(29.3)$ & $840(31.0)$ & $1547(28.5)$ & \\
\hline 2008-2010 & $2791(34.3)$ & $892(32.9)$ & $1899(35.0)$ & \\
\hline 2011-2013 & $2963(36.4)$ & $980(36.1)$ & $1983(36.5)$ & \\
\hline Histology & & & & $<0.001$ \\
\hline Carcinoma & 7739 (95.1) & $2500(92.2)$ & $5239(96.5)$ & \\
\hline Neuroendocrine tumor & $402(4.9)$ & $212(7.8)$ & $190(3.5)$ & \\
\hline Tumor stage (TNM) & & & & $<0.001$ \\
\hline 1 & 2961 (36.4) & 1019 (37.6) & $1942(35.8)$ & \\
\hline$\|$ & 2335 (28.7) & $806(29.7)$ & $1529(28.2)$ & \\
\hline III & $1596(19.6)$ & $602(22.2)$ & $994(18.3)$ & \\
\hline II/III & $1047(12.9)$ & $236(8.7)$ & $811(14.9)$ & \\
\hline TN unknown & $202(2.5)$ & $49(1.8)$ & $153(2.8)$ & \\
\hline Treatment & & & & $<0.001$ \\
\hline No surgery or chemotherapy & $4782(58.7)$ & $1287(47.5)$ & $3495(64.4)$ & \\
\hline Palliative chemotherapy & $862(10 \cdot 6)$ & $265(9 \cdot 8)$ & $597(11 \cdot 0)$ & \\
\hline Surgery with curative intent & $2497(30 \cdot 7)$ & $1160(42 \cdot 8)$ & $1337(24 \cdot 6)$ & \\
\hline
\end{tabular}

Values in parentheses are percentages. ${ }^{*} \times 2$ test. 
Treatment $M_{0}$-pancreatic-cancer patients for centre of diagnosis in the Netherlands 2005-2013

Laparotomy pancreatic centre

Surgery with curative intent pancreatic contro
Laparotomy non-pancreatic centre

Surgery with curative intent non-pancreatic contro

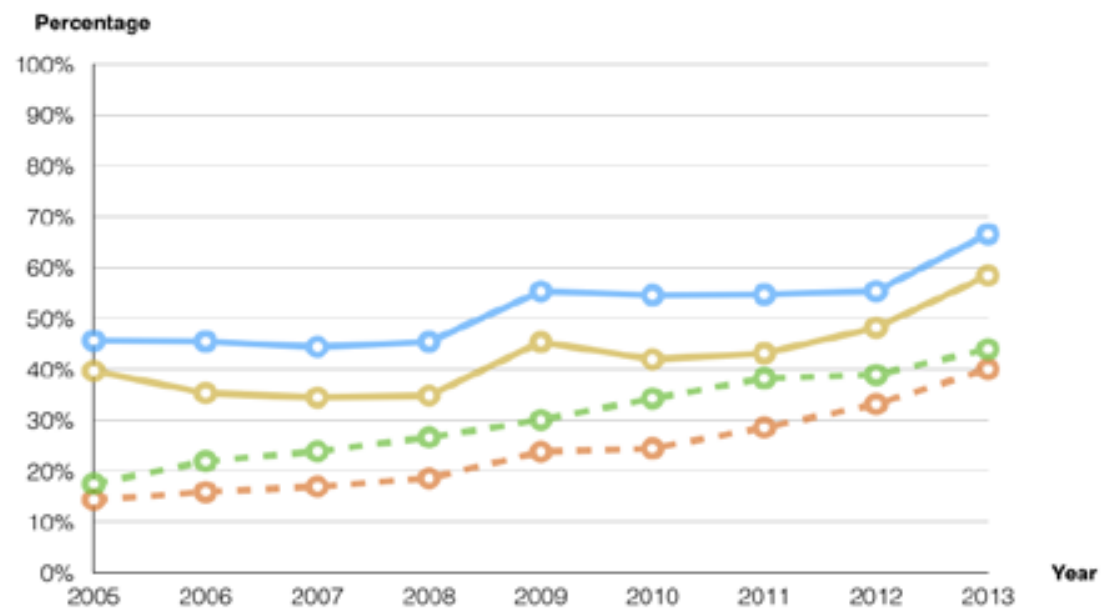

FIGURE 1. Treatment of MO pancreatic cancer by center of diagnosis in the Netherlands, 2005-2013

\section{LIKELIHOOD OF UNDERGOING SURGERY}

Results of multivariable logistic regression to determine factors influencing the likelihood of surgery are shown in Table 2. Patients initially diagnosed in a pancreatic center had a significantly higher likelihood of surgical treatment (OR 2.21, 95 percent c.i. 1.98 to 2.47). Patients aged 70 years or more were less likely to have surgical treatment than patients aged less than 60 years (age 70-79 years: OR $0.48,0.42$ to $0.56 ; 80$ years or older: OR $0.05,0.04$ to 0.06 ). Patients diagnosed in 2008 or later had a significantly higher likelihood of undergoing surgery than patients diagnosed before 2008.

\section{SURVIVAL}

There was a significant difference in 5-year survival between patients diagnosed in pancreatic centers versus non-pancreatic centers: 8.7 versus 5.7 percent respectively $(P$ $<0.001$ ) (Fig. 2). 
In multivariable Cox regression analyses, diagnosis in a pancreatic center was associated with reduced long-term mortality compared with diagnosis in a nonpancreatic center, but this was not statistically significant (HR 0.95, 95 percent c.i. 0.91 to 1.00 ) (Table 3).

TABLE 2. Multivariable regression analyses of factors influencing the likelihood of undergoing exploratory laparotomy for pancreatic cancer between 2005 and 2013 in the Netherlands

\begin{tabular}{|c|c|c|}
\hline & $\begin{array}{l}\text { Exploratory laparotomy } \\
\qquad(n=3123)^{*}\end{array}$ & Odds ratio† \\
\hline \multicolumn{3}{|l|}{ Age (years) } \\
\hline$<60$ & $859(56.6)$ & 1.00 (reference) \\
\hline $60-69$ & $1124(52.3)$ & $0.89(0.77,1.03)$ \\
\hline $70-79$ & $1008(38.4)$ & $0.48(0.42,0.56)$ \\
\hline$\geq 80$ & $132(7.1)$ & $0.05(0.04,0.06)$ \\
\hline \multicolumn{3}{|l|}{ Sex } \\
\hline M & $1653(42.0)$ & 1.00 (reference) \\
\hline $\mathrm{F}$ & $1470(35.0)$ & $0.88(0.79,0.98)$ \\
\hline \multicolumn{3}{|l|}{ Hospital of diagnosis } \\
\hline Pancreatic center & $1421(52.4)$ & $2.21(1.98,2.47)$ \\
\hline Non-pancreatic center & $1702(31.4)$ & 1.00 (reference) \\
\hline \multicolumn{3}{|l|}{ Interval of diagnosis } \\
\hline $2005-2007$ & $704(29.5)$ & 1.00 (reference) \\
\hline 2008-2010 & $1043(37.4)$ & $1.62(1.41,1.85)$ \\
\hline 2011-2013 & $1376(46.4)$ & $2.28(2.00,2.61)$ \\
\hline \multicolumn{3}{|l|}{ Histology } \\
\hline Carcinoma & 2819 (36.4) & 1.00 (reference) \\
\hline Neuroendocrine tumor & $304(75.6)$ & $2.44(1.87,3.18)$ \\
\hline \multicolumn{3}{|l|}{ Tumor stage (TNM) } \\
\hline 1 & $1358(45.9)$ & 1.00 (reference) \\
\hline ॥ & 1205 (51.6) & $0.98(0.86,1.11)$ \\
\hline III & $421(26.4)$ & $0.24(0.21,0.28)$ \\
\hline II/III & $119(11.4)$ & $0.16(0.13,0.20)$ \\
\hline
\end{tabular}

Values in parentheses are *percentages and +95 percent c.i. 
TABLE 3. Cox regression analyses of predictors of long-term mortality in patients with pancreatic cancer diagnosed between 2005 and 2013

\begin{tabular}{|c|c|}
\hline & Hazard ratio \\
\hline \multicolumn{2}{|l|}{ Age (years) } \\
\hline$<60$ & 1.00 (reference) \\
\hline $60-69$ & $1.16(1.08,1.25)$ \\
\hline $70-79$ & $1.30(1.20,1.39)$ \\
\hline$\geq 80$ & $1.48(1.36,1.61)$ \\
\hline \multicolumn{2}{|l|}{ Sex } \\
\hline M & 1.00 (reference) \\
\hline $\mathrm{F}$ & $0.99(0.94,1.04)$ \\
\hline \multicolumn{2}{|l|}{ Center of diagnosis } \\
\hline Pancreatic center & $0.95(0.91,1.00)$ \\
\hline Non-pancreatic center & 1.00 (reference) \\
\hline \multicolumn{2}{|l|}{ Interval of diagnosis } \\
\hline $2005-2007$ & 1.00 (reference) \\
\hline 2008-2010 & $0.93(0.87,0.98)$ \\
\hline 2011-2013 & $0.97(0.92,1.03)$ \\
\hline \multicolumn{2}{|l|}{ Tumor stage (TNM) } \\
\hline 1 & 1.00 (reference) \\
\hline ॥ & $1.36(1.28,1.45)$ \\
\hline III & $1.32(1.23,1.42)$ \\
\hline$\| / I I I$ & $1.31(1.21,1.42)$ \\
\hline TN unknown & $1.15(0.99,1.34)$ \\
\hline \multicolumn{2}{|l|}{ Treatment } \\
\hline No surgery or chemotherapy & 1.00 (reference) \\
\hline Palliative chemotherapy & $0.57(0.53,0.62)$ \\
\hline Surgery with curative intent & $0.33(0.31,0.35)$ \\
\hline
\end{tabular}

Values in parentheses are 95 percent c.i. Patients with neuroendocrine tumors were excluded from the survival analysis. 


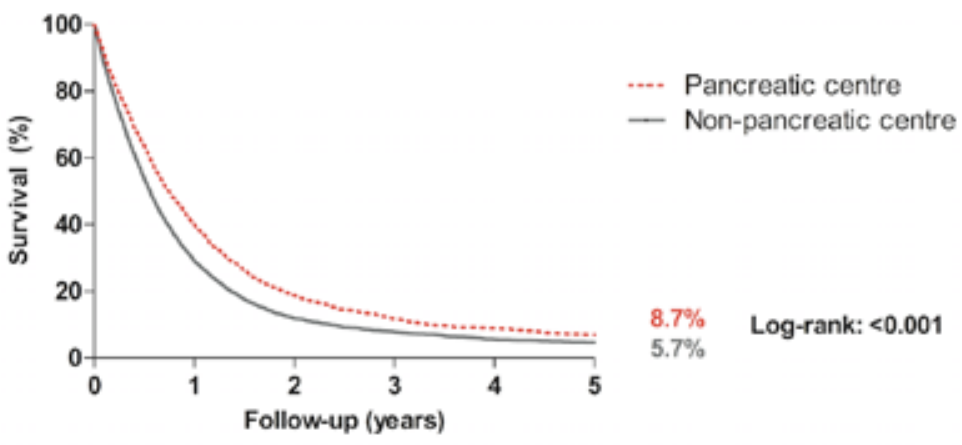

Number at risk

$\begin{array}{lllllll}\text { Non-pancreatic centre } & 5,429 & 1,524 & 561 & 293 & 173 & 111\end{array}$

$\begin{array}{lllllll}\text { Pancreatic centre } & 2,712 & 1,000 & 402 & 211 & 134 & 87\end{array}$

FIGURE 2. Survival of patients with MO pancreatic cancer by center of diagnosis. $\mathrm{P}<0.001$ (log rank test)

\section{DISCUSSION}

The centralization of pancreatic cancer surgery in the Netherlands has resulted in a reduction in postoperative mortality, improved survival and increased resection rates. ${ }^{4,12,13}$ However, the diagnostic evaluation and staging of patients with pancreatic cancer is still performed in most Dutch hospitals. In 74 of 93 hospitals, patients with pancreatic cancer were discussed in a multidisciplinary tumor board meeting without involvement of a specialized pancreatic surgeon. Hence, the grounds for the decision to refer a patient to a pancreatic cancer center for surgical treatment could be questioned. This population-based study has shown that the likelihood of undergoing surgical treatment for pancreatic cancer is higher in centers with a high-volume pancreatic surgery service. Recognition as a pancreatic cancer center in the Netherlands is currently based solely on the annual volume of pancreatectomies. In 2007, a minimum of ten pancreatoduodenectomies per year was specified and this increased to 20 procedures in 2010. As a result, the number of hospitals performing pancreatic surgery decreased from 
40 in 2005 to 19 in 2013. As all 19 centers performed pancreatic surgery during the entire study interval, these hospitals were defined as pancreatic cancer centers in the present study.

A previous nationwide study ${ }^{14}$ in the USA demonstrated that patients with clinical stage I pancreatic adenocarcinoma treated in low-volume centers between 1995 and 2004 were less likely to undergo surgery than patients treated in high-volume centers (OR $0.36,95$ percent c.i. 0.30 to 0.45 ). The same study reported a nationwide undertreatment of patients with pancreatic cancer because only 29 percent of those with stage I disease underwent surgery. This percentage was unexpectedly low as stage I pancreatic cancer is potentially resectable. Reasons for no surgical treatment were old age, presence of comorbidities or patient refusal. There was no identifiable reason for not opting for surgery in 52 percent of the patients. An Irish nationwide study ${ }^{15}$ also reported undertreatment of patients with pancreatic cancer between 1994 and 2003. Some 42 percent of the patients did not receive any therapy and only a minority underwent resection. These studies suggest underutilization of potentially curative surgery in patients without clear contraindications, especially in low-volume hospitals.

In the present study, tumor resection was carried out in 13.3 percent of all patients with pancreatic cancer and in 30.7 percent of those with stage I disease. This is in line with previous studies showing that only 10-20 percent of patients with pancreatic cancer undergo surgery with curative intent. ${ }^{1,12,15,16}$ Reasons for no surgery were older age and advanced tumor stage with vascular involvement of the tumor. Patients' preference and co-morbidity may also have influenced choice of treatment, but these data were not available from the NCR. The classification of pancreatic cancer as resectable, borderline resectable, locally advanced or metastatic can be complex, and requires an experienced multidisciplinary team with up-to-date knowledge of all treatment strategies. ${ }^{16}$ Previous studies have shown that exposure to a higher volume of surgery improves more than surgical skill. Dedicated CT performed at high-volume centers resulted in improved preoperative staging compared with CT at low-volume centers. ${ }^{17}$ The present authors speculate that the experience of the entire multidisciplinary tumor board might be of great importance and explain the difference in resection rates between centers. Furthermore, a more nihilistic approach to surgery for pancreatic cancer might still exist in non-pancreatic centers. ${ }^{18}$ This may be especially true for elderly patients, given the 
findings that such patients had a lower likelihood of surgery. Patients aged more than 70 years, or even 80 years, have a higher risk of postoperative morbidity and mortality after pancreatoduodenectomy, but they still have a better chance of survival than patients who are not treated surgically. ${ }^{19-22}$ Hence, elderly patients should be selected carefully and informed about all treatment options; they should not be denied surgery just because of their age. ${ }^{21,22}$ Assessment by an experienced multidisciplinary team may be particularly of benefit for this vulnerable patient group.

Diagnosis in a pancreatic center was associated with reduced long-term mortality compared with diagnosis in a non-pancreatic center, but this was not statistically significant. Similar findings were published in a contemporary study ${ }^{23}$ of oesophageal cancer that showed an important influence of the center of diagnosis on survival and the likelihood of undergoing surgical treatment.

Although the NCR used for this study is a reliable and complete database, comorbidity was not registered and could not be used for correction of case mix. This may have influenced the results. ${ }^{3,24}$ In the Netherlands, patients can choose a hospital of their own preference, but it is likely that they will follow the advice of their general practitioner. Age may have biased referral patterns, as patients diagnosed in pancreatic centers were younger than those diagnosed in non-pancreatic centers. However, the greater likelihood of surgical treatment in pancreatic centers remained present after multivariable analyses correcting for age. This once more suggests that the experience of the multidisciplinary tumor board results in a more adequate assessment and selection for surgery with curative intent. Concentration of care in pancreatic centers may further improve outcomes in patients with pancreatic cancer.

\section{ACKNOWLEDGEMENTS}

The authors thank the registrars of the NCR for data collection. This study was funded by a grant from the Dutch Cancer Society (KWF) (grant number 2013-649). The funding source had no role in the study design, data collection and analysis, the writing of the manuscript or the submission for publication. Disclosure: The authors declare no conflict of interest. 


\section{REFERENCES}

1. Vincent A, Herman J, Schulick R, Hruban RH, Goggins M. Pancreatic cancer. Lancet 2011; 378: 607-620.

2. Ferlay J, Steliarova-Foucher E, Lortet-Tieulent J, Rosso S, Coebergh JW, Comber H et al. Cancer incidence and mortality patterns in Europe: estimates for 40 countries in 2012. Eur J Cancer 2013; 49: 1374-1403.

3. Hartwig W,Werner J, Jager D, Debus J, Büchler MW. Improvement of surgical results for pancreatic cancer. Lancet Oncol 2013; 14: e476-e485.

4. Lemmens VE, Bosscha K, van der Schelling G, Brenninkmeijer S, Coebergh JW, de Hingh IH. Improving outcome for patients with pancreatic cancer through centralization. Br J Surg 2011; 98: 1455-1462.

5. deWilde RF, Besselink MG, van der Tweel I, de Hingh IH, van Eijck CH, Dejong CH et al.; Dutch Pancreatic Cancer Group. Impact of nationwide centralization of pancreaticoduodenectomy on hospital mortality. Br J Surg 2012; 99: 404-410.

6. Oncoline. Pancreascarcinoom. http://www.oncoline.nl/pancreascarcinoom [accessed 15 May 2015].

7. Fuhrman GM, Leach SD, Staley CA, Cusack JC, Charnsangavej C, Cleary KR et al. Rationale for en bloc vein resection in the treatment of pancreatic adenocarcinoma adherent to the superior mesenteric-portal vein confluence. Pancreatic Tumor Study Group. Ann Surg 1996; 223: $154-162$.

8. Fritz AG. International Classification of Diseases for Oncology: ICD-O (3rd edn).World Health Organization: Geneva, 2000.

9. Sobin LH,Wittekind C. TNM Classification of Malignant Tumors (6th edn).Wiley-Blackwell: New Jersey, 2002.

10. Sobin LH, Gospodarowicz MK,Wittekind C. TNM Classification of Malignant Tumors (7th edn). Wiley-Blackwell: New Jersey, 2009.

11. Guinee VF. The international cancer patient data exchange system (ICPDES). Health Rep 1993; 5: 97-103.

12. Gooiker GA, Lemmens VE, Besselink MG, Busch OR, Bonsing BA, Molenaar IQ et al. Impact of centralization of pancreatic cancer surgery on resection rates and survival. BrJ Surg 2014; 101: 1000-1005. 
13. Nienhuijs SW, van den Akker SA, de Vries E, de Hingh IH, Visser O, Lemmens VE. Nationwide improvement of only short-term survival after resection for pancreatic cancer in the Netherlands. Pancreas 2012; 41: 1063-1066.

14. Bilimoria KY, Bentrem DJ, Ko CY, Stewart AK, Winchester DP, Talamonti MS. National failure to operate on early stage pancreatic cancer. Ann Surg 2007; 246:173-180.

15. Sharp L, Carsin AE, Cronin-Fenton DP, O'Driscoll D, Comber H. Is there under-treatment of pancreatic cancer? Evidence from a population-based study in Ireland. Eur J Cancer 2009; 45: 1450-1459.

16. Varadhachary GR, Tamm EP, Abbruzzese JL, Xiong HQ, Crane CH,Wang H et al. Borderline resectable pancreatic cancer: definitions, management, and role of preoperative therapy. Ann Surg Oncol 2006; 13: 1035-1046.

17. Walters DM, Lapar DJ, de Lange EE, Sarti M, Stokes JB, Adams RB et al. Pancreas-protocol imaging at a high-volume center leads to improved preoperative staging of pancreatic ductal adenocarcinoma. Ann Surg Oncol 2011;18: 2764-2771.

18. Chamberlain RS, Gupta C, Paragi P. In defense of the Whipple: an argument for aggressive surgical management of pancreatic cancer. Oncologist 2009; 14: 586-590.

19. Melis M, Marcon F, Masi A, Pinna A, Sarpel U, Miller G et al. The safety of a pancreaticoduodenectomy in patients older than 80 years: risk vs. benefits. HPB (Oxford) 2012; 14: 583-588.

20. Gerstenhaber F, Grossman J, Lubezky N, Itzkowitz E, Nachmany I, Sever R et al. Pancreaticoduodenectomy in elderly adults: is it justified in terms of mortality, long-term morbidity, and quality of life? J Am Geriatr Soc 2013; 61:1351-1357.

21. Oguro S, Shimada K, Kishi Y, Nara S, Esaki M, Kosuge T. Perioperative and long-term outcomes after pancreaticoduodenectomy in elderly patients 80 years of age and older. Langenbecks Arch Surg 2013; 398: 531-538.

22. Adham M, Bredt LC, Robert M, Perinel J, Lombard-Bohas C, Ponchon T et al. Pancreatic resection in elderly patients: should it be denied? Langenbecks Arch Surg 2014; 399: 449-459.

23. Koeter M, van Steenbergen LN, Lemmens VE, Rutten HJ, Roukema JA,Wijnhoven BP et al. Hospital of diagnosis and probability to receive a curative treatment for oesophageal cancer. Eur J Surg Oncol 2014; 40: 1338-1345. 
24. Mayo SC, Gilson MM, Herman JM, Cameron JL, Nathan H, Edil BH et al. Management of patients with pancreatic adenocarcinoma: national trends in patient selection, operative management, and use of adjuvant therapy. J Am Coll Surg 2012; 214: 33-45. 
Q 810

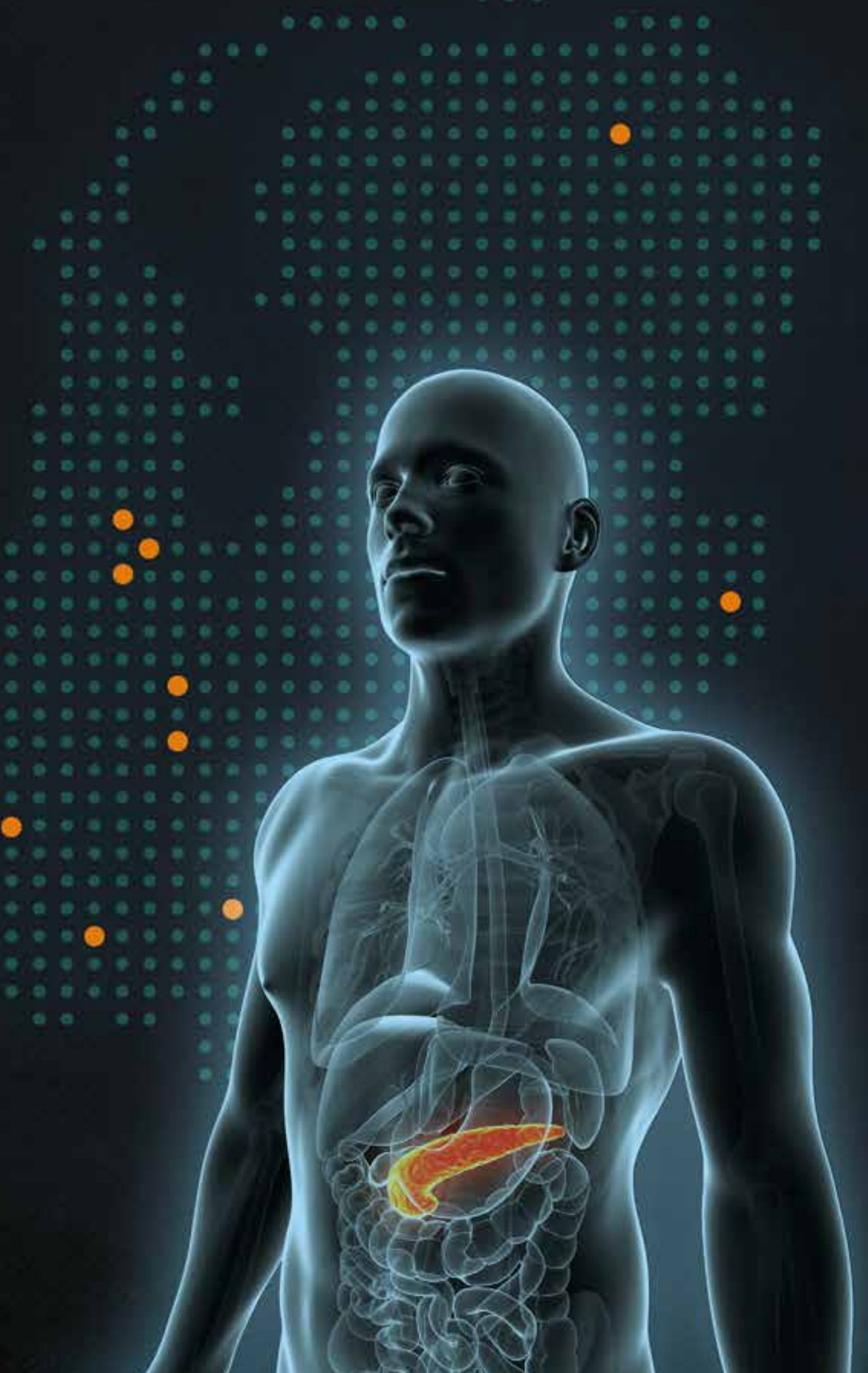

00080000000000000

0.00000000000000

0.000 .00 .0

0.0000000

$\ldots$

0000000000

Q

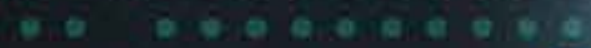

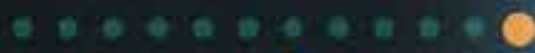

0.0000000008

0.000 .0 .00

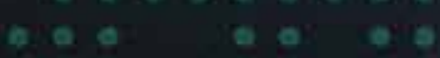

$\ldots$

a: 


\title{
EVALUATION OF PREOPERATIVE BILIAIRY DRAINAGE IN PATIENTS UNDERGOING PANCREATODUODENECTOMY FOR SUSPECTED PANCREATIC OR PERIAMPULLARY CANCER
}

\author{
M.J.A.M. Bakens ${ }^{1}$ ｜ L.B. van Rijssen² | V. van Woerden ${ }^{3}$ ～M.G. Besselink² \\ D. Boerma ${ }^{4}$ | O.R. Busch² | C.H.C. Dejong ${ }^{3,5,10 ~ \mid ~ M . F . ~ G e r h a r d s ~}{ }^{6}$ \\ J.E. van Hooft ${ }^{11}$ | Y. Keulemans ${ }^{7}$ | J.M. Klaase ${ }^{8}$ | M.D. Luyer ${ }^{1}$ | I.Q. Molenaar ${ }^{9}$ \\ J.E. Oor ${ }^{4}$ | E.J.Schoon ${ }^{12}$ | W.Steen ${ }^{6}$ | D.S. Tseng9 | D.J. Gouma² \\ I.H.J.T. de Hingh ${ }^{1}$
}

J Pancreas 2018 Jan 29; 19(1):1-6.

1 Department of Surgery, Catharina Hospital, Eindhoven, the Netherlands

2 Department of Surgery, Cancer Center Amsterdam, Academic Medical Center Amsterdam, the Netherlands

${ }^{3}$ Department of Surgery, Maastricht University Medical Center, Maastricht, the Netherlands

${ }^{4}$ Department of Surgery, Sint Antonius, Nieuwegein, the Netherlands

5 NUTRIM School for Nutrition Toxicology and Metabolism, and GROW School for Oncology \& Developmental Biology, Maastricht, the Netherlands

${ }^{6}$ Department of Surgery, Onze Lieve Vrouwe Gasthuis, Amsterdam, the Netherlands.

7 Department of Gastroenterology, Maastricht University Medical Center, Maastricht, the Netherlands

8 Department of Surgery, Medical Spectrum Twente, Enschede, the Netherlands

9 Department of Surgery, Utrecht Medical Center, Utrecht, the Netherlands

${ }^{10}$ Department of Surgery, Universitätsklinikum Aachen, Aachen, Germany

${ }^{11}$ Department of Gastroenterology, Academic Medical Center Amsterdam, the Netherlands

${ }^{12}$ Department of Gastroenterology, Catharina Hospital, Eindhoven, the Netherlands 


\section{ABSTRACT}

Background A Dutch randomized trial showed that patients with obstructive jaundice due to periampullary tumors and a bilirubin below $250 \mu \mathrm{mol} / \mathrm{l}$ have a higher rate of complications after preoperative biliary drainage (PBD) as compared to early surgery. Therefore, in the Netherlands the recommended treatment is early surgery without PBD. This study investigated adherence to this recommendation.

Methods A retrospective multicenter cohort study was performed in patients undergoing pancreatoduodenectomy (PD) for suspected malignancy in a 2-years period in seven Dutch high-volume centers. The proportion of and reasons for PBD were studied.

Results PD was performed in 609 patients, of whom 401 (66\%) presented with preoperative jaundice. Of these, 245 patients had bilirubin levels below $250 \mu \mathrm{mol} / \mathrm{l}$. PBD was performed in $165(67 \%)$ of these patients. In the majority of patients, no medical reason justifying a PBD could be retrieved from the medical charts $(n=102,62 \%)$. PBD was mostly performed in the hospital of diagnosis prior to referral to a pancreatic center (53\%). After referral, the rate of PBD varied considerably between pancreatic centers $(13 \%-58 \%, \mathrm{p}<0.001)$.

Conclusion In the Netherlands, more than half of the patients with obstructive jaundice still undergo PBD prior to surgery in the Netherlands without an urgent medical reason. Given the negative influence of PBD on outcome, this practice should be improved. 


\section{INTRODUCTION}

Most patients with a pancreatic and periampullary tumor present with obstructive jaundice. Elevated bilirubin levels are known to result in coagulation disorders, impaired cell-mediated immunity, impaired anastomotic healing and a higher risk for developing sepsis..$^{1-3}$

For these reasons, preoperative biliary drainage (PBD) to lower bilirubin levels prior to pancreatoduodenectomy (PD) was routinely used for decades to improve the patients' general condition and to decrease the chance of postoperative morbidity and mortality.

Since the PBD introduces a risk for complications by itself (e.g. post-ERCP pancreatitis and cholangitis), it has been a matter of debate whether PBD should be performed routinely or only on indication. ${ }^{4-11}$ In a Dutch randomized controlled multicenter trial which compared PBD with plastic endoprothesis to early surgery (within one week of diagnosis $)^{12}$, patients with obstructive jaundice in periampullary tumors with bilirubin levels below $250 \mu \mathrm{mol} / \mathrm{l}$ at the time of randomization appeared to have a significantly higher rate of complications after PBD. Therefore, in the Netherlands the preferred treatment in these patients is currently early surgery, preferably performed within one week after diagnoses and without PBD. ${ }^{13}$

The aim of this study was to investigate the current practice of PBD in the Netherlands in patients operated for suspected periampullary tumors. Furthermore, we aimed to gain insight in the reasons for PBD prior to pancreatoduodenectomy.

\section{METHODS}

\section{DATA COLLECTION}

Data were retrospectively collected from medical patient charts in seven Dutch highvolume ( $\geq 20$ PDs for pancreatic cancer/year) centers (Academic Medical Center, Amsterdam; Catharina Cancer Institute, Eindhoven; Medical Spectrum Twente, Enschede; Maastricht University Medical Center, Maastricht; OLVG, Amsterdam; Sint Antonius Hospital, Nieuwegein; University Medical Center, Utrecht) and included patient characteristics, preoperative diagnostic and treatment procedures and tumor characteristics. 
The aim of the study was to determine the proportion of PBD in patients with obstructive jaundice with bilirubin levels lower than $250 \mu \mathrm{mol} / \mathrm{l}$. Furthermore, documented reasons for drainage were collected as well as differences in the proportion of patients undergoing PBD in high volume centers.

\section{PATIENT SELECTION}

All patients undergoing PD for suspected-periampullary malignancy in 2013 and 2014 were analyzed. Patients undergoing PD in an emergency setting were excluded. Preoperative bilirubin levels were recorded and only patients presenting with jaundice and bilirubin levels between $21 \mu \mathrm{mol} / \mathrm{l}$ and $250 \mu \mathrm{mol} / \mathrm{l}$ were included for further analysis. The cut-off point of $250 \mu \mathrm{mol} / \mathrm{l}$ was chosen since only patients with bilirubin levels lower than $250 \mu \mathrm{mol} / \mathrm{l}$ were included in the RCT demonstrating the negative impact of preoperative biliary drainage. ${ }^{12}$ In patients with bilirubin levels above $250 \mu \mathrm{mol} / \mathrm{l}$ the decision whether or not to perform preoperative drainage is still under debate.

\section{PREOPERATIVE BILIARY DRAINAGE}

PBD was defined as preoperative biliary drainage performed by endoscopic retrograde cholangiography (ERCP) or percutaneous transhepatic bile duct drainage (PTCD). The type of drainage and type of stent (plastic or metal) that was used was recorded.

\section{INDICATIONS FOR PBD}

All hospital charts of patients undergoing PBD were scrutinized to identify the main reason of the treating physicians to perform a PBD. In total 6 categories could be identified: 'diagnostic' (if PBD was performed after contrast injection in the bile duct during ERCP for diagnostic reasons), "cholangitis / pancreatitis", "suspicion of choledocholithiasis", "waiting list" (if early surgery could not be provided in the expert center), "neo-adjuvant therapy" and "no medical reasons" (if none of the previous reasons were identified).

\section{ETHICS}

All methods were carried out in accordance with the Helsinki Declaration of 1964 and later versions. The medical ethical committee was consulted and they concluded that according to the Dutch law on Medical Research in Humans and given the retrospective 
design, the current study did not require informed consent by involved patients. According to Good Clinical Practice, all patient derived data were anonymised.

\section{STATISTICAL ANALYSIS}

Statistic analyses were performed by using IBM SPSS statistics version 22. P-values lower than 0.05 were considered statistically significant.

\section{RESULTS}

In total, 609 patients underwent a PD for suspected pancreatic or periampullary cancer. Elevated bilirubin levels were present in 401 (66\%) of these patients: below $250 \mu \mathrm{mol} / \mathrm{l}$ in $245(61 \%)$ patients and above $250 \mu \mathrm{mol} / \mathrm{l}$ in 114 patients (28\%). In $42(11 \%)$ patients pre-operative bilirubin levels were missing and these patients were excluded from further analysis. The 245 jaundiced patients were further analysed. Baseline characteristics of the patients included in this study are presented in Table 1.

In $80(33 \%)$ patients presenting with bilirubin levels below $250 \mu \mathrm{mol} / \mathrm{l}$ early surgery without PBD was performed. The remaining patients $(n=165,67 \%)$ underwent PBD prior to surgery. In the majority of patients, no medical reason to justify a PBD could be retrieved from the medical charts $(n=102,62 \%)$, Table 2 . 
TABLE 1. Characteristics of patients undergoing pancreatoduodenectomy in the Netherlands 2013-2014.

\begin{tabular}{|c|c|c|c|c|c|c|}
\hline \multirow[b]{2}{*}{ Characteristics } & \multicolumn{3}{|c|}{$\begin{array}{c}\text { Bilirubin }<\mathbf{2 5 0} \boldsymbol{\mu m o l} / \mathbf{l} \\
(n=245)\end{array}$} & \multicolumn{3}{|c|}{ 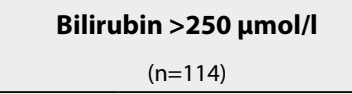 } \\
\hline & $\begin{array}{c}\text { PBD } \\
(n=165) \\
(\%)\end{array}$ & $\begin{array}{c}\text { No PBD } \\
(\mathrm{n}=\mathbf{8 0}) \\
(\%)\end{array}$ & $P$ & $\begin{array}{c}\text { PBD } \\
(\mathrm{n}=91) \\
(\%)\end{array}$ & $\begin{array}{c}\text { No PBD } \\
(n=23) \\
(\%)\end{array}$ & $P$ \\
\hline Sex & & & 0.302 & & & 0.819 \\
\hline Male & $92(56)$ & $39(49)$ & & $53(58)$ & $14(61)$ & \\
\hline Female & $73(44)$ & $41(51)$ & & $38(42)$ & $9(39)$ & \\
\hline Age & & & 0.832 & & & 0.349 \\
\hline$<60$ & $35(21)$ & $19(24)$ & & $18(35)$ & $8(20)$ & \\
\hline $60-74$ & $98(59)$ & $44(55)$ & & $54(59)$ & $11(48)$ & \\
\hline${ }^{3} 75$ & $32(19)$ & $17(21)$ & & $19(21)$ & $4(17)$ & \\
\hline ASA-score & & & 0.425 & & & 0.448 \\
\hline 1 & $28(17)$ & $9(11)$ & & $19(21)$ & $6(26)$ & \\
\hline 2 & $102(62)$ & 59 (74) & & $55(60)$ & $11(48)$ & \\
\hline 3 & $30(18)$ & $10(13)$ & & $16(18)$ & $5(22)$ & \\
\hline 4 & $1(0.6)$ & $0(0)$ & & $0(0)$ & $0(0)$ & \\
\hline Missing & $4(2)$ & $2(3)$ & & $1(4)$ & $1(1)$ & \\
\hline Tumor location & & & 0.075 & & & 0.342 \\
\hline Pancreatic head (excl bile duct) & $95(58)$ & $54(68)$ & & $48(53)$ & $17(74)$ & \\
\hline Distal bile duct & $36(22)$ & $7(9)$ & & $20(22)$ & $3(13)$ & \\
\hline Papil Vater & $28(17)$ & $14(15)$ & & $17(19)$ & $2(9)$ & \\
\hline Duodenum & $2(1)$ & $3(4)$ & & $1(1)$ & $1(4)$ & \\
\hline Other & $1(0.6)$ & $0(0)$ & & $1(1)$ & $0(0)$ & \\
\hline Missing & $3(2)$ & 2 (3) & & $4(4)$ & $0(0)$ & \\
\hline
\end{tabular}


TABLE 2. Reasons for PBD in jaundiced patients with bilirubin levels below 250 $\mu \mathrm{mol} / \mathrm{l}$ undergoing pancreatoduodenectomy in the Netherlands 2013-2014.

\begin{tabular}{|c|c|c|c|c|c|}
\hline Reason for PBD $(n=165)$ & $\begin{array}{c}\text { Total PBD } \\
\text { n=165 } \\
(\%)\end{array}$ & $\begin{array}{c}\text { Plastic } \\
\text { stent } \\
n=112 \\
(\%)\end{array}$ & $\begin{array}{c}\text { Metal } \\
\text { stent } \\
\mathbf{n}=23 \\
(\%)\end{array}$ & $\begin{array}{c}\text { PTCD } \\
n=16 \\
(\%)\end{array}$ & $\begin{array}{c}\text { Missing } \\
\text { stent type } \\
\mathrm{n}=14 \\
(\%)\end{array}$ \\
\hline No medical reason & $102(62)$ & $70(63)$ & $12(52)$ & $11(69)$ & $9(64)$ \\
\hline Diagnostic & $22(13)$ & $17(15)$ & $4(17)$ & 1 (6) & $0(0)$ \\
\hline Cholangitis or pancreatitis & $21(13)$ & $15(13)$ & $2(9)$ & $1(6)$ & $3(21)$ \\
\hline Suspected Choledocholithiasis & $10(6)$ & $5(4)$ & 1 (4) & $3(19)$ & $1(7)$ \\
\hline Waiting list & $9(5)$ & $5(4)$ & $3(13)$ & $0(0)$ & $1(7)$ \\
\hline Neo-adjuvant therapy & $1(0.6)$ & $0(0)$ & $1(4)$ & $0(0)$ & $0(0)$ \\
\hline
\end{tabular}

More than half of the stented patients were already stented in the hospital of diagnosis prior to referral to an expert center $(n=88,53 \%)$. Another 61 patients $(37 \%)$ underwent $\mathrm{PBD}$ in the expert center after referral. The total proportion of PBD differed significantly between pancreatic centers (Table 3 ).

TABLE 3. Data on preoperative biliary drainage versus no drainage in jaundiced patients (bilirubin levels below $250 \mu \mathrm{mol} / \mathrm{l}$ ) undergoing pancreatoduodenectomy in pancreatic centers in the Netherlands 2013-2014.

\begin{tabular}{|c|c|c|c|c|c|c|}
\hline $\begin{array}{l}\text { Pancreatic } \\
\text { center }(n=245)\end{array}$ & $\begin{array}{c}\text { No PBD } \\
(n=80)\end{array}$ & $\begin{array}{c}\text { PBD } \\
\text { total ( } \\
n=165)\end{array}$ & $\begin{array}{c}\text { PBD } \\
\text { Referring } \\
\text { center } \\
(n=88) \\
\end{array}$ & $\begin{array}{c}\text { PBD } \\
\text { Pancreatic } \\
\text { center } \\
(n=61) \\
\end{array}$ & $\begin{array}{c}\text { PBD Center } \\
\text { missing } \\
(n=16)\end{array}$ & $P$ \\
\hline$A(n=41)(\%)$ & $9(22)$ & $32(78)$ & 7 (17) & $17(41)$ & $8(20)$ & \multirow{7}{*}{$<0.001$} \\
\hline B $(n=38)(\%)$ & $11(29)$ & $27(71)$ & $12(32)$ & $15(39)$ & $0(0)$ & \\
\hline$C(n=27)(\%)$ & $4(15)$ & $23(85)$ & $17(63)$ & $4(15)$ & $2(7)$ & \\
\hline$D(n=54)(\%)$ & $16(30)$ & $38(70)$ & $23(43)$ & $11(20)$ & $4(7)$ & \\
\hline$E(n=35)(\%)$ & $17(49)$ & $18(51)$ & $12(34)$ & $4(11)$ & $2(6)$ & \\
\hline$F(n=19)(\%)$ & $10(53)$ & $9(47)$ & $1(5)$ & $8(42)$ & $0(0)$ & \\
\hline G (n=31) (\%) & $13(42)$ & $18(58)$ & $16(52)$ & $2(6)$ & $0(0)$ & \\
\hline
\end{tabular}


Also the proportion of PBD performed after referral differed significantly between centers ranging from $13 \%$ to $58 \%$ ( $\mathrm{p}<0.001$ ) (Figure 1). PBD was most often performed by using a plastic stent $(\mathrm{n}=112,68 \%)$.

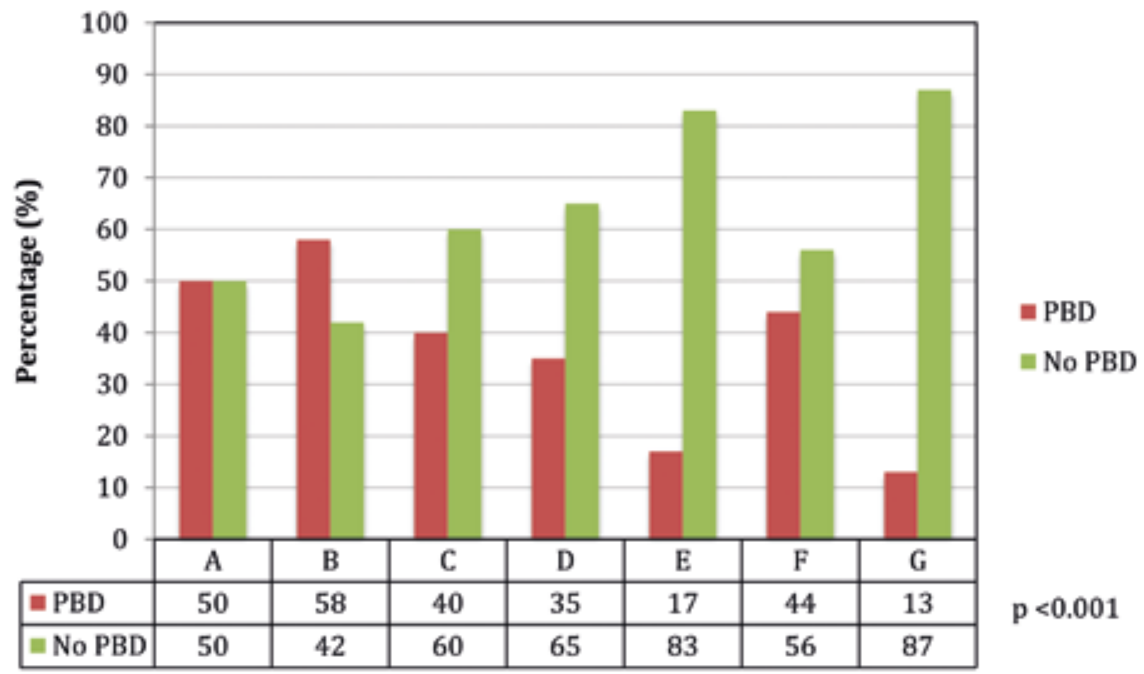

FIGURE 1. Proportion of PBD performed in pancreatic centers after referral of jaundiced patients (bilirubin levels below $250 \mu \mathrm{mol} / \mathrm{l}$ ) undergoing pancreatoduodenectomy in the Netherlands 2013-2014.

\section{DISCUSSION}

The current study revealed that the vast majority of jaundiced patients with a pancreatic or periampullary cancer still undergo PBD prior to surgery in the Netherlands. In total $66 \%$ of patients with bilirubin levels $<250 \mu \mathrm{mol} / 1$ underwent PBD and in most of them, no obvious medical reason to justify a PBD could be retrieved from the medical charts. In most patients, PBD was performed already before referral to a surgical unit in an expert center. However, a relevant proportion of patients underwent PBD prior to surgery in pancreatic centers after referral. The proportion of patients being stented in expert centers varied significantly between centers. 
PBD has been subject of debate for many years. In 2010 Van der Gaag et al. published the results of the Dutch RCT that randomized patients with a bilirubin below $250 \mu \mathrm{mol} / 1$ to undergo PBD prior to surgery with plastic endoprothesis versus early surgery alone. Early surgery was defined, as 'preferably within one week after randomization'. The reason to have a maximum waiting time in the early surgery group is that andomization a maximum bilirubin level of $250 \mu \mathrm{mol} / \mathrm{l}$ was accepted and by waiting longer than a week, bilirubin levels may become to high for safe surgery. The RCT showed that a higher proportion of patients in the $\mathrm{PBD}$-group suffered postoperative and drainagerelated complications compared to patients in the early surgery group without PBD. ${ }^{12}$ Severe complications occurred in $73.5 \%$ of the drainage group, compared to $39.4 \%$ in the early surgery group. ${ }^{12}$ This difference was mainly caused by post PBD complications such as cholangitis (26\%). Since then, the recommendation in the Netherlands has been to perform early surgery without PBD whenever bilirubin levels are $<250 \mu \mathrm{mol} / \mathrm{l}$. This recommendation was accepted by all expert centers in the Netherlands, as they had all been participating in the RCT. However, adhering to this recommendation was anticipated to be challenging, as the interval of only one week between diagnosis and surgery may be difficult to achieve, especially as most patients are diagnosed in hospitals that do not perform surgery.

The current study investigated the daily clinical practice in the Netherlands 3-4 years after publication of the RCT. Rather surprisingly it was revealed that the majority of patients with bilirubin levels below $250 \mu \mathrm{mol} / \mathrm{l}$ still underwent PBD prior to surgery. In the majority of patients, no urgent medical reason could be retrieved from the medical charts. Although "waiting list / inability to operate within one week" was specifically mentioned in a small proportion of the patients, this may have played a major role in the patients in whom no specific medical reason was noted. In the RCT, the median time to surgery was already 9 days in the surgery group without PBD, hinting towards difficulties to perform surgery within one week. ${ }^{12}$

The proportions of PBD after referral performed in pancreatic centers differed considerably between centers, varying between 13 and 58 percent for patients with bilirubin levels below $250 \mu \mathrm{mol} / \mathrm{l}$. As referral to expert centers is based upon regional patterns, it is unlikely that case-mix variations within patients account for this difference in the amount of patients undergoing PBD. Therefore, it may well be assumed that this 
difference is caused by logistical hurdles within the expert centers themselves to realize surgical treatment within one week after referral.

If PBD by ERCP seems to be indicated, the type of stent that will be used, plastic vs metal, should also be considered. The use of plastic stents has been one of the criticisms on the Dutch RCT. ${ }^{12}$ PBD is still indicated in case of extreme hyperbilirubinemie, cholangitis, and the necessity for nutritional support or if it is not possible to perform early surgery because of logistical hurdles. Furthermore, PBD can be indicated in patients who undergo neo-adjuvant treatment. ${ }^{14}$ A recent study by Tol et al. showed that the use of a covered metal stent instead of plastic stent reduces stent related complications (metal $6 \%$ vs. plastic $30 \%$ ) and is cost-effective in spite if the higher costs of the metal stent itself. $^{14-16}$

Although it might have been interesting, the current study does not describe postoperative complications after $\mathrm{PBD}$ as compared to early surgery since the retrospective design of this study does not allow a reliable collection of these data.

The current study should raise awareness in pancreatic centers that in spite of the well-investigated and published beneficial effects of early surgery without PBD, this is not yet achieved in the majority of patients. In the absence of obvious medical reasons in the charts to justify PBD, logistic problems to perform early surgery in the expert centers are the most likely explanation for this practice. Therefore, improving logistics within expert centers, as well as within the referring hospitals is needed to improve the outcome of these patients.

\section{ACKNOWLEDGEMENTS}

The authors thank all participating hospitals and the Dutch pancreatic cancer group.

This study was funded by a grant from the Dutch Cancer Society (KWF) (grant number 2013-649). The funding source had no role in the study design, data collection and analysis, the writing of the manuscript or the submission for publication. 


\section{REFERENCES}

1. Katz, S. C. et al. Obstructive jaundice expands intrahepatic regulatory T cells, which impair liver T lymphocyte function but modulate liver cholestasis and fibrosis. J Immunol 187, 11501156, doi:10.4049/jimmunol.1004077 (2011).

2. Kawarabayashi, N. et al. Immunosuppression in the livers of mice with obstructive jaundice participates in their susceptibility to bacterial infection and tumor metastasis. Shock 33, 500506, doi:10.1097/SHK.0b013e3181c4e44a (2010).

3. Chowdhury, A. H. et al. Immune dysfunction in patients with obstructive jaundice before and after endoscopic retrograde cholangiopancreatography. Clin Sci (Lond) 130, 1535-1544, doi:10.1042/CS20160326 (2016).

4. Moole, H., Bechtold, M. \& Puli, S. R. Efficacy of preoperative biliary drainage in malignant obstructive jaundice: a meta-analysis and systematic review. World J Surg Oncol 14, 182, doi:10.1186/s12957-016-0933-2 (2016).

5. Liu, C. et al. Association of Preoperative Biliary Drainage with Postoperative Morbidity after Pancreaticoduodenectomy. Gastroenterol Res Pract 2015, 796893, doi:10.1155/2015/796893 (2015).

6. Sugiyama, H. et al. Current status of preoperative drainage for distal biliary obstruction. World J Hepatol 7, 2171-2176, doi:10.4254/wjh.v7.i18.2171 (2015).

7. Arkadopoulos, N. et al. Preoperative biliary drainage of severely jaundiced patients increases morbidity of pancreaticoduodenectomy: results of a case-control study. World J Surg 38, $2967-$ 2972, doi:10.1007/s00268-014-2669-x (2014).

8. Lai, E. C. et al. Preoperative endoscopic drainage for malignant obstructive jaundice. Br J Surg 81, 1195-1198 (1994).

9. Fang, Y. et al. Meta-analysis of randomized clinical trials on safety and efficacy of biliary drainage before surgery for obstructive jaundice. Br J Surg 100, 1589-1596, doi:10.1002/ bjs.9260 (2013).

10. Sewnath, M. E. et al. A meta-analysis on the efficacy of preoperative biliary drainage for tumors causing obstructive jaundice. Ann Surg 236, 17-27 (2002).

11. Scheufele, F. et al. Effect of preoperative biliary drainage on bacterial flora in bile of patients with periampullary cancer. Br J Surg 104, e182-e188, doi:10.1002/bjs.10450 (2017). 
12. van der Gaag, N. A. et al. Preoperative biliary drainage for cancer of the head of the pancreas. N Engl J Med 362, 129-137, doi:10.1056/NEJMoa0903230 (2010).

13. Oncoline. Pancreascarcinoom, <http://www.oncoline.nl/pancreascarcinoom > (2011).

14. Tol, J. A. et al. Metal or plastic stents for preoperative biliary drainage in resectable pancreatic cancer. Gut, doi:10.1136/gutjnl-2014-308762 (2015).

15. Song, T. J. et al. Metal versus plastic stents for drainage of malignant biliary obstruction before primary surgical resection. Gastrointest Endosc 84, 814-821, doi:10.1016/j.gie.2016.04.018 (2016).

16. Gardner, T. B. et al. Cost-effectiveness and clinical efficacy of biliary stents in patients undergoing neoadjuvant therapy for pancreatic adenocarcinoma in a randomized controlled trial. Gastrointest Endosc 84, 460-466, doi:10.1016/j.gie.2016.02.047 (2016). 
Q 810

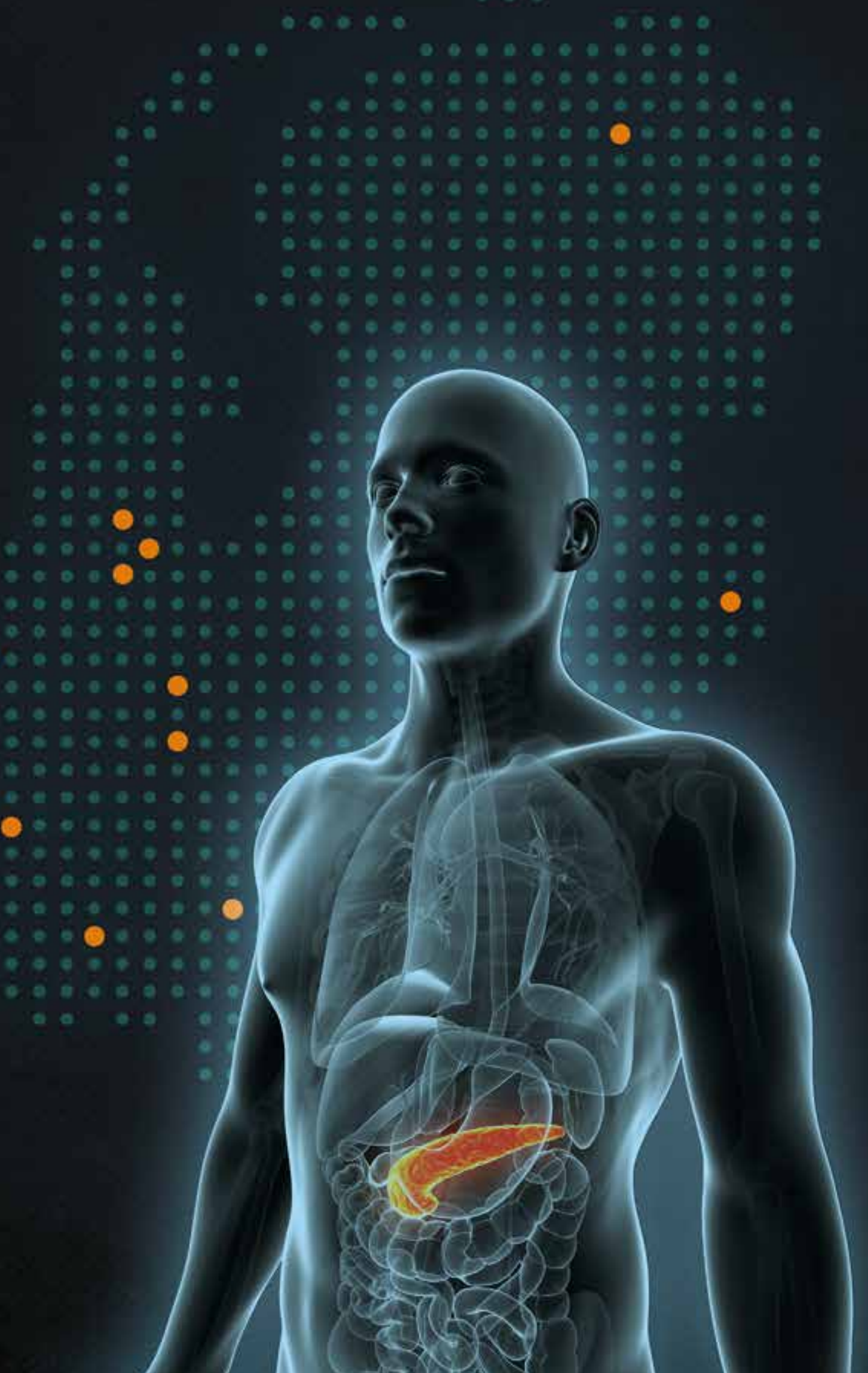

00080000000000000

0.00000000000000

0.000 .00 .0

0.0000000

$\ldots$

0000000000

Q

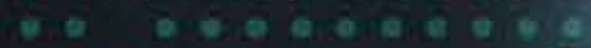

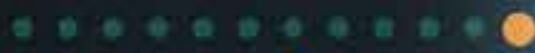

0.0000000008

0.000 .0 .00

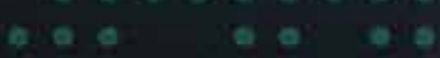

$\ldots$

a: 


\title{
THE USE OF ADJUVANT CHEMOTHERAPY FOR PANCREATIC CANCER VARIES WIDELY BETWEEN HOSPITALS: A NATIONWIDE POPULATION-BASED ANALYSIS
}

\author{
M.J.A.M. Bakens ${ }^{1,2}$ ｜Ｌ.G.M. van der Geest ${ }^{2}$ | M. van Putten ${ }^{2}$ \\ H.W.M. van Laarhoven ${ }^{3}$ | GJ Creemers ${ }^{4}$ | M.G. Besselink ${ }^{5}$ \\ V.E.P.P. Lemmens ${ }^{2,6}$ | I.H.J.T. de Hingh ${ }^{1}$ \\ for the Dutch Pancreatic Cancer Group
}

Cancer Med. 2016 Oct;5(10):2825-2831.

1 Department of Surgery, Catharina Hospital, Eindhoven, the Netherlands

2 Netherlands Cancer Registry, Netherlands Comprehensive Cancer Organization (IKNL), Utrecht, the Netherlands

${ }^{3}$ Department of Medical Oncology, Academic Medical Center, Amsterdam, the Netherlands

${ }^{4}$ Department of Oncology, Catharina Hospital, Eindhoven, the Netherlands

${ }^{5}$ Department of Surgery, Academic Medical Center, Amsterdam, the Netherlands

${ }^{6}$ Department of Public Health, Erasmus Medical Center, Rotterdam, the Netherlands 


\section{ABSTRACT}

Background Adjuvant chemotherapy after pancreatoduodenectomy for pancreatic cancer is currently considered standard of care. In this nationwide study we investigated which characteristics determine the likelihood of receiving adjuvant chemotherapy and its effect on overall survival.

Methods The data were obtained from the Netherlands Cancer Registry. All patients alive 90 days after pancreatoduodenectomy for M0-pancreatic cancer between 2008 and 2013 in the Netherlands were included in this study. The likelihood to receive adjuvant chemotherapy was analyzed by multilevel logistic regression analysis and differences in time-to-first-chemotherapy were tested for significance by Mann-Whitney $\mathrm{U}$ test. Overall survival was assessed by Kaplan-Meier method and Cox-regression analysis.

Results Of the 1195 patients undergoing a pancreatoduodenectomy for pancreatic cancer, 642 (54\%) patients received adjuvant chemotherapy. Proportions differed significantly between the 19-pancreatic centers, ranging from $26 \%$ to $74 \%$ $(\mathrm{p}<0.001)$. Median time-to-first-chemotherapy was 6.7 weeks and did not differ between centers. Patients with a higher tumor stage, younger age and diagnosed more recently, were more likely to receive adjuvant treatment. The five year overall-survival was significantly prolonged in patients treated with adjuvant chemotherapy $23 \%$ versus $17 \%, \log$-rank $=0.01$. In Cox-regression analysis treatment with adjuvant chemotherapy significantly prolonged survival compared with treatment without adjuvant chemotherapy.

Conclusion The finding that elderly patients and patients with a low tumor stage are less likely to undergo treatment needs further attention, especially since adjuvant treatment is known to prolong survival in most of these patients. 


\section{INTRODUCTION}

Pancreatic cancer has a very poor prognosis. Currently, surgical resection is the only possible treatment to obtain long-term survival. ${ }^{1}$ The recent CONKO-001 randomized clinical trial has demonstrated an additional benefit of adjuvant chemotherapy on disease-free and overall survival for pancreatic cancer. ${ }^{2}$ These results were obtained in all age groups, for both sexes and independent of tumor stage. ${ }^{2}$ Given these results, adjuvant chemotherapy is now considered standard of care in most countries including the Netherlands, where adjuvant chemotherapy (Gemcitabine) has been recommended by the Dutch society of Medical Oncology (NVMO) since $2008 .^{3}$

In the Netherlands, surgery for pancreatic cancer is only performed in centers performing at least 20 pancreatoduodenectomies (PD) annually. This centralization significantly improved outcomes of pancreatic surgery in terms of post-operative morbidity and mortality. ${ }^{4,5}$ In contrast, systemic treatment of pancreatic cancer patients, including adjuvant chemotherapy in operated patients is given in almost all hospitals in the Netherlands. Previous studies have shown that a considerable amount of patients do not receive adjuvant chemotherapy after recovery from a pancreatoduodenectomy. ${ }^{6-8}$ It is currently unknown which factors determine the likelihood for receiving adjuvant chemotherapy. Therefore this nationwide study investigated the variation between pancreatic centers in adjuvant treatment and which characteristics determine the likelihood of receiving adjuvant chemotherapy in the Netherlands. By doing so, correctable reasons for underutilization of adjuvant chemotherapy may be identified, thereby raising the possibility to further improve the treatment of pancreatic cancer patients.

\section{PATIENTS AND METHODS}

\section{DATA COLLECTION}

Data were obtained from the nationwide Netherlands Cancer Registry (NCR). This registry contains data of all newly diagnosed cancer patients in the Netherlands (approximately 16.8 million inhabitants in 2013), which is routinely extracted from the medical records in all hospitals and registered by specially trained, independent administrators. The NCR 
contains patient, tumor and treatment characteristics. The extent of disease was defined by pathological findings, and was staged by using the TNM classification or pathologic extend of disease (pEoD). pEoD classifications were converted to TNM classification. ${ }^{9} 10$ In $\mathrm{pEoD}$ classification tumor involvement of the truncus coeliacus or arteria mesenterica superior (AMS) is not specified. Therefor no differentiation between TNM stage II or III could be made, and these patients were categorized as TNM II/III.

\section{PATIENT SELECTION}

All non-metastatic (M0) patients diagnosed with adenocarcinoma of the pancreas (ICD C25) ${ }^{11}$ between 1 January 2008 and 31 December 2013 in the Netherlands and surgically treated by PD in a pancreatic center were included in this study. Patients diagnosed with carcinoma-in-situ (Tis), neuroendocrine tumors, patients with missing data on tumor stage and patients deceased within 90 days after surgical treatment were excluded from further analysis $(\mathrm{n}=218)$. This landmark at 90 -days postoperative was chosen to minimize the possible effect of postoperative complications on the administration of adjuvant chemotherapy and to deal with immortal time bias of patients receiving chemotherapy. Adjuvant chemotherapy was defined as any chemotherapeutical treatment starting within 16 weeks after surgery.

\section{PANCREATIC CENTER}

In the Netherlands, a minimum of 20 PDs per year is currently required to be considered as a pancreatic center. This resulted in 19 pancreatic centers in the Netherlands in 2013, including 8 university hospitals.

\section{STATISTICAL ANALYSIS}

Differences in patient- and tumor characteristics between patients who underwent adjuvant chemotherapy and patients who did not were compared with chi-square tests. To analyze the hierarchically structured data of patients nested within pancreatic centers, a multilevel logistic regression analysis was used. Multilevel regression analyses provide more accurate estimates when dealing with hierarchically structured data than traditional regression analyses as they account for dependency of patients within pancreatic 
centers. $^{12,13}$ The outcome variable was adjuvant chemotherapy (0, no; 1 , yes). Patientand tumor-related variables (sex, age, TNM-stage, year of diagnosis) were added to the multivariable multilevel model. The effect of a variable on the likelihood of adjuvant chemotherapy was expressed as an odds ratio (OR) with 95\% Confidence Interval (CI).

Each patient's adjusted chance to undergo adjuvant chemotherapy was given by the following formula: $\mathrm{P}=\mathrm{eL} /(1+\mathrm{eL})$, where $\mathrm{L}$ is the calculated value from the logistic regression for that particular patient. The mean adjusted probability to undergo adjuvant chemotherapy for each pancreatic center was defined as the mean adjusted surgical probability of the patients within that pancreatic center. This resulted in a range of probabilities to undergo adjuvant chemotherapy adjusted for differences in patient- and tumor characteristics between pancreatic centers. The variation in adjuvant chemotherapy probabilities between pancreatic centers was tested for statistical significance by means of ANOVA with Bonferroni correction.

The differences in comparisons made for the time period between surgery and start of adjuvant chemotherapy, defined as time to adjuvant chemotherapy in weeks, were tested for significance using the non-parametric Mann-Whitney $U$ test.

\section{CONDITIONAL SURVIVAL}

Data retrieved from the Municipal Personal Records Database (BRP) were used to calculate survival. In the BRP all deaths or emigrations of Dutch inhabitants are registered. Survival time was defined as time from diagnosis to death, or until 1 January 2015 for patients who were still alive. The Kaplan-Meier method was used to determine five-year survival. The effect of the time to adjuvant chemotherapy on the overall survival was assessed by log-rank test. Multivariable cox regression analysis was undertaken to investigate the prognostic impact of adjuvant chemotherapy on overall survival, after adjustment for patient characteristics. Results from survival analyses using Cox regression analysis were reported as hazard ratios (HR) with 95\% CI.

All analyses were performed using Statistical Analysis Software (SAS) version 9.4 and a $\mathrm{P}<0.05$ was considered statistically significant. 


\section{RESULTS}

\section{PATIENTS}

Between 2008 and 2013, 5846 patients were diagnosed with M0-pancreatic-cancer in the Netherlands of whom 1413 (24\%) underwent PD in a pancreatic center. In total, 218 patients were excluded. The main reasons for exclusion were diagnosis of a neuroendocrine tumor $(n=78)$ and death within 90-days after surgery $(n=84)$. The remaining 1195 patients were included in the current study. Adjuvant chemotherapy was administered to 642 (54\%) of these patients, either in the pancreatic center where the surgery was performed (56\%) or in the referring hospital (44\%). Baseline characteristics differed between patients treated with and without adjuvant chemotherapy, with patients receiving chemotherapy being younger (median 64 vs. 70 years respectively, $\mathrm{P}<0.001$ ) and being diagnosed with a higher TNM tumor stage (Table 1).

TABLE 1. Baseline characteristics of $M_{0}$-pancreatic cancer patients treated by pancreatoduodenectomy between 2008 and 2013 in the Netherlands.

\begin{tabular}{|c|c|c|c|c|}
\hline Variables & $n=1195$ & $\begin{array}{c}\text { Adjuvant } \\
\text { Chemotherapy } \\
\text { n=642 (54\%) }\end{array}$ & $\begin{array}{c}\text { No adjuvant } \\
\text { chemotherapy } \\
n=553(46 \%)\end{array}$ & $P$-value \\
\hline Sex & & & & 0.871 \\
\hline Male & 615 (51\%) & $329(51 \%)$ & $286(52 \%)$ & \\
\hline Female & 580 (49\%) & 313 (49\%) & 267 (48\%) & \\
\hline Age & & & & $<0.001$ \\
\hline$<60$ Years & 285 (24\%) & 201 (31\%) & 84 (15\%) & \\
\hline 60 - 75 Years & 715 (60\%) & 409 (64\%) & 306 (55\%) & \\
\hline$\geq 75$ Years & 195 (16\%) & $32(5 \%)$ & 163 (30\%) & \\
\hline TNM Stage & & & & $<0.001$ \\
\hline 1 & 157 (13\%) & $54(8 \%)$ & 103 (19\%) & \\
\hline II / III & 1038 (87\%) & 588 (92\%) & 450 (81\%) & \\
\hline Year of diagnosis & & & & $<0.001$ \\
\hline 2008 & $129(11 \%)$ & $42(7 \%)$ & 87 (16\%) & \\
\hline 2009 & $162(14 \%)$ & 87 (13\%) & 75 (13\%) & \\
\hline 2010 & $162(14 \%)$ & 84 (13\%) & $78(14 \%)$ & \\
\hline 2011 & 188 (15\%) & $98(15 \%)$ & 90 (16\%) & \\
\hline 2012 & 278 (23\%) & 164 (26\%) & 114 (21\%) & \\
\hline 2013 & $276(23 \%)$ & 167 (26\%) & 109 (20\%) & \\
\hline
\end{tabular}




\section{CENTER OF SURGERY}

The observed proportion of patients receiving adjuvant chemotherapy differed significantly between the 19 pancreatic centers in the Netherlands and ranged from $26 \%$ to $74 \%, \mathrm{p}<0.001$ (Figure 1).

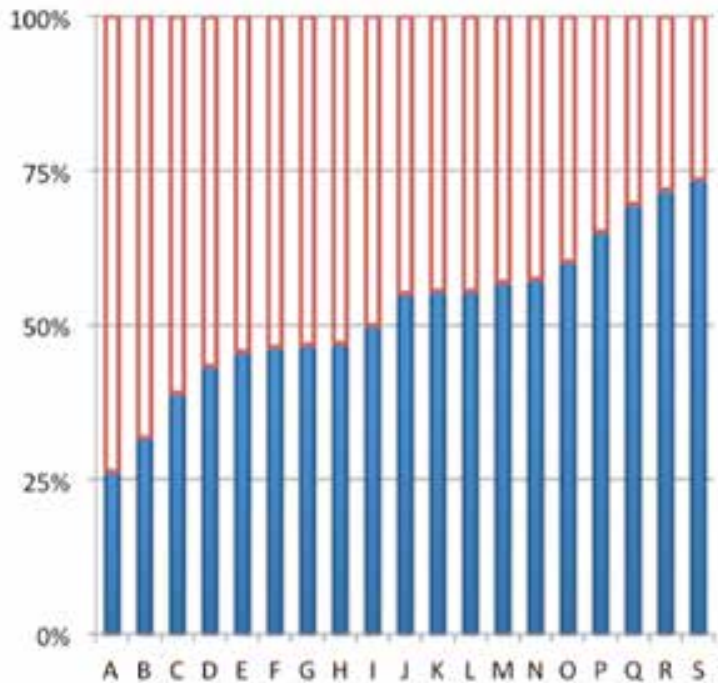

[No adjuvant chemotherapy

adjuvant chemotherapy

Pancreatic centers

(Center of surgery)

FIGURE 1. Observed percentage of adjuvant chemotherapy treatment in pancreatic cancer patients undergoing pancreatoduodenectomy in pancreatic centers between 2008 and 2013 in the Netherlands.

Multi-level logistic regression confirmed the effect of the pancreatic center on the probability to undergo adjuvant chemotherapy. The case-mix adjusted probability for adjuvant chemotherapy treatment ranged between $35 \%$ and $68 \%$ according to the pancreatic centers (Figure 2; $\mathrm{p}<0.001$ ).

No significant difference was found in the observed treatment percentages between university pancreatic centers or non-university pancreatic centers ( $55 \%$ vs. $52 \%$, $\mathrm{p}=0.245$ ). 


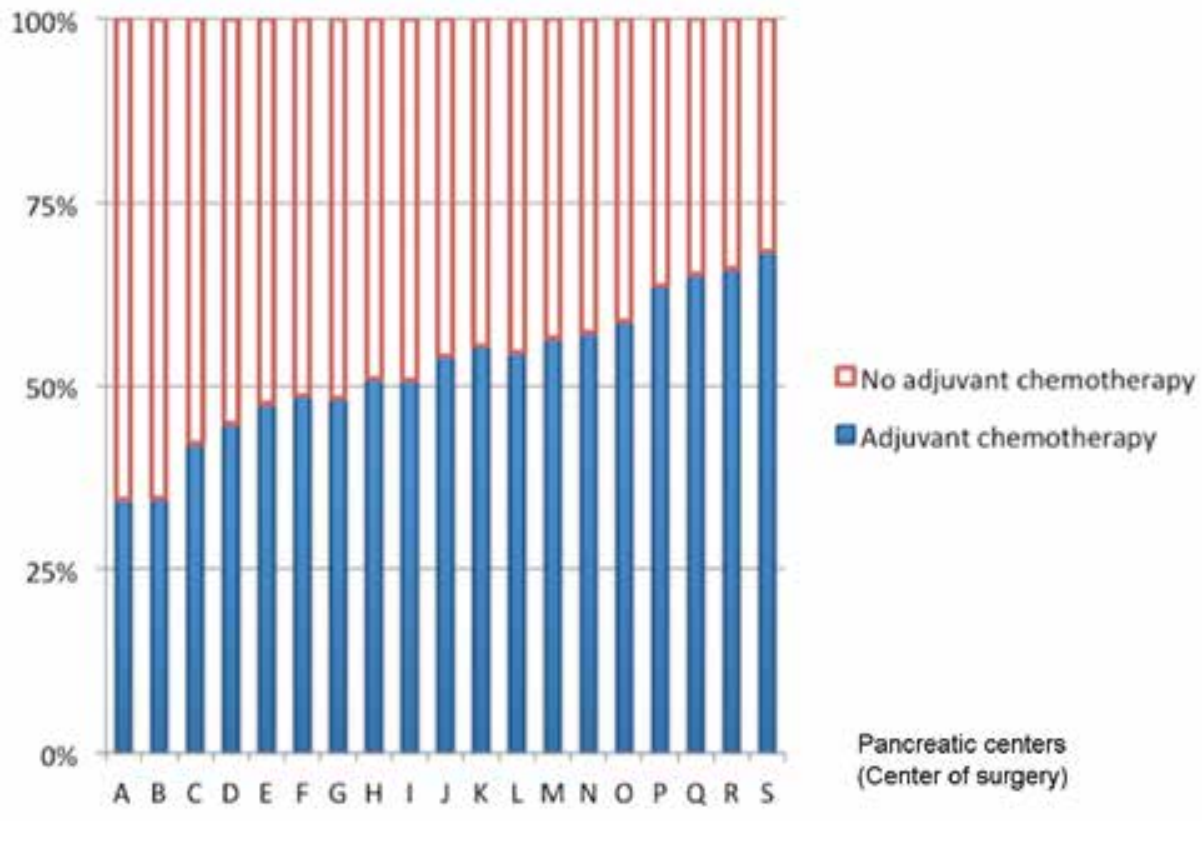

FIGURE 2. Multilevel case- mix adjusted probability for adjuvant chemotherapy treatment for pancreatic centers in the Netherlands between 2008 and 2013.

Variables influencing the likelihood of receiving adjuvant chemotherapy are presented in Table 2. Multi-level logistic regression model showed that an increased likelihood of adjuvant treatment was observed in patients with a TNM tumor stage II or III compared to TNM stage I (respectively $57 \%$ vs. $34 \%$ OR $2.7195 \%$ CI 1.77-4.15). Furthermore, patients older than 60 years were less likely to undergo adjuvant chemotherapy $(70 \%<$ 60 years versus $57 \% 60-75$ years, OR $0.48,95 \%$ CI $0.34-0.67$ ). Patients older than 75 years were the least likely to receive chemotherapy ( $16 \%$, OR $0.06,95 \%$ CI $0.04-0.10)$.

Over time, the use of adjuvant chemotherapy increased from $33 \%$ in 2008 to $61 \%$ in 2013. Patients diagnosed in the year 2013 were more likely to undergo adjuvant treatment compared to patients diagnosed in 2008 (OR 4.63, 95\%CI 2.73-7.87). 
Table 2. Multi-level logistic regression analyses for the likelihood of adjuvant chemotherapy treatment among $\mathrm{M}_{0}$-pancreatic cancer patients diagnosed between 2008 and 2013 and surgically treated by pancreatoduodenectomy in the Netherlands.

\begin{tabular}{|c|c|c|c|}
\hline Variable & $\begin{array}{c}\text { Adjuvant } \\
\text { chemotherapy } \\
\mathrm{N}=642(54 \%)\end{array}$ & Odds Ratio & [95\% CI] \\
\hline \multicolumn{4}{|l|}{ Sex } \\
\hline Male & $329(54 \%)$ & 1 & \\
\hline Female & $313(54 \%)$ & 1.06 & [0.81- 1.40] \\
\hline \multicolumn{4}{|l|}{ Age } \\
\hline$<60$ Years & 201 (71\%) & 1 & \\
\hline 60 - 75 Years & 409 (57\%) & $0.48 *$ & {$[0.34-0.67]$} \\
\hline$\geq 75$ Years & $32(16 \%)$ & $0.06 *$ & {$[0.04-0.10]$} \\
\hline \multicolumn{4}{|l|}{ TNM Stage } \\
\hline 1 & $54(34 \%)$ & 1 & \\
\hline II / III & $588(57 \%)$ & $2.71 *$ & [1.77- 4.15$]$ \\
\hline \multicolumn{4}{|l|}{ Year of diagnosis } \\
\hline 2008 & $42(33 \%)$ & 1 & \\
\hline 2009 & 87 (54\%) & $2.83 *$ & {$[1.61-4.98]$} \\
\hline 2010 & $84(52 \%)$ & $2.85 *$ & {$[1.61-5.05]$} \\
\hline 2011 & $98(52 \%)$ & $3.42 *$ & [1.96 - 5.99] \\
\hline 2012 & 164 (59\%) & $4.39 *$ & [2.59- 7.46$]$ \\
\hline 2013 & 167 (61\%) & $4.63 *$ & [2.73 - 7.87] \\
\hline
\end{tabular}

Corrected for pancreatic center, Intercept 0.275 , SE 0.127

* Significantly different

\section{TIME TO ADJUVANT CHEMOTHERAPY}

In $400(62 \%)$ patients adjuvant chemotherapy was initiated within 8 weeks after PD, in $134(21 \%)$ patients between 8 and 12 weeks postoperatively, and in 23 (4\%) patients treatment was started more than 12 weeks after PD. In 85 (13\%) patients information on time to adjuvant chemotherapy was missing. Median time to adjuvant chemotherapy was 6.6 weeks (Interquartile range (IQR): 2.9) The time to adjuvant chemotherapy did not significantly differ between patients resected in university centers versus nonuniversity centers, $\mathrm{p}=0.803$ (respectively median 6.7 , IQR: 2.7 vs. median: 6.4, IQR: 3.3). 
Furthermore, no difference in time to adjuvant chemotherapy was found for patients treated in a pancreatic center versus patients referred to a non-pancreatic center for receiving adjuvant chemotherapy $\mathrm{p}=0.194$ (respectively median: 6.3, IQR: 2.9 vs. median: 7.0, IQR: 3.4).

\section{CONDITIONAL SURVIVAL}

Kaplan Meier analysis (Figure 3) revealed a significant difference in five-year overall survival rates based on whether patients were treated by adjuvant chemotherapy $23 \%$ vs. $17 \%$ if not treated by adjuvant chemotherapy (Log-rank <0.001). Patients treated with adjuvant chemotherapy had a five-year survival rate of $22 \%$ if time to adjuvant chemotherapy was $\leq 6$ weeks vs. $21 \%$ for time to adjuvant chemotherapy $>6$ weeks.

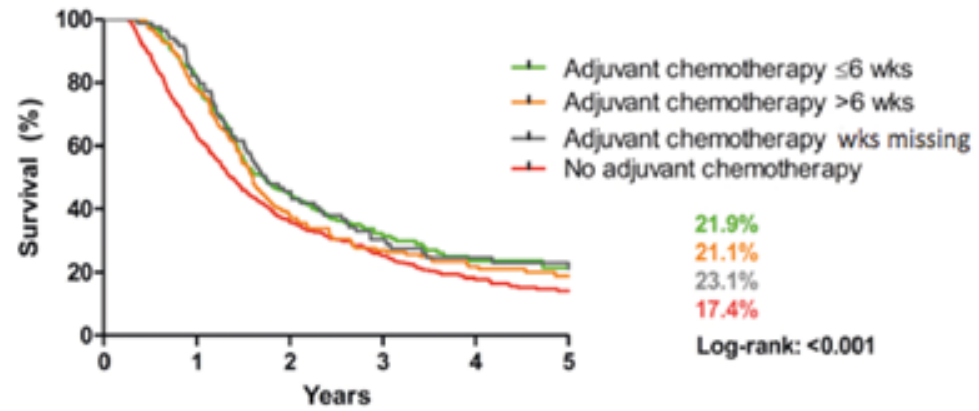

Number at risk

$\begin{array}{lcccccc}\text { Adjv. Chemo } \leq 6 \text { wks } & 307 & 251 & 100 & 40 & 18 & 9 \\ \text { Adjv. Chemo > 6wks } & 250 & 195 & 74 & 41 & 28 & 16 \\ \text { Adjv. Chemo wks missing } & 85 & 71 & 38 & 23 & 16 & 13 \\ \text { No adjv. Chemotherapy } & 553 & 351 & 170 & 91 & 45 & 27\end{array}$

FIGURE 3. Kaplan-Meier, 5- year overall survival adjuvant chemotherapy versus no adjuvant chemotherapy after pancreatoduodenectomy in pancreatic cancer patients in the Netherlands between 2008 and 2013. 
In Cox regression analyses (Table 3), adjuvant chemotherapy treatment was a significant predictor of prolonged survival for both adjuvant chemotherapy within 6 weeks as well as for adjuvant chemotherapy after 6 weeks compared with no adjuvant chemotherapy (HR 0.68, 95\%CI 0.56-0.82 vs. HR 0.79, 95\%CI 0.66-0.95). A tumor stage TNM II/III was a significant variable for shortened survival (HR 1.97 95\%CI: 1.58-2.47).

TABLE 3. Cox regression analyses among $M_{0}$-pancreatic cancer patients diagnosed between 2008 and 2013 in the Netherlands and surgically treated by pancreatoduodenectomy.

\begin{tabular}{|c|c|c|}
\hline Variable & Hazard Ratio & {$[95 \% \mathrm{Cl}]$} \\
\hline \multicolumn{3}{|l|}{ Sex } \\
\hline Male & 1 & \\
\hline Female & 0.93 & {$[0.82-1.07]$} \\
\hline \multicolumn{3}{|l|}{ Age } \\
\hline$<60$ Years & 1 & \\
\hline $60-75$ Years & 1.06 & {$[0.90-1.26]$} \\
\hline$\geq 75$ Years & 1.16 & {$[0.92-1.47]$} \\
\hline \multicolumn{3}{|l|}{ TNM Stage } \\
\hline 1 & 1 & \\
\hline II / III & $1.97 *$ & {$[1.58-2.47]$} \\
\hline \multicolumn{3}{|l|}{ Year of diagnosis } \\
\hline 2008 & 1 & \\
\hline 2009 & $0.70 *$ & {$[0.54-0.91]$} \\
\hline 2010 & 0.90 & {$[0.69-1.16]$} \\
\hline 2011 & 0.87 & {$[0.67-1.12]$} \\
\hline 2012 & 0.93 & {$[0.72-1.18]$} \\
\hline 2013 & 1.10 & {$[0.85-1.43]$} \\
\hline \multicolumn{3}{|l|}{ Adjuvant Chemotherapy } \\
\hline No & 1 & \\
\hline Yes (started $\leq 6$ weeks postoperative) & $0.68 *$ & {$[0.56-0.82]$} \\
\hline Yes (started >6 weeks postoperative) & $0.79 *$ & {$[0.67-0.95]$} \\
\hline Yes (date of start missing) & $0.71 *$ & {$[0.54-0.93]$} \\
\hline
\end{tabular}

* Significantly different 


\section{DISCUSSION}

The current population-based study revealed that $54 \%$ of the pancreatic cancer patients received adjuvant chemotherapy following $\mathrm{PD}$. Elderly patients were less likely to undergo adjuvant chemotherapy. Interestingly, the likelihood of receiving adjuvant chemotherapy treatment varied significantly between pancreatic centers. Survival analyses showed that the addition of adjuvant chemotherapy was associated with a prolonged survival. This was seen in patients receiving adjuvant chemotherapy within 6 weeks postoperatively but also in patients receiving chemotherapy more than 6 weeks after PD.

Our findings on overall survival are in line with a recent RCT and a previous population-based study in the USA showing a positive influence of adjuvant chemotherapy on overall survival. ${ }^{2,6}$ This again stresses the beneficial effect of treating patients with adjuvant chemotherapy if possible. A recent study in the Netherlands showed limited compliance to quality indicators in pancreatic cancer care based on the Dutch guideline. The administration of adjuvant chemotherapy increased from $45 \%$ of patients in 2010 to $54 \%$ in $2012 .{ }^{14}$ Nevertheless, the proportion of patients treated by adjuvant chemotherapy in the current study is comparable to percentages described in literature. Mayo et al. reported adjuvant treatment in 51\% of patients undergoing any type of surgery for pancreatic adenocarcinoma in Medicare beneficiaries in the USA. ${ }^{6}$ A multicenter study in Japan demonstrated that $66 \%$ of the pancreatic cancer patients received adjuvant chemotherapy. ${ }^{15}$ Finally, a study by Aloia et al. showed the highest percentage: $74 \%$ of patients received adjuvant therapy after PD. However, in spite of this high percentage the authors suggested that at least $90 \%$ of patients with localized pancreatic adenocarcinoma and good pre-treatment performance status would have been candidates for postoperative adjuvant therapy. ${ }^{7}$

A similar limited use of adjuvant chemotherapy has been shown in other tumors. For instance, only $60 \%$ patients with colon cancer and lymph node metastases received adjuvant chemotherapy in the Netherlands. ${ }^{16}$

Remarkably, the proportion of patients receiving adjuvant chemotherapy varied significantly between pancreatic centers in this study. This finding was not in line with expectations, as all pancreatic centers are supposed to have expert knowledge in the treatment of pancreatic cancer and to adhere to the national guidelines. The differences 
in the probability to receive adjuvant chemotherapy remained present after adjustment for available case-mix variables; sex, age, TNM-stage, year of diagnosis. There may be various explanations for this phenomenon. First of all, the multidisciplinary tumor boards (MDTB) in the 19-pancreatic centers may have various attitudes towards the guideline recommendations, resulting in a different tendency to advice adjuvant chemotherapy. Since a significant proportion of the patients (44\%) were not treated in the pancreatic center but in the referring hospital, medical oncologists from referring hospitals may choose to react differently on the advice of the MDTB. Furthermore, it should be acknowledged that in some cases patients choose to not undergo adjuvant chemotherapy. This decision-making process will be the subject of further research.

In this study, age was an important variable in selecting patients with older patients being less likely to receive adjuvant chemotherapy. Previous retrospective studies have reported also an effect of age on the selection of patients for adjuvant chemotherapy. ${ }^{8,17}$ However, it was shown in the CONKO-001 trial that the beneficial effects of adjuvant chemotherapy were obtained regardless of age. ${ }^{2}$ Also in the cohort study by Nagrial et al. it was demonstrated that adjuvant chemotherapy in elderly patients was associated with an improved survival to at least a similar degree as for younger patients. ${ }^{17}$ Furthermore, it is known that PDs can be safely performed in elderly patients with good postoperative outcomes. ${ }^{18,} 19$ Therefore, physicians may be too reluctant in prescribing adjuvant chemotherapy to elderly patients.

Patients diagnosed with a tumor stage TNM II or III, were more likely to receive adjuvant chemotherapy treatment as compared to patients with stage I disease. Given the worse prognosis in stage TNM II or III patients, especially in the case of lymph-node metastases, treating physicians may be more willing to administer adjuvant chemotherapy in these patients. However, as was shown by Oettle and colleges, the beneficial results of adjuvant chemotherapy were not only achieved in high-staged tumors but also in lowstaged tumors. $^{2}$ Therefore, adjuvant chemotherapy treatment of patients with stage I disease needs further attention.

This study had some limitations. Although the NCR registry is a reliable and complete database, data like resection status (R0/R1), postoperative complications, comorbidities and performance status are lacking. These factors may have influenced the likelihood of receiving adjuvant chemotherapy treatment. Insurance status is not likely to affect 
the likelihood for adjuvant chemotherapy because of the equally accessible health care system in the Netherlands. Data on type of chemotherapy and completion rates in patients undergoing adjuvant chemotherapy were not registered. In our study, an effort to minimize the possible effect of postoperative complications on the administration of adjuvant chemotherapy was undertaken by excluding patients deceased within 90 -days. A correlation between severe complications and omission of adjuvant treatment was reported earlier by Wu et al. ${ }^{8}$ Furthermore, they described a decreased likelihood for adjuvant chemotherapy if the length of postoperative stay exceeded 9 days. ${ }^{8}$ The results of that study showed that withdrawal of adjuvant chemotherapy in some cases could be explained by a prolonged postoperative recovery were early initiation of adjuvant chemotherapy could not be achieved caused by postoperative complications. ${ }^{6-8}$ However, recently, Valle et al. reported that survival following start of adjuvant chemotherapy treatment within 8-12 weeks postoperatively did not differ from initiation within 8 weeks postoperatively. Completion of the full course of the treatment was a more important factor determining outcomes. ${ }^{20}$ Likelihood of completion of the full course was maximized by an adequate postoperative recovery. Consequently, an inability of administering adjuvant chemotherapy prior to 8 weeks postoperatively does not eliminate the beneficial effect of chemotherapy, as was confirmed by our study. ${ }^{20}$ The observed median time of 6.6 weeks between PD and initiation of adjuvant chemotherapy, however, suggests there might have been a nihilistic approach to a late start of adjuvant chemotherapy. In summary, there is an underuse of adjuvant chemotherapy for pancreatic cancer in the Netherlands. Even in the last year of this study only $61 \%$ of the patients received adjuvant treatment. Elderly patients were less likely to undergo adjuvant chemotherapy, despite the beneficial effect of such treatment also in this age group. Interestingly, the likelihood of receiving adjuvant chemotherapy treatment varied significantly between pancreatic centers, a finding that may not be explained by case-mix alone. This finding clearly needs further attention and more research, especially since in this study treatment with adjuvant chemotherapy resulted in a significantly prolonged overall survival. The Dutch Pancreatic Cancer Project (PACAP) including prospective audit, are used for improvements in the use of adjuvant chemotherapy and other relevant factors in survival for pancreatic cancer in the Netherlands. 


\section{FUNDING}

The Dutch Cancer Society (KWF) [Grant No. 2013-649] funded this study. The funding source had no role in the study design, data collection and analysis, the writing of the manuscript or the submission for publication.

\section{ACKNOWLEDGEMENTS}

The authors thank the registration team of the Netherlands Comprehensive Cancer Organization (IKNL) for the collection of data for the NCR. They also thank all participating hospitals in the Netherlands.

\section{DISCLOSURE}

The authors declare no conflict of interest. 


\section{REFERENCES}

1. Vincent A, Herman J, Schulick R, Hruban RH, Goggins M. Pancreatic cancer. Lancet 2011;378(9791): 607-620.

2. Oettle H, Neuhaus P, Hochhaus A, Hartmann JT, Gellert K, Ridwelski K, Niedergethmann M, Zulke C, Fahlke J, Arning MB, Sinn M, Hinke A, Riess H. Adjuvant chemotherapy with gemcitabine and long-term outcomes among patients with resected pancreatic cancer: the CONKO-001 randomized trial. JAMA 2013;310(14): 1473-1481.

3. Pancreascarcinoom. http://www.oncoline.nl/pancreascarcinoom [15 May 2015].

4. Gooiker GA, Lemmens VE, Besselink MG, Busch OR, Bonsing BA, Molenaar IQ, Tollenaar RA, de Hingh IH, Wouters MW. Impact of centralization of pancreatic cancer surgery on resection rates and survival. Br J Surg 2014;101(8): 1000-1005.

5. Lemmens VE, Bosscha K, van der Schelling G, Brenninkmeijer S, Coebergh JW, de Hingh IH. Improving outcome for patients with pancreatic cancer through centralization. Br J Surg 2011;98(10): 1455-1462.

6. Mayo SC, Gilson MM, Herman JM, Cameron JL, Nathan H, Edil BH, Choti MA, Schulick RD, Wolfgang CL, Pawlik TM. Management of patients with pancreatic adenocarcinoma: national trends in patient selection, operative management, and use of adjuvant therapy. J Am Coll Surg 2012;214(1): 33-45.

7. Aloia TA, Lee JE, Vauthey JN, Abdalla EK, Wolff RA, Varadhachary GR, Abbruzzese JL, Crane $\mathrm{CH}$, Evans DB, Pisters PW. Delayed recovery after pancreaticoduodenectomy: a major factor impairing the delivery of adjuvant therapy? J Am Coll Surg 2007;204(3): 347-355.

8. Wu W, He J, Cameron JL, Makary M, Soares K, Ahuja N, Rezaee N, Herman J, Zheng L, Laheru D, Choti MA, Hruban RH, Pawlik TM, Wolfgang CL, Weiss MJ. The impact of postoperative complications on the administration of adjuvant therapy following pancreaticoduodenectomy for adenocarcinoma. Ann Surg Oncol 2014;21(9): 2873-2881.

9. Sobin LH, Wittekind C. TNM Classification of Malignant Tumors, 6th edition (6th edition edn), 2002.

10. Sobin LH, Gospodarowicz MK, Wittekind C. TNM classification of malignant tumors, 7th edition (7th edition edn), 2009.

11. Fritz AG. International classification of diseases for oncology : ICD-O (3rd edn). World Health Organization: Geneva, 2000; vii, 240 p. 
12. Twisk J. Applied Multilevel Analysis. Cambridge University Pres, 2006.

13. Austin PC, Tu JV, Alter DA. Comparing hierarchical modeling with traditional logistic regression analysis among patients hospitalized with acute myocardial infarction: should we be analyzing cardiovascular outcomes data differently? Am Heart J 2003;145(1): 27-35.

14. van Rijssen LB, van der Geest LG, Bollen TL, Bruno MJ, van der Gaast A, Veerbeek L, Ten Kate FJ, Busch OR. National compliance to an evidence-based multidisciplinary guideline on pancreatic and periampullary carcinoma. Pancreatology 2015.

15. Sata N, Kurashina K, Nagai H, Nagakawa T, Ishikawa O, Ohta T, Oka M, Kinoshita H, Kimura W, Shimada H, Tanaka M, Nakao A, Hirata K, Yasuda H. The effect of adjuvant and neoadjuvant chemo(radio)therapy on survival in 1,679 resected pancreatic carcinoma cases in Japan: report of the national survey in the 34th annual meeting of Japanese Society of Pancreatic Surgery. J Hepatobiliary Pancreat Surg 2009;16(4): 485-492.

16. van der Geest LG, Portielje JE, Wouters MW, Weijl NI, Tanis BC, Tollenaar RA, Struikmans H, Nortier JW, All Nine Hospitals in the Leiden Region of the Comprehensive Cancer Centre The N. Complicated postoperative recovery increases omission, delay and discontinuation of adjuvant chemotherapy in patients with Stage III colon cancer. Colorectal Dis 2013;15(10): e582-591.

17. Nagrial AM, Chang DK, Nguyen NQ, Johns AL, Chantrill LA, Humphris JL, Chin VT, Samra JS, Gill AJ, Pajic M, Australian Pancreatic Cancer Genome I, Pinese M, Colvin EK, Scarlett CJ, Chou A, Kench JG, Sutherland RL, Horvath LG, Biankin AV. Adjuvant chemotherapy in elderly patients with pancreatic cancer. Br J Cancer 2014;110(2): 313-319.

18. Oguro S, Shimada K, Kishi Y, Nara S, Esaki M, Kosuge T. Perioperative and long-term outcomes after pancreaticoduodenectomy in elderly patients 80 years of age and older. Langenbecks Arch Surg 2013;398(4): 531-538.

19. Adham M, Bredt LC, Robert M, Perinel J, Lombard-Bohas C, Ponchon T, Valette PJ. Pancreatic resection in elderly patients: should it be denied? Langenbecks Arch Surg 2014;399(4): 449-459.

20. Valle JW, Palmer D, Jackson R, Cox T, Neoptolemos JP, Ghaneh P, Rawcliffe CL, Bassi C, Stocken DD, Cunningham D, O’Reilly D, Goldstein D, Robinson BA, Karapetis C, Scarfe A, Lacaine F, Sand J, Izbicki JR, Mayerle J, Dervenis C, Olah A, Butturini G, Lind PA, Middleton MR, Anthoney A, Sumpter K, Carter R, Buchler MW. Optimal duration and timing of adjuvant chemotherapy after definitive surgery for ductal adenocarcinoma of the pancreas: ongoing lessons from the ESPAC-3 study. J Clin Oncol 2014;32(6): 504-512. 
Q 810

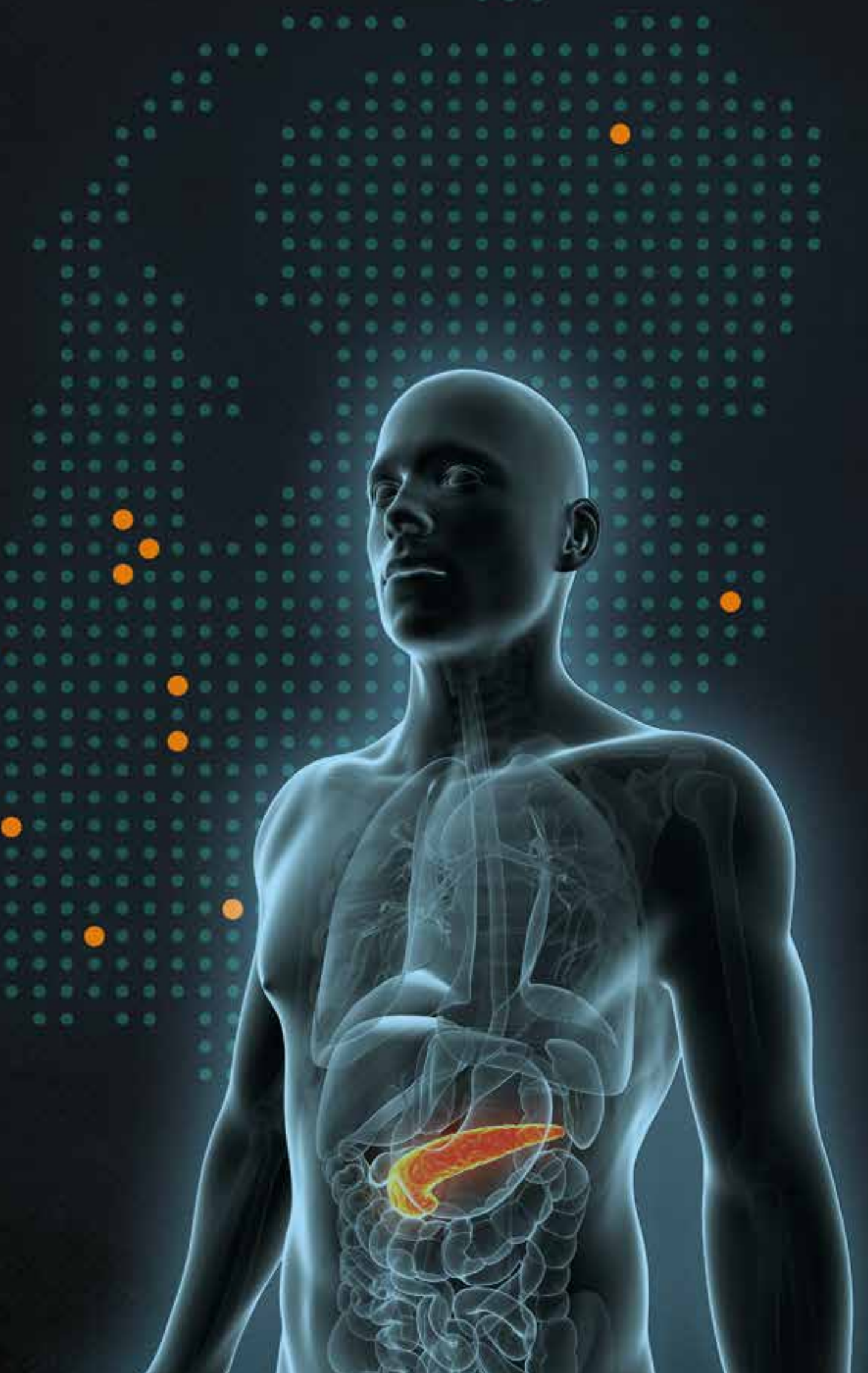

00080000000000000

0.00000000000000

0.000 .00 .0

0.0000000

$\ldots$

0000000000

Q

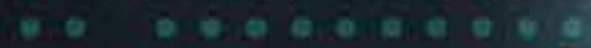

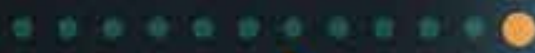

0.0000000008

0.000 .0 .00

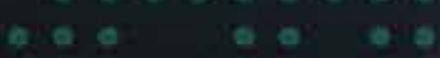

$\ldots$

a: 


\title{
SOCIO-ECONOMIC STATUS
} INFLUENCES THE LIKELIHOOD OF UNDERGOING SURGICAL TREATMENT FOR PANCREATIC CANCER IN THE NETHERLANDS

\author{
M.J.A.M. Bakens ${ }^{1,2}$ | V.E.P.P. Lemmens ${ }^{2,3}$ | I.H.J.T. de Hingh ${ }^{1}$
}

HPB. 2017 May; 19(5):443-448.

1 Department of Surgery, Catharina Hospital, Eindhoven, the Netherlands

2 Department of Research, Netherlands Comprehensive Cancer Organisation (IKNL), Utrecht, The Netherlands

3 Department of Public Health, Erasmus MC Medical Center, Rotterdam, The Netherlands 


\section{ABSTRACT}

Backgroud Surgical resection offers the only prospect of cure in pancreatic cancer patients. The probability of undergoing surgery is determined by several factors. The influence of socio-economic status (SES) on surgical treatment and survival was investigated in the Netherlands, a country with a widely accessible healthcare system.

Methods Data on all patients with non-metastasised pancreatic cancer between 2005-2013 were analyzed in the Eindhoven Cancer Registry (ECR). SES was categorized as low, intermediate or high. The influence of SES on the likelihood for surgery was assessed by multivariable logistic regression analyses.

The influence on overall survival was analyzed by multivariable Cox regression analyses.

Results 698 M0-patients were included, of whom 276 underwent surgery. Patients with low and intermediate SES were less likely to undergo surgery (32\% vs $37 \%)$ than high-SES patients (48\%) $(\mathrm{p}=0.002$; low SES: OR0.63, 95\%CI [0.40-0.98]; intermediate SES: OR0.62, 95\%CI [0.42-0.92]).

Survival did not differ between SES groups (low SES: HR1.05 95\%CI [0.85-1.30]; intermediate SES: HR1.11, 95\%CI [0.91-1.35]), $\mathrm{p}=0.181$.

Conclusion SES in pancreatic cancer patients determined the likelihood for surgery. However, SES had no influence on survival. It is important to provide more insights in the causes of these inequalities to minimalize the effects of SES in pancreatic cancer care. 


\section{INTRODUCTION}

Pancreatic cancer is currently the fourth leading cause of cancer related death in Europe and the USA. ${ }^{1}$ The only option to improve long-term survival is surgical treatment with or without neo-adjuvant chemotherapy, ideally followed by adjuvant chemotherapy. ${ }^{1,2}$ Nevertheless, up to $80 \%$ of pancreatic cancer patients are not treated with surgery. ${ }^{3}$ The most important reasons in refraining from surgical treatment are vascular involvement of the primary tumor and the presence of metastatic disease at the time of diagnosis. However, the choice of treatment is not solely based on tumor characteristics. Patient characteristics such as age and general condition are usually taken into account given the complexity and impact of the surgical procedure. We recently described that presence of surgical experience in the hospital in which the patient is initially diagnosed with pancreatic cancer plays an important role in whether or not to proceed with surgery. ${ }^{4}$

Another factor that may also influence the choice of treatment in complex oncological procedures is the socio-economic status (SES) of the patient. ${ }^{5}$ In previous studies, the effect of SES was mostly attributed to the nature of the health care system such as in the USA, where care may not be equally accessible to all patients. ${ }^{6,7}$ The health care system in the Netherlands differs from that in the USA in that all Dutch residents regardless of income or social status are covered by equitable health care insurance. The current study was undertaken to investigate whether SES also plays a role in the treatment of pancreatic cancer.

\section{METHODS}

\section{PATIENT SELECTION}

Patients with a clinical or histological diagnosis of pancreatic cancer (C25) diagnosed between 1st January 2005 and $31^{\text {st }}$ December 2013 in the southern region of the Netherlands were selected. ${ }^{8}$ This part of the Netherlands consists of approximately $15 \%$ of the Dutch population (16.7 million inhabitants in 2012).

TNM classification or Clinical Extent of Disease (CEoD) was used in staging the pancreatic tumors. Only non-metastasised (M0) pancreatic-cancer patients were 
included in the present study. Patients with missing tumor stage or diagnosed with tumor in situ (TNM 0) and patients with missing data on SES or categorized as institutionalized were excluded.

\section{DATA COLLECTION}

Data on patient and tumor characteristics was collected from the Eindhoven Cancer Registry maintained by the Netherlands Comprehensive Cancer organization (IKNL). Specially trained registers routinely register all patients with a newly diagnosed malignancy in the southern part of the Netherlands. Comorbidities were scored according to a slightly modified Charlson comorbidity index. ${ }^{9}$

\section{SOCIO-ECONOMIC STATUS (SES)}

SES was determined at neighborhood level using postal codes combined with mean value of housing and mean household income. These data were provided by the Netherlands Statistics Agency (CBS, Rijswijk, the Netherlands) and were derived from individual fiscal data available on an aggregated level. SES was divided into 3 predefined SES categories, low (first to third decile), intermediate (fourth to seventh decile) and high (eight to tenth decile). Postal codes were assigned to one of these categories.

\section{HOSPITAL OF DIAGNOSIS}

Hospital of initial diagnosis was defined as the first hospital in which the clinical diagnosis of pancreatic cancer was made. Hospitals were classified as 'pancreatic center' or 'non-pancreatic center'. This classification was based on the annual volume of pancreatoduodenectomies (PD) performed in 2013 for a suspected malignancy in the pancreatic head. Centers performing 20 or more PDs annually were classified as 'pancreatic center'. In the south region of the Netherlands 3 out of 10 hospitals fulfilled this criterion. 


\section{STUDY OUTCOMES}

\section{SURGERY}

Surgical treatment was defined as any laparotomy with curative intent. Tumor resection included pancreatoduodenectomy, pancreatic body resection or distal pancreatectomy.

\section{SURVIVAL}

Overall survival was calculated making use of data retrieved from the Municipal Personal Records Database. This database contains all deaths or emigrations in the Netherlands. Overall survival was calculated from time of diagnosis to either death or end of follow-up (January 2014).

\section{STATISTICAL ANALYSIS}

Differences in categorical variables between patients in the different SES and treatment groups were tested using Chi-square tests. A p-value under 0.05 was defined as statistically significant. The relationship between SES and likelihood of surgical treatment was tested by multivariable logistic regression analysis. Results were reported as Odds Ratios (OR) and $95 \%$ confidence intervals (95\%CI). Survival analysis was performed by KaplanMeier method and differences were assessed by the log-rank test. Differences in median survival were tested for significance by Mann Whitney U test. Cox proportional hazards regression analysis was performed to assess the effect of treatment and SES on overall survival. Analyses were performed using Statistical Analysis Software (SAS) version 9.4.

\section{RESULTS}

\section{POPULATION}

Of the M0 pancreatic cancer patients, 131 patients were excluded in this study.

There were 66 patients with missing tumor stage or diagnosed with tumor in situ (TNM 0) data were missing on SES or categorized as institutionalized $(n=65)$. In total, 698 patients diagnosed with M0 pancreatic cancer were included in the current study. Of these patients, 276 (40\%) underwent a laparotomy and in 232 patients (33\%) a resection of the tumor could be performed. 
Table 1. Baseline characteristics of pancreatic cancer patients diagnosed between 2005 and 2013 in the Eindhoven Cancer Registry in the Netherlands, categorized by socio-economic status (SES)

\begin{tabular}{|c|c|c|c|c|}
\hline Characteristics & $\begin{array}{c}\text { Low SES } \\
(n=184) \\
(\%)\end{array}$ & $\begin{array}{c}\text { Intermediate } \\
\text { SES }(n=275) \\
(\%)\end{array}$ & $\begin{array}{c}\text { High SES } \\
(n=239) \\
(\%)\end{array}$ & $p$ \\
\hline Sex & & & & 0.628 \\
\hline Male & $83(45)$ & $136(49)$ & $117(49)$ & \\
\hline Female & $101(55)$ & $139(51)$ & $122(51)$ & \\
\hline Age (years) & & & & 0.074 \\
\hline$<60$ & $51(28)$ & $77(28)$ & $77(32)$ & \\
\hline $60-69$ & $23(13)$ & $61(22)$ & $51(21)$ & \\
\hline $70-79$ & $72(39)$ & $92(33)$ & $78(33)$ & \\
\hline$\geq 80$ & $38(21)$ & $45(16)$ & $33(14)$ & \\
\hline Diagnosis in pancreatic center & & & & 0.026 \\
\hline Yes & $71(39)$ & $135(49)$ & $122(51)$ & \\
\hline No & $113(61)$ & $140(51)$ & $117(49)$ & \\
\hline Period of diagnosis & & & & 0.205 \\
\hline $2005-2007$ & $64(35)$ & $83(30)$ & $74(31)$ & \\
\hline 2008-2010 & $76(41)$ & $104(38)$ & $83(35)$ & \\
\hline 2011-2013 & $44(24)$ & $88(32)$ & $82(34)$ & \\
\hline Comorbidities & & & & 0.453 \\
\hline 0 & $36(20)$ & $57(21)$ & $58(24)$ & \\
\hline 1 & $48(26)$ & $92(33)$ & $65(27)$ & \\
\hline$\geq 2$ & $92(50)$ & $116(42)$ & $105(44)$ & \\
\hline Missing & $8(4)$ & $10(4)$ & $11(5)$ & \\
\hline Tumor Stage & & & & 0.002 \\
\hline I & $65(35)$ & $81(29)$ & $48(20)$ & \\
\hline II/III & $119(65)$ & $194(71)$ & $191(80)$ & \\
\hline Laparotomy & & & & 0.002 \\
\hline Yes & $59(32)$ & $102(37)$ & $115(48)$ & \\
\hline No & $125(68)$ & $173(63)$ & $124(52)$ & \\
\hline Tumor resection & & & & 0.001 \\
\hline Yes & $48(26)$ & $84(31)$ & $100(42)$ & \\
\hline No & $136(74)$ & $191(69)$ & $139(58)$ & \\
\hline
\end{tabular}


Table 2. Multivariable logistic regression analyses of likelihood for surgical treatment in pancreatic cancer patients diagnosed between 2005 and 2013 in the Eindhoven Cancer Registry, the Netherlands

\begin{tabular}{|c|c|c|}
\hline Variable & Laparotomy $n=276$ & Odds Ratio [95\%Cl] \\
\hline \multicolumn{3}{|l|}{ Sex } \\
\hline Male & 139 (41\%) & 1 \\
\hline Female & $137(38 \%)$ & $1.05[0.74-1.48]$ \\
\hline \multicolumn{3}{|l|}{ Age (years) } \\
\hline$<60$ & $71(53 \%)$ & 1 \\
\hline $60-69$ & $105(51 \%)$ & $0.99[0.62-1.58]$ \\
\hline $70-79$ & $96(40 \%)$ & $0.62[0.39-1.00]$ \\
\hline$\geq 80$ & $4(3 \%)$ & $0.03 *[0.01-0.09]$ \\
\hline \multicolumn{3}{|c|}{ Diagnosis in pancreatic center } \\
\hline Yes & $155(47 \%)$ & $1.89 *[1.34-2.67]$ \\
\hline No & $121(33 \%)$ & 1 \\
\hline \multicolumn{3}{|c|}{ Period of diagnosis } \\
\hline $2005-2007$ & $68(31 \%)$ & $0.32 *[0.21-0.50]$ \\
\hline 2008-2010 & $89(34 \%)$ & $0.50 *[0.33-0.76]$ \\
\hline 2011-2013 & $119(56 \%)$ & 1 \\
\hline \multicolumn{3}{|c|}{ Socio-economic Status } \\
\hline Low & $59(32 \%)$ & $0.63 *[0.40-0.98]$ \\
\hline Intermediate & $102(37 \%)$ & $0.62^{*}[0.42-0.92]$ \\
\hline High & $115(48 \%)$ & 1 \\
\hline \multicolumn{3}{|l|}{ Comorbidities } \\
\hline 0 & $65(43 \%)$ & 1 \\
\hline 1 & $86(42 \%)$ & $1.40[0.87-2.26]$ \\
\hline$\geq 2$ & $115(37 \%)$ & $1.20[0.76-1.91]$ \\
\hline Missing & $10(35 \%)$ & $1.05[0.43-2.56]$ \\
\hline \multicolumn{3}{|l|}{ Tumor Stage } \\
\hline 1 & $53(27 \%)$ & 1 \\
\hline$\| / I I I$ & 223 (44\%) & $1.08[0.71-1.65]$ \\
\hline
\end{tabular}


Baseline characteristics are provided in Table 1. Patients categorized as low SES were more often diagnosed in a non-pancreatic center compared to high SES patients and patients with a high SES were more often diagnosed with a higher tumor stage. Surgical treatment was performed more often in patients categorized as high SES.

\section{LOGISTIC REGRESSION ANALYSIS}

The likelihood for surgical treatment was higher in patients with high SES as compared to low and intermediate SES (Table 2) but decreased with age and diagnosis in a pancreatic center. The likelihood for surgical treatment increased over time.

\section{SURVIVAL}

Median survival after surgical resection was 18 months (Interquartile range (IQR): 23) and 6 months without surgery (IQR: 8), $\mathrm{p}=0.010$. In addition, 5-year survival rates were significantly different for resection compared to no resection (20.4\% vs $2.1 \%)$. Median survival for low SES patients was 13 months (IQR:13), for intermediate SES 13 months (IQR: 11) and for high SES 16 months (IQR: 16) ( $\mathrm{p}=0.18)$. Survival differences between SES groups were not different (Fig. $1 \mathrm{~A}$ and B). When tested in a multivariable cox regression analysis, the influence of SES on survival showed no significant correlation (Table 3). In this regression analysis, surgical resection correlated with improved survival, whereas higher age and advanced tumor stage correlated with decreased survival (Table $3)$. 
a

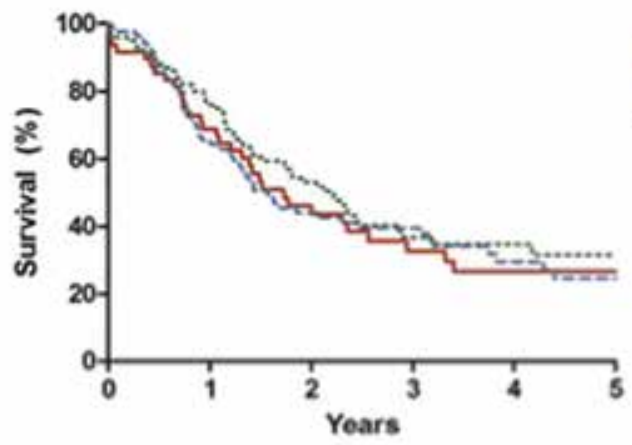

- LOW SES

-2. Intermediate SES

A. High SES

$29.7 \%$

$27.1 \%$

$31.6 \%$

Log.rank: 0.658

\section{Number at risk}

\section{Low SES}

Intermediate SES

High SES

b

Number at risk

\section{Low SES}

Intermediate SES

High SES

$\begin{array}{llllll}48 & 34 & 20 & 12 & 9 & 8 \\ 84 & 56 & 32 & 24 & 14 & 10 \\ 100 & 77 & 42 & 21 & 12 & 10\end{array}$

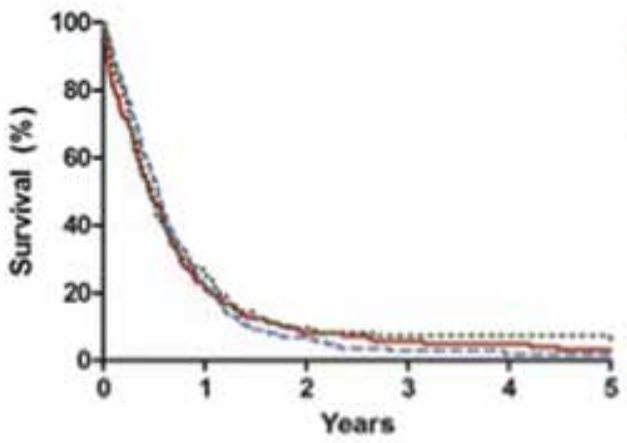

- LOW SES

-t. Intermediate SES

.t. High SES

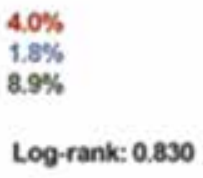

$\begin{array}{llllll}136 & 11 & 7 & 8 & 7 & 5 \\ 191 & 12 & 3 & 5 & 3 & 3 \\ 139 & 13 & 6 & 8 & 6 & 5\end{array}$

FIGURE 1. a) Kaplan-Meier of M0-panceatic cancer patients diagnosed between 2005-2013 in het ECR in the Netherlands and treated by surgical resection, divided in SES groups. b) Kaplan-Meier of M0-panceatic cancer patients diagnosed between 2005-2013 in het ECR in the Netherlands and not surgically treated, divided in SES groups 
Table 3. Cox regression analyses in pancreatic cancer patients diagnosed between 2005 and 2013 in the Eindhoven Cancer Registry, the Netherlands

\section{Variable}

Sex

Male

Female

Age (years)

$<60$

60-69

$70-79$

$\geq 80$

Diagnosis in pancreatic center

Yes

No

Period of diagnosis

2005-2007

2008-2010

2011-2013

Surgical tumor resection

Yes

No

Adjuvant chemotherapy

Yes

No

Socio-economic Status

Low

Intermediate

High

Comorbidities

0

1

$\geq 2$

Missing

Tumor Stage

।

II/III
Hazard Ratio [95\% $\mathrm{Cl}]$

1

$1.01[0.85-1.19]$

1

1.21 [0.94-1.56]

$1.62 *[1.26-2.08]$

$2.53 *[1.87-3.44]$

$0.99[0.84-1.17]$

1

1.24 [0.99-1.55]

$1.24[1.00-1.53]$

1

$0.37^{*}[0.30-0.47]$

1

$0.79[0.57-1.11]$

1

1.05 [0.85-1.30]

1.11 [0.91-1.35]

1

1

1.00 [0.79-1.26]

1.03 [0.82-1.30]

0.74 [0.48-1.15]

1

$1.33^{*}[1.09-1.63]$

* Significantly different. 


\section{DISCUSSION}

This population-based study analyzed the influence of SES on the likelihood for pancreatic cancer patients of receiving surgical treatment. This confirmed findings from previous studies that the hospital of initial diagnosis and age are important factors determining the prospect for surgical treatment. ${ }^{4}$ Besides previously known factors such as age and hospital of diagnosis, patients with a lower SES were identified to have a lower likelihood of receiving surgical treatment. ${ }^{4}$ In the present study, there was a non-significant trend that patients with fewer comorbidities or a lower tumor stage were more likely to undergo surgical treatment.

The effect of SES on choice of treatment in pancreatic cancer has been previously reported in two studies from the USA. Our own findings concur with those of Seyedin et al. who reported that tumors of patients categorized to a low-income group were resected less often (33\%) compared to patients in the high-income group (46\%). ${ }^{7}$

Sun et al. showed that SES was a predictor for survival, with a mean overall survival in the low-SES group of 40 months compared to 50 months in the high SES group. ${ }^{6}$ The authors explained that these survival differences were a possible result of less medical consultation and less treatment in the low SES group. A correlation between SES and survival was not observed in the current study, potentially because it was underpowered or possibly as a result of the poor survival in pancreatic cancer in general even after surgical treatment. However, age, tumor stage and surgical resection did show a significant correlation with survival.

In a recent German study, self reported SES-surrogates in pancreatic cancer patients were analyzed. In contrast to the current study, this did not reveal an influence of any of the surrogate parameters of SES on the likelihood for a curative resection. ${ }^{10}$ These results were in line with the authors' expectations as in the German multi-payer health care system, all patients have equal access to health care. This is however similar to the situation in the Netherlands, although our study and the previously mentioned US study did reveal differences in the chance to receive surgery. An explanation may be that the method to determine the SES varied between these studies. SES was determined by median family income in the USA studies and in the German study only self-reported SES surrogates such as education level were used. The current study determined SES by 
using data on mean value of housing and mean household income at a neighborhood level and may therefore be a more accurate measure to assess SES. However, using zipcode equivalents to determine SES might still confound results.

Several mechanisms may be responsible for the difference in the chance for surgical treatment regarding SES. Some studies have argued that patients with a low SES present at a later stage of their disease, possibly caused by a delay in symptom awareness. ${ }^{5-7,11,12}$ This was for instance observed in a study on oesophageal cancer patients investigating the effect of SES on treatment. ${ }^{5}$ Patients in the low-SES group were diagnosed at a later stage compared to high SES patients but this was not the case in the current study.

The level of education might be another mechanism responsible for the differences between SES groups. Patients categorized as low SES more often have a lower educational level compared to patients categorized as high SES. A higher educational level might result in better-informed patients seeking for the best treatment options. This might explain a contribution of educational level to socioeconomic inequalities. ${ }^{13}$ Another factor may be life-style related factors associated with low SES such as smoking, alcohol consumption and obesity, making patients less suitable for undergoing major surgery. ${ }^{11}$ Unfortunately these factors are not registered in the cancer registry (NCR) but smoking, alcohol consumption and obesity are known to be more prevalent in patients with low SES. Social support may also play a role. Given the impact of pancreatic surgery on quality of life, elderly patients, in particular, may require long-lasting support after surgery. ${ }^{14,15}$ The possibility of securing such support may depend on SES and affect the choice of treatment.

The effect of SES in the USA was mostly attributed to their health care system which is not equally accessible to all patients. ${ }^{6,716}$ Abraham et al. showed that patients' insurance status was of great importance in terms of likelihood for surgical treatment. The health care system in the Netherlands differs from that in the USA with all Dutch inhabitants being insured and having equal access to health care facilities regardless of the SES. Nevertheless, in the current study, patients with a high SES were more likely to be referred to a center with surgical expertise. The insurance status is not a likely explanation for this practice in the Dutch situation. It may be that patients or their relatives are responsible for this phenomenon with high SES patients, being more well-informed and demanding about their treatment possibilities, requesting referral to a pancreatic center. Additionally, 
low SES patients might more often refuse treatment, as suggested by Zell et al. in a California population. ${ }^{16}$

The differences in treatment between SES groups might also be influenced by decision making of physicians. Bernheim et al. showed that patients' SES affected physician clinical management decisions. ${ }^{17}$ Furthermore, Williams et al. showed that in medical decision-making high SES patients were more likely to receive treatment according to recommendations. ${ }^{18}$

The strength of this study is the complete database including all consecutive patients with a clinically or pathologically proven malignancy in the South of the Netherlands. Only pancreaticoduodenectomies for pancreatic cancer were included in the current study as these procedures are now centralized in the Netherlands as opposed to distal pancreatectomies. Unfortunately no information on patients' lifestyle such as BMI, smoking, education or race are registered which may have played a role in decision making. Overall, the inequalities probably have multifactorial causes and can be both patient-related as well as physician-related. ${ }^{19}$ Information on the influence of patient's SES on physician decision-making has not been studied before and might be an interesting topic for future research. By addressing this issue and making physicians aware of this phenomenon differences in health care within the population may be reduced which is one of the targets of the WHO. ${ }^{20}$

\section{ACKNOWLEDGEMENTS}

The authors thank the Netherlands Comprehensive Cancer Organisation (IKNL) and in particular the registers of the Eindhoven Cancer Registry for collecting the data used in this study.

\section{FUNDING}

This study was funded by a grant from the Dutch Cancer Society (KWF). Grant number 2013-649.

\section{CONFLICTS OF INTEREST}

None to declare. 


\section{REFERENCES}

1. Vincent A, Herman J, Schulick R, Hruban RH, Goggins M. (2011) Pancreatic cancer. Lancet 378:607-620.

2. Oettle H, Neuhaus P, Hochhaus A, Hartmann JT, Gellert K, Ridwelski K et al. (2013) Adjuvant chemotherapy with gemcitabine and long-term outcomes among patients with resected pancreatic cancer: the CONKO-001 randomized trial. JAMA 310:1473-1481.

3. Hidalgo M. (2010) Pancreatic cancer. N Engl J Med 362:1605-1617.

4. Bakens MJ, van Gestel YR, Bongers M, Besselink MG, Dejong CH, Molenaar IQ et al. (2015 Dec) Hospital of diagnosis and likelihood of surgical treatment for pancreatic cancer. Br J Surg 102:1670-1675.

5. Bus P, Aarts MJ, Lemmens VE, van Oijen MG, Creemers GJ, Nieuwenhuijzen GA et al. (2012) The effect of socioeconomic status on staging and treatment decisions in esophageal cancer. J Clin Gastroenterol 46:833-839.

6. Sun H, Ma H, Hong G, Sun H, Wang J. (2014) Survival improvement in patients with pancreatic cancer by decade: a period analysis of the SEER database, 1981-2010. Sci Rep 4:6747.

7. Seyedin S, Luu C, Stabile BE, Lee B. (2012) Effect of socioeconomic status on surgery for pancreatic adenocarcinoma. Am Surg 78:1128-1131.

8. Fritz AG. (2000) International classification of diseases for oncology: ICD-O (3rd ed., vii. Geneva: World Health Organization, p. 240. ISBN 924.1545348.

9. Charlson ME, Pompei P, Ales KL, MacKenzie CR. (1987) A new method of classifying prognostic comorbidity in longitudinal studies: development and validation. J Chronic Dis 40:373-383.

10. Standop J, Kuhn Y, Glowka TR, Schaefer N, Overhaus M, Schmitz V et al. (2012) Association of socio-economic status and stage of pancreatic cancer at time of surgery in a German setting. Hepatogastroenterology 59:2614-2617.

11. Cheung MC, Yang R, Byrne MM, Solorzano CC, Nakeeb A, Koniaris LG. (2010) Are patients of low socioeconomic status receiving suboptimal management for pancreatic adenocarcinoma? Cancer 116:723-733.

12. Kim J, Artinyan A, Mailey B, Christopher S, Lee W, McKenzie S et al. (2011) An interaction of race and ethnicity with socioeconomic status in rectal cancer outcomes. Ann Surg 253:647654. 
13. Batty GD, Der G, Macintyre S, Deary IJ. (2006) Does IQ explain socioeconomic inequalities in health? Evidence from a population based cohort study in the west of Scotland. BMJ 332:580584.

14. Heerkens HD, Tseng DS, Lips IM, van Santvoort HC, Vriens MR, Hagendoorn J et al. (2016) Health-related quality of life after pancreaticresection for malignancy. Br J Surg 103:257-266.

15. Eaton AA, Gonen M, Karanicolas P, Jarnagin WR, D’Angelica MI, DeMatteo R et al. (2016 Jul) Health-related quality of life after pancreatectomy: results from a randomized controlled trial. Ann Surg Oncol 23:2137-2145.

16. Zell JA, Rhee JM, Ziogas A, Lipkin SM, Anton-Culver H. (2007) Race, socioeconomic status, treatment, and survival time among pancreatic cancer cases in California. Cancer Epidemiol Biomarkers Prev 16:546-552.

17. Bernheim SM, Ross JS, Krumholz HM, Bradley EH. (2008) Influence of patients' socioeconomic status on clinical management decisions: a qualitative study. Ann Fam Med 6:53-59.

18. Williams RL, Romney C, Kano M, Wright R, Skipper B, Getrich CM et al. (2015) Racial, gender, and socioeconomic status bias in senior medical student clinical decision-making: a national survey. J Gen Intern Med 30:758-767.

19. Abraham A, Al-Refaie WB, Parsons HM, Dudeja V, Vickers SM, Habermann EB. (2013) Disparities in pancreas cancer care. Ann Surg Oncol 20:2078-2087.

20. World Health Organization 2015. Available from: http://www.who.int/social_determinants/ en/. 
Q 810

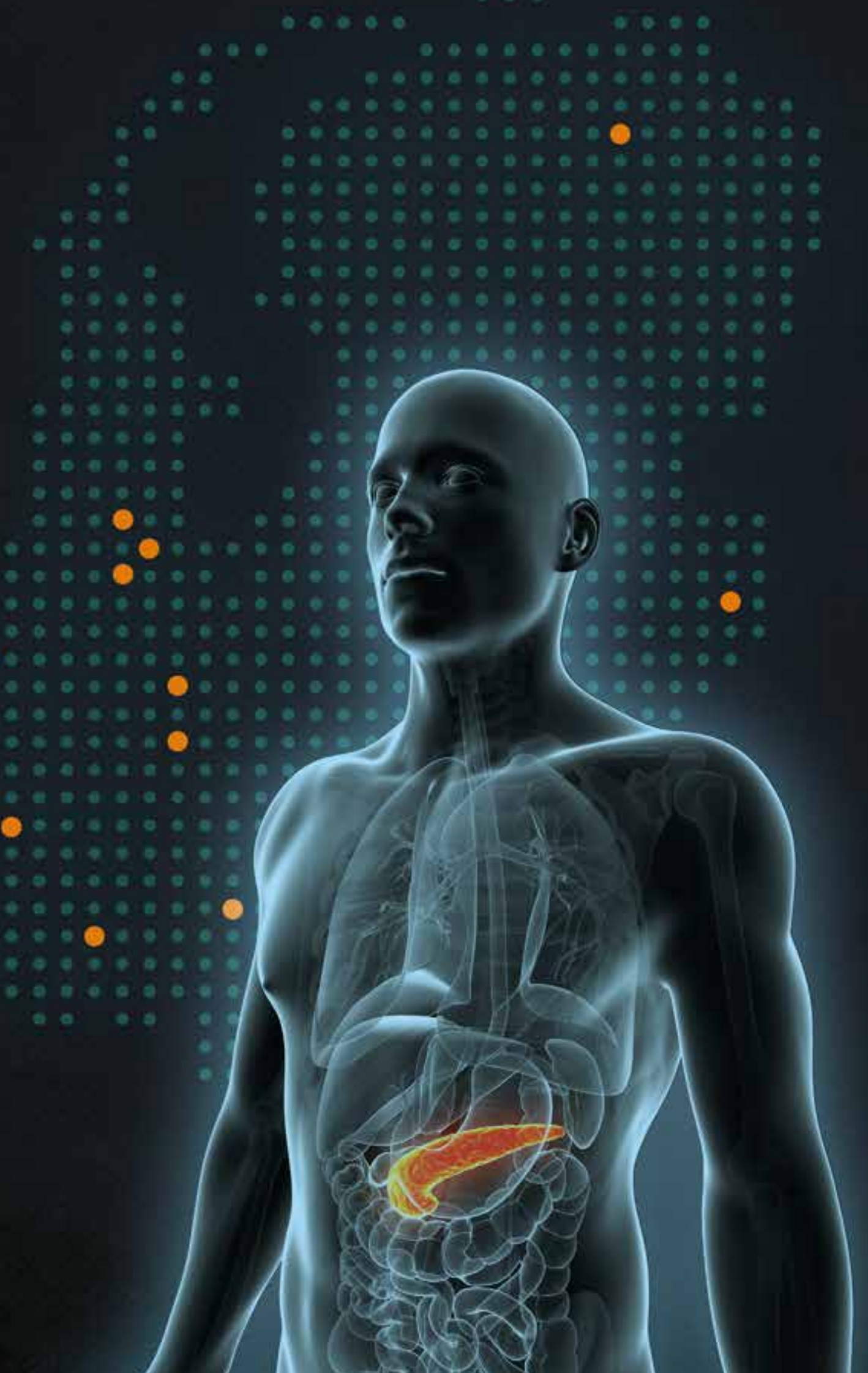

00080000000000000

0.00000000000000

0.000 .00 .0

0.0000000

$\ldots$

0000000000

Q

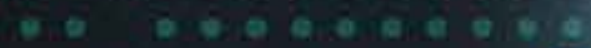

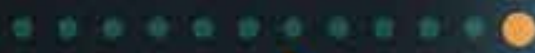

0.0000000008

0.000 .0 .00

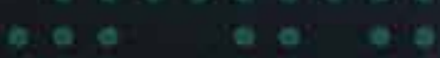

$\ldots$

a: 


\title{
IMPLEMENTING AN ENHANCED RECOVERY PROGRAM AFTER PANCREATICODUODENECTOMY IN ELDERLY PATIENTS: IS IT FEASIBLE?
}

\author{
M.M.E. Coolsen ${ }^{1}$ | M.J.A.M. Bakens ${ }^{1}$ | R.M. van Dam¹ \\ S.W.M. Olde Damink ${ }^{1,2}$ | C.H.C. Dejong ${ }^{1,2}$
}

World J Surg. 2015 Jan;39(1):251-8.

1 Department of Surgery, Maastricht University Medical Centre, Maastricht, The Netherlands

2 NUTRIM School of Nutrition and Translational Research in Metabolism, Maastricht University, Maastricht, The Netherlands 


\section{ABSTRACT}

Background An enhanced recovery after surgery (ERAS) program aims to reduce the stress response to surgery and thereby accelerate recovery. It is unclear whether these programs can be safely implemented for elderly patients, especially in highly complex surgery such as pancreaticoduodenectomy (PD).

The objective of this study was to evaluate the feasibility of an ERAS program in elderly patients undergoing PD.

Methods Implementation of the ERAS protocol was studied prospectively in a consecutive series of patients undergoing PD between January 2009 and August 2013. Patients were divided into two groups: $\leq 65$ years and $\geq 70$ years. Endpoints were length of stay (LOS), readmissions, morbidity, mortality, and compliance with ERAS targets.

Results Of a total of 110 patients, 55 were $\leq 65$ years (median 57) and 55 $\geq 70$ years (median 77). Median LOS was 14 days in both groups. In patients without complications median LOS was 9 days. Both mortality and readmissions did not differ between groups (mortality $n=3(5.5 \%)$ in younger versus $n=6(10.9 \%)$ in older patients, $\mathrm{p}=0.49$, readmissions: $\mathrm{n}=11(20 \%)$ versus $\mathrm{n}=7(12.7 \%), \mathrm{p}=0.44)$. CT-drainage and relaparotomy-rates were not different between groups, nor was overall morbidity $(n=31$ $(56.3 \%)$ in the older versus $n=35(63.3 \%)$ in the younger group, $\mathrm{p}=0.44)$. There were no differences in compliance with elements of the ERAS protocol between groups.

Conclusion An ERAS program seems feasible and safe for patients $\geq 70$ years of age undergoing PD. 


\section{INTRODUCTION}

In the Netherlands, approximately 2000 patients are affected by cancer of the pancreas and periampullary region each year. Without treatment, median survival after diagnosis is only 4-6 months. Patients with potentially curable disease ( $\pm 20 \%)$ may undergo surgery with curative intent, but after 'curative' resection the prognosis is still poor with 5-year survival rates of $10-20 \% .{ }^{1}$ Pancreaticoduodenectomy (PD) remains the only curative option for the majority of pancreatic and periampullary tumors. With an increasingly aging population, more elderly people suffering from pancreatic cancer will be presented for PD. In the past, surgeons were reluctant to perform PD on elderly patients. Common reasons were a reduced physical fitness and increased co-morbidity. Recent reports, however, show that PD is feasible in the elderly population with acceptable mortality and morbidity rates. ${ }^{2-6}$

To diminish the surgical stress response and speed up recovery, 'Enhanced Recovery After Surgery' (ERAS) or 'fast track' pathways have been implemented in several forms of surgery. ${ }^{7-10}$ Avoidance of pre- and postoperative fastening, optimized analgesia and early mobilization are typical elements of the ERAS protocol, which accelerates recovery and reduces hospital costs without compromising postoperative morbidity and mortality. ${ }^{11-14}$ In PD, a complex surgical procedure with high postoperative morbidity rates, ERAS protocols have also been successfully implemented. ${ }^{15-17}$ Recently, perioperative guidelines for PD have been published by the ERAS group. ${ }^{18}$

When postoperative complications do occur, the elderly in particular seem to have an increased 30-day mortality risk. ${ }^{19}$ Interestingly, two recent meta-analyses on ERAS in PD and colonic surgery suggest that postoperative morbidity rates may be lower in patients managed in an ERAS program. ${ }^{11,12}$ Therefore, it might be beneficial to implement ERAS programs also for an older population. However, some authors raise doubts about subjecting the elderly to ERAS programs with immediate postoperative feeding and forced mobilization. ${ }^{20}$

The aim of this study was to prospectively evaluate the feasibility and safety of implementing an ERAS program in elderly patients ( $>70$ years) undergoing PD and compare compliance and outcome with patients below 65 years of age. 


\section{METHODS}

\section{PATIENTS}

Perioperative outcome data were retrieved from a database in which all patients undergoing PD in Maastricht University Medical Centre in a period between January 2009 and August 2013 were entered prospectively. Patients were divided into two groups: below 65 years of age and above 70 years of age. The 5-year gap was arbitrary chosen to create a real difference between the older and younger group (e.g., otherwise two people who differ two days in age could be in different groups). From January 2009 onwards, a multimodal ERAS program for PD was implemented in our institution and all patients undergoing PD from that date onwards were managed accordingly. There were no exclusion criteria. Data of the study group were compared to historical data from a group of patients undergoing PD between 2000 and 2005.

\section{PERIOPERATIVE MANAGEMENT}

A detailed description of the ERAS protocol for PD is shown in Table 1. Preoperatively, patients were informed at the out-patient clinic about the ERAS protocol and possible postoperative complications. Before the operation, an assessment was made of ASA classification and comorbidity. All patients received antibiotic prophylaxis and midthoracic epidural analgesia.

Four surgeons, all with extensive experience in PD, performed the operative procedures. Bilateral subcostal transverse abdominal incisions were used. The biliodigestive anastomosis, gastrojejunostomy, and pancreaticojejunostomy were hand sewn, and a prophylactic abdominal silicon drain was placed near the pancreaticojejunostomy at the end of the procedure. NG tubes were not placed or were removed after the procedure directly before transportation to the recovery ward.

Patients were allowed to restart oral intake of water on the day of surgery, to drink freely up to $1.5 \mathrm{~L}$ on the first postoperative day (POD) and resume their normal diet on the second postoperative day. Furthermore, patients received magnesium oxide 1000 mg twice daily. Mobilization out of bed was started on POD 1. Epidural analgesia was stopped on POD 3 and replaced by NSAIDs. The prophylactic abdominal drain was removed on POD 4 if amylase was less than 3 times the serum amylase concentration 
or drain production was less than $50 \mathrm{~mL}$ per day. Patients were discharged if functional recovery criteria were met (good pain control with oral analgesia only,tolerance for solid food, no intravenous fluids, passage of stool and being independently mobile at the preoperative level) and if the patient was willing to go home.

\section{Table 1. ERAS protocol for pancreaticoduodenectomy}

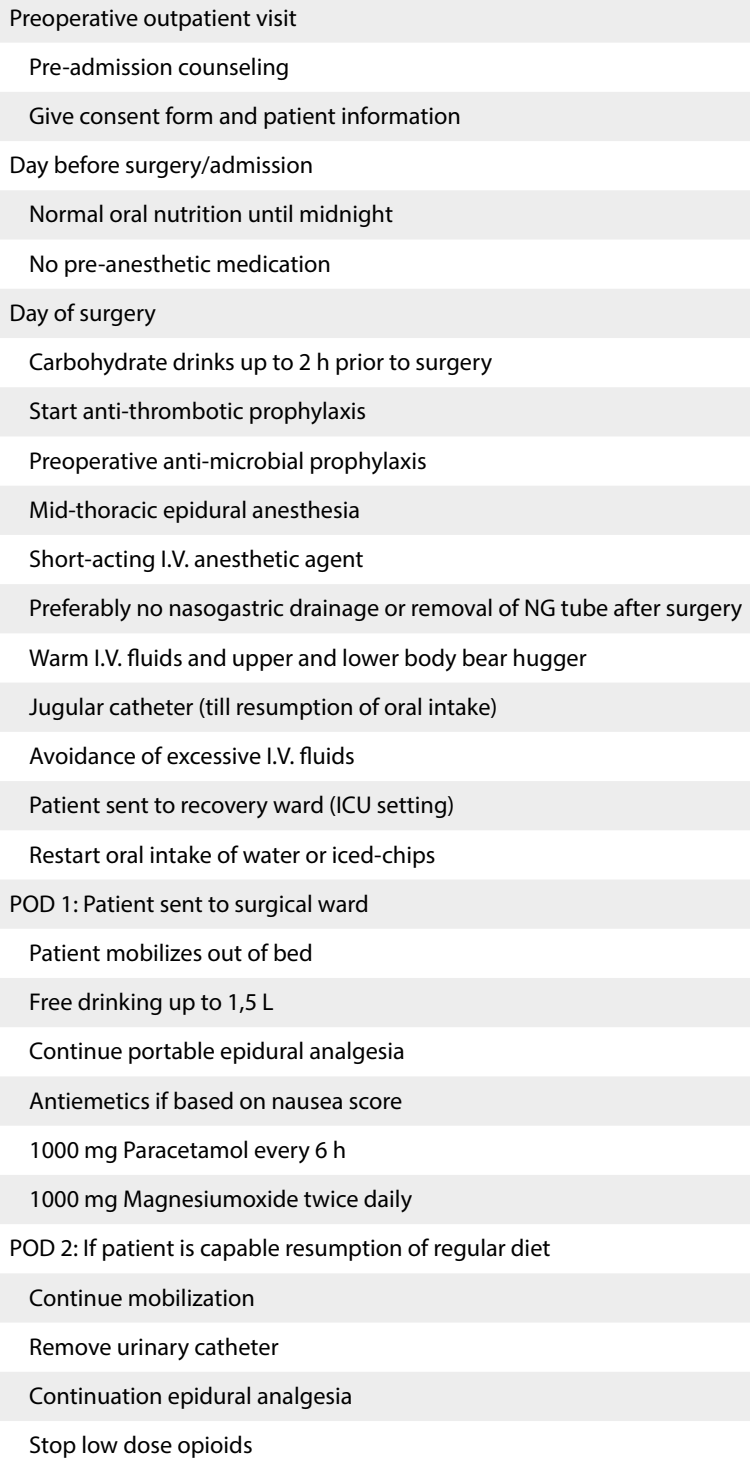




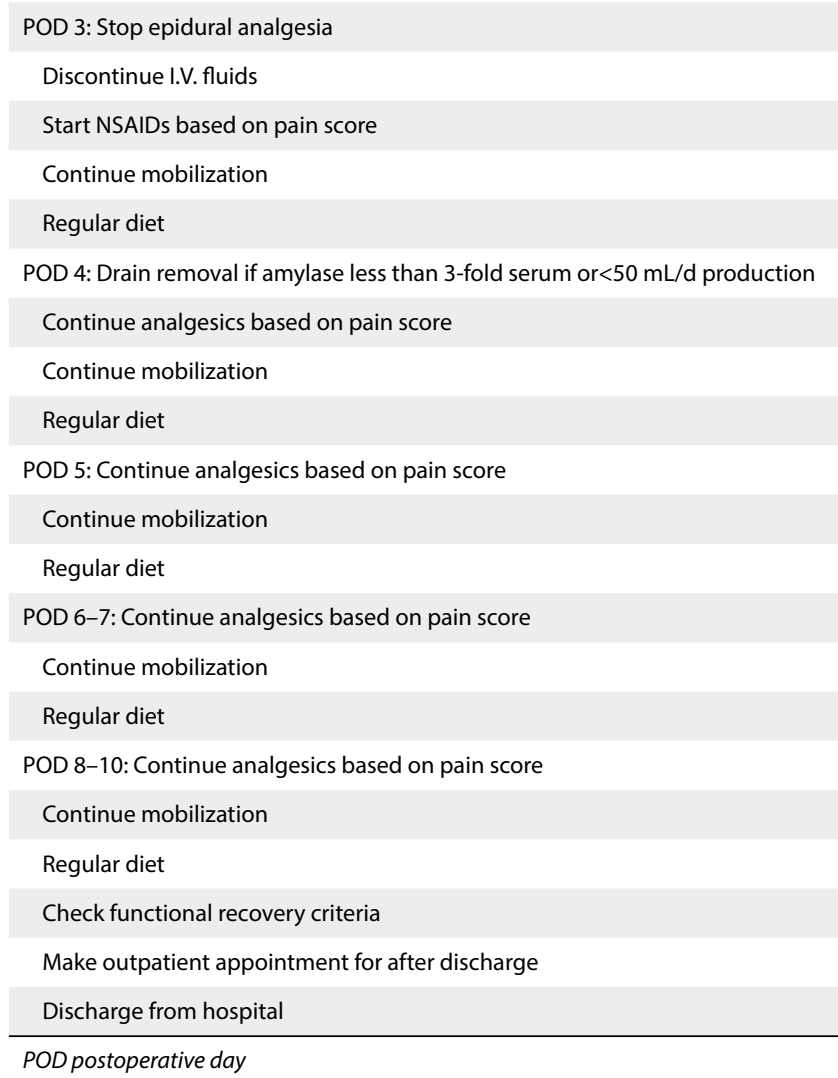

\section{PRIMARY AND SECONDARY ENDPOINTS}

The primary endpoint was postoperative length of stay (LOS), defined as nights spent in hospital after the operation. Secondary endpoints were postoperative complications, mortality, readmissions, postoperative interventions, and compliance with various elements of the ERAS protocol.Complications were defined as any deviation from the normal postoperative course. Definitions used for specific complications were according to the literature (Appendix 1) ${ }^{21-26}$ and further classified according to the Dindo-Clavien classification. ${ }^{27}$ Data were recorded prospectively during hospital stay and the 30-day period after surgery in an electronic registration system (SAP) as well as in a database. For mortality, the follow-up was 90 days. In the morning after discharge, complications were registered in SAP for each patient.Postoperative data in SAP were also cross-checked 
with existing in-house databases containing prospectively collected complications. Readmissions were recorded if related to the index operation within a time period of 6 months.

Adherence to various ERAS protocol elements that were specifically reviewed included resumption of oral fluid and solid intake, mobilization from POD 1, drain removal on POD 4, urinary catheter removal on POD 2, and removal of epidural analgesia on POD 3.

\section{DATA ANALYSIS AND STATISTICS}

Continuous data are given as median (range). Categorical variables were analyzed using the $\chi 2$ test or Fisher's exact test, quantitative variables with Student's $t$ test. Postoperative length of stay was analyzed using the non-parametric Mann-Whitney $U$ test. A p value $<0.05$ was considered significant. Statistical analysis was performed using SPSS for Windows, version 19.

\section{RESULTS}

\section{DEMOGRAPHICS AND OPERATIVE OUTCOME}

A consecutive series of 110 patients undergoing PD between January 2009 and August 2013 were included in this study. Of these, 55 patients were below 65 years of age and 55 patients were older than 70 years (Table 2). The median age for the $\leq 65$ years group was 57 (range 45-65) and for the $\geq 70$ years group was 77 (range 71-86). There were significantly more patients with a higher ASA classification in the older group. Furthermore, cardiac and pulmonary co-morbidity was more frequently present in the older group $(\mathrm{p}<0.016$ and $\mathrm{p}<0.014$, respectively). Body mass index (BMI) and type of pancreatic pathology did not differ between groups. In both groups most resections were performed for malignancies and more PPPDs than classical Whipple procedures were performed (84 vs. $16 \%$ in the younger group and 85 vs. $15 \%$ in the older group). Mean operative time did not differ between groups. 
Table 2. Patient demographics, pathology, and operative data

\begin{tabular}{|c|c|c|c|}
\hline & $\begin{array}{l}\leq 65 \text { years of age } \\
(n=55)\end{array}$ & $\begin{array}{c}\geq 70 \text { years of age } \\
(n=55)\end{array}$ & $p$ value \\
\hline Age median (range) & $57(45-65)$ & $77(71-86)$ & \\
\hline \multicolumn{4}{|l|}{ Sex } \\
\hline Male/female & $35 / 20$ & $22 / 33$ & 0.013 \\
\hline \multicolumn{4}{|l|}{ ASA class } \\
\hline 1 & $28(51 \%)$ & $1(2 \%)$ & $>0.001^{*}$ \\
\hline II & $21(38 \%)$ & $34(62 \%)$ & 0.013 \\
\hline III & $5(9 \%)$ & $20(36 \%)$ & $0.001^{*}$ \\
\hline IV & $1(2 \%)$ & $0(0 \%)$ & $0.315^{*}$ \\
\hline \multicolumn{4}{|l|}{ Co-morbidity } \\
\hline Cardiovascular & $13(24 \%)$ & $25(45 \%)$ & 0.016 \\
\hline Pulmonary & $2(4 \%)$ & $10(18 \%)$ & $0.014^{*}$ \\
\hline Diabetes & $6(11 \%)$ & $12(21.8 \%)$ & $0.122^{*}$ \\
\hline Renal disease & $1(2 \%)$ & $6(10.9 \%)$ & $0.056^{*}$ \\
\hline BMI (range) & $24.9(18.0-36.1)$ & $24.4(18.6-36.8)$ & 0.656 \\
\hline \multicolumn{4}{|l|}{ Pathology } \\
\hline Pancreatic head carcinoma & $34(62 \%)$ & $33(60 \%)$ & 0.845 \\
\hline Duodenal cancer & $2(4 \%)$ & $3(5 \%)$ & $1.000^{*}$ \\
\hline Ampullary carcinoma & $8(15 \%)$ & $12(22 \%)$ & $0.459^{*}$ \\
\hline Distal cholangiocarcinoma & $5(9 \%)$ & $5(9 \%)$ & $1.000^{*}$ \\
\hline Metastasis in head of pancreas & $1(1.8 \%)$ & $0(0 \%)$ & $1.000^{*}$ \\
\hline Chronic pancreatitis & $2(4 \%)$ & $2(4 \%)$ & $1.000^{*}$ \\
\hline IPMN & $1(2 \%)$ & $0(0 \%)$ & $1.000^{*}$ \\
\hline Neuro-endocrine tumor & $2(4 \%)$ & $0(0 \%)$ & $0.495^{*}$ \\
\hline \multicolumn{4}{|l|}{ Operation type } \\
\hline Whipple & $9(16 \%)$ & $8(15 \%)$ & 1.000 \\
\hline PPPD & $46(84 \%)$ & $47(85 \%)$ & 0.792 \\
\hline Duration of OR time ( $\mathrm{min})$ & $345(180-810)$ & $340(217-715)$ & $0.986^{\dagger}$ \\
\hline
\end{tabular}

ASA American Society of Anesthesiologists, BMI body mass index, PPPD pylorus preserving pancreaticoduodenectomy All statistics were performed with Chi-square, marked ${ }^{*}$ with the Fisher's exact test, marked ${ }^{+}$with $t$ test 


\section{POSTOPERATIVE OUTCOME}

Postoperative outcomes parameters are shown in Table 3. Median LOS was not different between the two groups (both 14 days with ranges 6-100 and 6-65, respectively), nor was median LOS for younger and older patients discharged without complications ( 9 days with ranges 6-15 and 6-22, respectively). Readmissions within 6 months of the index hospitalization were not significantly different between the two groups (18.1 and $12.7 \%$, respectively). The same holds true for mortality rates although a trend to an increased mortality rate in the older groups was observed 5.5 and $10.9 \%$, respectively).

In the older group,three patients died after sepsis (bilateral pneumonia after 50 days $(\mathrm{n}=1)$, leakage of the hepaticojejunostomy and necrosis of the omentum after 56 days ( $\mathrm{n}$ $=1$ ) and after pancreaticojejunostomy leakage and abdominal compartment syndrome after 21 days $(n=1))$. Also, two patients died after a major post-pancreatectomy hemorrhage after 6 and 3 days, respectively. One patient was found to had expired during the night rounds on the ward 6 days after surgery. Permission to perform autopsy was not granted. In the younger group, two patients died after sepsis caused by leakage of the pancreaticojejunostomy and hepatojejunostomy 83 and 14 days postoperatively and one after a readmission because of late post-pancreatectomy hemorrhage. There were no differences in postoperative intervention rate (CT/US-drainage and relaparotomy) and in minor (Dindo-Clavien grade I and II), moderate (grade IIIa/b) or severe (grade IVa/ IVb) complications between the groups. Median LOS was also calculated for DindoClavien grades below and above III. Patients who suffered from complications in the elderly group had a longer median postoperative length of stay than those in the younger group for Clavien-Dindo grades $<$ III ( $\mathrm{p}=0.028$ ).

In both groups discharge toward home was possible in the majority of the patients (91 and $80 \%$, respectively in younger and older group). There was a trend toward a more frequent discharge to a nursing facility or discharge with home health care in the older group, however, this was not significant. 
Table 3. Postoperative outcomes

\begin{tabular}{|c|c|c|c|}
\hline & $\begin{array}{l}\leq 65 \text { years of age } \\
(n=55)\end{array}$ & $\begin{array}{c}\geq 70 \text { years of age } \\
(n=55)\end{array}$ & $p$ value \\
\hline \multicolumn{4}{|l|}{ Dindo-Clavien classification } \\
\hline Minor (I/II) & $15(27.2 \%)$ & $20(36.3 \%)$ & 0.409 \\
\hline Moderate (IIla/b) & $15(27.2 \%)$ & $8(14.5 \%)$ & $0.159^{*}$ \\
\hline Severe (IVa en IVb) & $0(0 \%)$ & $2(3.6 \%)$ & $0.495^{*}$ \\
\hline Mortality $<90$ days & $3(5.5 \%)$ & $6(10.9 \%)$ & $0.489 *$ \\
\hline Readmissions $<6$ months & $11(20 \%)$ & $7(12.7 \%)$ & $0.440^{*}$ \\
\hline Median LOS (range) & $14(6-100)$ & $14(6-65)$ & 0.186 \\
\hline \multicolumn{4}{|l|}{ Interventions } \\
\hline CT/US-drainage & $10(18.1 \%)$ & $8(14.5 \%)$ & $0.797^{*}$ \\
\hline Re-operation & $6(10.9 \%)$ & $4(7.2 \%)$ & $0.742^{*}$ \\
\hline Median LOS uncomplicated (range) & $9(6-15)$ & $9(6-22)$ & 0.275 \\
\hline Median LOS Dindo-Clavien grade < III (range) & $10(6-100)$ & $14(7-59)$ & 0.028 \\
\hline Median LOS Dindo-Clavien grade >III (range) & $32(11-83)$ & $33(14-65)$ & 0.488 \\
\hline \multicolumn{4}{|l|}{ Discharge placement } \\
\hline Discharge other than home ${ }^{a}$ & $2(3.6 \%)$ & $5(9.1 \%)$ & $0.433^{*}$ \\
\hline Discharge home with or without home health care & $50(91 \%)$ & $44(80 \%)$ & 0.625 \\
\hline Discharge home with home health care & $7(12.7 \%)$ & $14(25.4 \%)$ & $0.138^{*}$ \\
\hline
\end{tabular}

\section{MORBIDITY}

Table 4 summarizes the overall and specific complications in both groups. Overall morbidity was $56.3 \%$ in the $\leq 65$ years group and $63.3 \%$ in the $\geq 70$ years group ( $p=n s$ ). The incidence of specific complications did not differ between groups.

A comparison to patients managed in traditional care (Table 5) shows the postoperative outcomes from a historical control group of patients undergoing PD (2000-2005). Patient demographics of the historical control group were not different from the ERAS group (data not shown). The outcomes are similar to patients managed in an ERAS program. However, LOS decreased in the ERAS group. 
For better interpretation of the results, Appendix 2 shows ASA status of patients who suffered from complications matched to Dindo-Clavien grade of <III and > III. Patients who suffered from complications with a Dindo-Clavien grade $>$ III tended to have a higher ASA status.

Table 4. Complications specified

\begin{tabular}{lccc}
\hline & $\begin{array}{c}\mathbf{6 5} \text { years of age } \\
(\mathbf{n}=\mathbf{5 5})(\%)\end{array}$ & $\begin{array}{c}\mathbf{7} \mathbf{7 0} \text { years of age } \\
(\mathbf{n}=\mathbf{5 5})(\%)\end{array}$ & p value \\
\hline Overall morbidity & $31(56.3)$ & $35(63.3)$ & $0.436^{*}$ \\
\hline Intra-abdominal abscess & $7(13)$ & $7(13)$ & 1.000 \\
\hline Wound infection & $7(13)$ & $7(13)$ & 1.000 \\
\hline Pancreatic fistula & $9(16)$ & $5(9)$ & 0.392 \\
\hline Pneumonia & $2(3.6)$ & $2(3.6)$ & 1.000 \\
\hline Delayed gastric emptying grade & $5(9)$ & $5(9)$ & 1.000 \\
\hline Biliodigestive anastomosis leakage & $3(6)$ & $1(2)$ & 0.618 \\
\hline Sepsis/MOF & $2(4)$ & $6(11)$ & 0.271 \\
\hline Post pancreaticoduodenectomy & $5(9)$ & $5(9)$ & 1.000 \\
hemorrhage & & $5(9)$ & 0.761 \\
\hline Urinary tract infection & $3(6)$ & $0(0)$ & 0.850 \\
\hline Gastrojejunostomy leak & $1(2)$ & $2(4)$ & 0.495 \\
\hline Chylus leakage & $0(0)$ & $3(6)$ & 0.618 \\
\hline Diabetes mellitus de novo & $1(1.8)$ & $9(16)$ & 0.850 \\
\hline CVA & $0(0)$ & & 0.580 \\
\hline Cardiac & $6(11)$ & $1(2)$ & \\
\hline $\begin{array}{l}\text { All statistics with fisher's exact test } \\
{ }^{*} \text { Chi-square }\end{array}$ & & & \\
\hline
\end{tabular}

\section{ERAS OUTCOMES}

NG tubes were either not placed or directly removed after surgery in all patients. As Table 6 indicates compliance with resumption of oral fluid intake on POD 1 was high in both groups (96\% in the younger and $95 \%$ in the older group). Solid oral intake was started from POD 2 onwards in $56 \%$ of patients in the younger group and $51 \%$ of patients in the older group $(\mathrm{p}=\mathrm{ns})$. 
Table 5. Outcomes of a historical control group of patients undergoing PD between 2000 and 2005 under traditional care

\begin{tabular}{lcc}
\hline & $\begin{array}{c}\mathbf{6 5} \text { years of age } \\
(\mathbf{n = 3 0 )}\end{array}$ & $\begin{array}{c}\mathbf{7 0} \text { years of age } \\
\text { (n= 20) }\end{array}$ \\
\hline Overall morbidity & $16(53.3 \%)$ & $12(60 \%)$ \\
\hline Mortality $<90$ days & $1(3.3 \%)$ & $2(10 \%)$ \\
Readmissions $<6$ months & $5(13.3 \%)$ & $3(15 \%)$ \\
Median LOS (range) & $15(7-112)$ & $18(11-82)$ \\
Median LOS uncomplicated & $12(7-14)$ & $13(11-15)$ \\
(range) & & $3(15 \%)$ \\
Interventions & $6(20 \%)$ & $2(10 \%)$ \\
\hline CT/US-drainage & $3(10 \%)$ & \\
\hline Re-operation & &
\end{tabular}

LOS postoperative length of stay

Table 6. ERAS outcomes

\begin{tabular}{lccc}
\hline & $\begin{array}{c}\mathbf{6 5} \text { years of age } \\
(\mathbf{n = 5 5 )}(\mathbf{\%})\end{array}$ & $\begin{array}{c}\mathbf{2 7 0} \text { years of age } \\
(\mathbf{n = 5 5 )}(\mathbf{\%})\end{array}$ & $\boldsymbol{p}$ value \\
\hline Resumption of fluid intake POD1 & $53(96)$ & $52(95)$ & 0.647 \\
\hline Resumption of solid intake POD2 & $31(56)$ & $35(63)$ & 0.436 \\
Mobilization from POD 1 & $33(60)$ & $35(63)$ & 0.695 \\
Drain removal on POD 4 & $26(47)$ & $28(51)$ & 0.703 \\
\hline Urinary catheter removal on POD 2 & $38(69)$ & $33(60)$ & 0.319 \\
\hline Removal epidural on POD 3 & $44(80)$ & $43(78)$ & 0.815 \\
\hline
\end{tabular}

All statistics were performed with Chi-square

Reasons for not starting solid intake were nausea and malaise. Mobilization on POD 1 was $60 \%$ in the younger and $63 \%$ in the older group. A lower compliance with mobilization was mainly due to weakness, hypotension, or pain. Prophylactic abdominal drains were removed in $47 \%$ of the patients on POD 4 in the younger group and $51 \%$ in the older group $(\mathrm{p}=\mathrm{ns})$. In half of the patients, the drain was not removed on POD 4 because the drain removal criteria were not met. In the other half, this was due to logistic problems (e.g., POD 4 fell on a weekend day and drain removal was overlooked or laboratory results came in back day later). The number of patients having their urinary catheter removed 
on POD 2 was lower than expected. This was mainly due to the fact that the epidural catheter was removed on POD 3 in a considerable number of patients. Consequently, urinary catheters were often removed only after epidural analgesia was stopped. Also, some patients needed longer catheterization because of bladder problems or in order to monitor urine output in critically ill patients.

For completeness, the results of the 25 patients in the age group that was left out (66-69 years) are presented in the Appendix 3, 4, and 5. These are similar to the results of both other groups.

\section{DISCUSSION}

This study describes the results of the implementation of an ERAS program in PD in elderly patients. It compares results in patients $\leq 65$ years of age with those in patients $\geq 70$ years. Implementing an ERAS program for PD in the elderly appeared to be feasible since compliance with the different ERAS protocol elements was similar in younger and older patients. Its safety also seems confirmed since readmission, morbidity, and mortality rates did not differ significantly between the two groups.

Several studies have evaluated risks and outcomes after PD in the elderly and have shown that it is possible to perform PD with acceptable morbidity and mortality rates. ${ }^{25}$ However, overall morbidity rates vary greatly between single-center studies (21-73\%). ${ }^{28}$ The variance may not only reflect differences in outcome between high- and low-volume HPB centers and registration flaws in retrospective studies, but also failure to use a standardized complication registration system and unanimous definitions for specific complications. In this study, universal definitions for complications were used and complications were classified according to Dindo-Clavien. ${ }^{27}$ Overall morbidity in the present study was roughly compared to the morbidity reported in a recent case series involving 2698 patients undergoing PD (42\%<80 years and $53 \% 80-89$ years). ${ }^{29}$ The slightly higher morbidity in the present study might be due to the meticulous prospective complication registration in the present study. Some studies report higher incidences of pancreatic fistula (PF) and DGE after PD in the elderly, but the current study did not confirm this. ${ }^{24,30}$ In line with previous reports, the mortality rate we recorded, though 
not significantly, tended to be higher in the older group than in the younger group (10.9 and $5.5 \%$, respectively, $\mathrm{p}=0.489) .{ }^{28,30-32}$ The mortality rate for the elderly as shown in our study was at the high end of the range reported in studies with similar sample sizes (mortality 0-10.5 \%). ${ }^{30,32-34}$ However, not all these studies defined mortality in an exact manner or restricted themselves to 30-day mortality rates, compared to a 90-day mortality defined in this study. Moreover, two population-based studies including 23518 and 3736 patients undergoing pancreatic resection showed even higher mortality rates in the elderly population (up to 15.5 and $11.4 \%$, respectively). ${ }^{34,35}$ This was also confirmed in a Dutch study including 2155 PD's ( $10.4 \%$ in patients $>70$ compared to $4.4 \%$ in the younger group). ${ }^{36}$

Planned discharge in this study was on POD 8-10. This target appeared to be feasible only in patients without postoperative complications (median discharge at day 9). The overall median length of stay was 14 days. This was probably due to the fact that more than half of the patients had complications. Another explanation of the relatively high median LOS might be the fact that physicians are reluctant to discharge PD patients early after surgery, since major complications can even occur with some delay after surgery. In a recent study in patients undergoing colonic surgery, only half of the patients were discharged when all discharge criteria were met $^{37}$, and $43 \%$ of this group was kept in hospital because of surgeons' judgment. For this reason, several authors advice to at least add data on time to recovery to LOS as outcome of enhanced recovery after surgery programs. $^{37,38}$

The reported length of stay in the present study is in line with other studies on reporting a postoperative length of stay after PD of approximately 13 days in the ERAS group. ${ }^{15,16}$ In other studies on PD in elderly with traditional care median length of stay varied from 13-25 in the older population..$^{34,35,39}$ The majority of patients were discharged home in both groups. Discharge with home health care and discharge to a nursing facility showed a more frequent trend in the older group. However, in a large population-based study of patients undergoing pancreatic resection within a traditional care program discharge toward a nursing facility was $20.2 \%$ and discharge home with health care was $27.8 \%$ in a 70-79 year group. ${ }^{35}$ This is higher than reported in our study which probably indicates that an earlier discharge is an effect of the ERAS program rather than better support care at home or more rehabilitation placement. 
Overall compliance with the various ERAS elements was acceptable (73\%). Ahmed et al. already showed that an ERAS protocol compliance of more than $77 \%$ does not further improve outcome in colorectal surgery. ${ }^{40}$ Also, it is still unclear which protocol elements are most important contributors to an improved outcome ${ }^{41}$. In the present study, removal of NG tubes and epidural analgesia and resumption of fluid intake were achieved for the majority of patients. However, compliance with other ERAS elements such as mobilization on POD 1, removal of urinary catheters on POD 2, and removal of prophylactic intraabdominal drains was lower. There is still considerable debate on if and when drains should be placed and removed. ${ }^{42-45}$ Early drain removal ( $<72 \mathrm{~h}$ ) may be advised for patients with a low risk of $P .^{18}$

There is no official definition for the term "elderly", but most studies performed on pancreatic resections in the elderly population use a cut-off age above 70 years., $32,33,46-48$ A recent analysis on a large cohort showed an age of 68.5 years can be considered as 'surgical oldness. ${ }^{49}$ We decided to define an interval centered on this age and considered older than 70 years as "elderly" and below 65 years as younger patients.

Resection is the sole curative option for patients with malignant disease of the pancreas. Also in the elderly the survival benefit after resection is not diminished. ${ }^{34}$ It is nevertheless crucial to carefully select older patients using meticulous preoperative assessment. ${ }^{50}$ Better selection of patients might also contribute to lowering mortality rates. Importantly, older patients should be well informed about the risks and the fact that hospital volume and surgeon experience play a significant role in the outcome. ${ }^{35,51,52}$

To conclude, this study evaluated the results of implementation of an ERAS program in elderly patients ( $\geq 70$ years) undergoing PD as compared to patients below 65 years of age. It shows that an ERAS program for the elderly is feasible and it can be safely implemented with comparable readmission, morbidity, and mortality rates.

\section{ACKNOWLEDGMENTS}

The authors would like to thank Margriet Rouflart, research nurse, for the use of her database in order to crosscheck complications.

\section{CONFLICT OF INTEREST}

No conflict of interest is reported. 


\section{APPENDIX}

\section{APPENDIX 1. Definitions of complications}

Mortality

Death of a patient, during or within 90 days after the initial surgical procedure that is related to the surgical procedure.

\section{Readmission}

Every re-hospitalization due to a complication of the index hospitalization within the first 6 months.

\section{Intra-abdominal abscess}

Any quantity of purulent fluid leaking via the abdominal drain; walled-off collection of pus in the abdominal cavity at the time of radiological imaging, reoperation or percutaneous drainage; fluid in drain or intra-abdominal collection should be culture positive.

\section{Wound infection}

Defined according to the Centers for Disease Control and Prevention ${ }^{21}$

Superficial incisional surgical-site infection and deep incisional surgical site infection which occurs within 30 days after surgery. This includes both the superficial surgical-site infections and the deep incisional surgical site infections. Most of this wound infections were opened at bedside of the patient by the physician or surgeon.

Pancreatic fistula/pancreaticojejunostomy leakage

Defined according to the International Study Group of Pancreatic Fistula 22

\section{Delayed gastric emptying}

Defined according to the International Study Group of Pancreatic Surgery ${ }^{23}$

\section{Biliodigestive anastomosis leakage}

Any quantity of bile leaking via the abdominal wound or drains at least $48 \mathrm{~h}$ after surgery, intra-abdominal collection of bile (confirmed radiologically) or cholangiographic evidence of contrast leakage. Laboratory: three times higher bilirubin in the drain or intra-abdominal collection compared with normal serum bilirubin levels.

\section{Sepsis/multi organ failure}

Definition from the 2001 International Sepsis Definitions Conference ${ }^{24}$

\section{Post pancreaticoduodenectomy hemorrhage}

Definition according to the ISGPS classification of post pancreaticoduodenectomy haemorrhage ${ }^{25}$

\section{Gastrojejunostomy leakage}

Incompetence of the gastrojejunostomy anastomosis documented either by confirmatory upper gastrointestinal contrast x-rays. CT scans, or reoperation ${ }^{26}$.

\section{CT-drainage}

Drainage of intra-abdominal fluid collections during CT by inserting a percutaneus drain during the hospitalization or readmission period.

\section{Relaparotomy}

Any complication after the initial PPPD or Whipple operation leading to a laparotomy as an intervention, during the index hospitalization or the readmission period. 
APPENDIX 2. ASA status matched to grade of complication

\begin{tabular}{lccc}
\hline & All patients & $\mathbf{5 6 5}$ years of age & $\mathbf{2 7 0}$ years of age \\
\hline Dindo-Clavien classification $<$ III & $\mathrm{n}=35$ & $\mathrm{n}=15$ & $\mathrm{n}=\mathbf{2 0}$ \\
ASA I & 12 & 12 & 0 \\
ASA II & 16 & 3 & 73 \\
ASA III & 7 & 0 & 0 \\
ASA IV & 0 & 0 & $\mathrm{n}=16$ \\
\hline Dindo-Clavien classification $>$ III & $\mathrm{n}=34$ & $\mathrm{n}=18$ & 0 \\
ASA I & 10 & 10 & 7 \\
ASA II & 11 & 4 & 9 \\
\hline ASA III & 12 & 3 & 0 \\
\hline ASA IV & 1 & 1 & 7 \\
\hline
\end{tabular}


APPENDIX 3. Patient demographics, pathology and operative data for the $66-69$ year group

\begin{tabular}{|c|c|c|c|}
\hline & $\begin{array}{c}\leq 65 \text { years of } \\
\text { age }(n=55)\end{array}$ & $\begin{array}{l}66-69 \text { years of } \\
\text { age }(n=25)\end{array}$ & $\begin{array}{c}\geq 70 \text { years of } \\
\text { age }(n=55)\end{array}$ \\
\hline Age median (range) & $57(45-65)$ & $68(65-69)$ & $77(70-86)$ \\
\hline \multicolumn{4}{|l|}{ Sex } \\
\hline Male/female & $35 / 20$ & $12 / 13$ & $22 / 33$ \\
\hline \multicolumn{4}{|l|}{ ASA class } \\
\hline I & $28(51 \%)$ & $8(32 \%)$ & $1(2 \%)$ \\
\hline II & $21(38 \%)$ & $13(52 \%)$ & $34(62 \%)$ \\
\hline III & $5(9 \%)$ & $4(16 \%)$ & $20(36 \%)$ \\
\hline IV & $1(2 \%)$ & 0 & $0(0 \%)$ \\
\hline \multicolumn{4}{|l|}{ Comorbidity } \\
\hline Cardiovascular & $13(24 \%)$ & $7(28 \%)$ & $25(45 \%)$ \\
\hline Pulmonary & $2(4 \%)$ & $3(12 \%)$ & $10(18 \%)$ \\
\hline Diabetes & $6(11 \%)$ & $6(24 \%)$ & $12(21.8 \%)$ \\
\hline Renal disease & $1(2 \%)$ & $2(8 \%)$ & $6(10.9 \%)$ \\
\hline BMI (range) & $24.9(18.0-36.1)$ & $24.6(18-47)$ & $24.4(18.6-36.8)$ \\
\hline \multicolumn{4}{|l|}{ Pathology } \\
\hline Pancreatic head carcinoma & $34(62 \%)$ & $12(48 \%)$ & $33(60 \%)$ \\
\hline Duodenal cancer & $2(4 \%)$ & $4(16 \%)$ & $3(5 \%)$ \\
\hline Ampullary carcinoma & $8(15 \%)$ & $5(20 \%)$ & $12(22 \%)$ \\
\hline Distal cholangiocarcinoma & $5(9 \%)$ & $3(12 \%)$ & $5(9 \%)$ \\
\hline Metastasis in pancreas head & $1(1,8 \%)$ & $1(4 \%)$ & $0(0 \%)$ \\
\hline Chronic pancreatitis & $2(4 \%)$ & $1(4 \%)$ & $2(4 \%)$ \\
\hline IPMN & $1(2 \%)$ & 0 & $0(0 \%)$ \\
\hline Neuro-endocrine tumor & $2(4 \%)$ & 0 & $0(0 \%)$ \\
\hline \multicolumn{4}{|l|}{ Operation type } \\
\hline Whipple & $9(16 \%)$ & $3(12 \%)$ & $8(15 \%)$ \\
\hline PPPD & $46(84 \%)$ & $22(88 \%)$ & 47 (85\%) \\
\hline Duration of OR time (min) & $345(180-810)$ & $310(190-610)$ & $340(217-715)$ \\
\hline
\end{tabular}

Abbreviation: ASA: American Society of Anesthesiologists, BMI: Body Mass Index. PPPD $=$ pylorys preserving pancreaticoduodenectomy 
APPENDIX 4. Postoperative outcomes for the 66-69 year group

\begin{tabular}{|c|c|c|c|}
\hline & $\begin{array}{c}\leq 65 \text { years of } \\
\text { age }(n=55)\end{array}$ & $\begin{array}{c}66-69 \text { years of } \\
\text { age }(n=25)\end{array}$ & $\begin{array}{c}\geq 70 \text { years of } \\
\text { age }(n=55)\end{array}$ \\
\hline \multicolumn{4}{|l|}{ Dindo-Clavien classification } \\
\hline Minor (I/II) & $15(27.2 \%)$ & $8(32 \%)$ & $20(36.3 \%)$ \\
\hline Moderate (IIla/b) & $15(27.2 \%)$ & $4(16 \%)$ & $8(14.5 \%)$ \\
\hline Severe (Iva en IVb) & $0(0 \%)$ & $1(4 \%)$ & $2(3.6 \%)$ \\
\hline Mortality $<90$ days & $3(5,5 \%)$ & $1(4 \%)$ & $6(10.9 \%)$ \\
\hline Readmissions $<6$ months & $11(20 \%)$ & $1(4 \%)$ & $7(12.7 \%)$ \\
\hline Median length of hospital stay (range) & $14(6-100)$ & $14(6-64)$ & $14(6-65)$ \\
\hline Length of stay uncomplicated (median) & $9(6-15)$ & $9(6-14)$ & $9(6-22)$ \\
\hline Median LOS Dindo-Clavien grade < III (range) & $10(6-100)$ & $14(6-60)$ & $14(7-59)$ \\
\hline Median LOS Dindo-Clavien grade $>$ III (range) & $32(11-83)$ & $51(26-64)$ & $33(14-65)$ \\
\hline \multicolumn{4}{|l|}{ Interventions } \\
\hline CT/US-drainage & $10(18.1 \%)$ & $3(12 \%)$ & $8(14.5 \%)$ \\
\hline Re-operation & $6(10.9 \%)$ & $1(4 \%)$ & $4(7.2 \%)$ \\
\hline
\end{tabular}

APPENDIX 5. ERAS outcomes for the 66-69 year group

\begin{tabular}{lccc}
\hline & $\begin{array}{c}\mathbf{5 6 5} \text { years of } \\
\text { age }(\mathbf{n = 5 5})\end{array}$ & $\begin{array}{c}\mathbf{6 6 - 6 9} \text { years of } \\
\text { age }(\mathbf{n = 2 5})\end{array}$ & $\begin{array}{c}\mathbf{2 7 0} \text { years of } \\
\text { age }(\mathbf{n = 5 5})\end{array}$ \\
\hline Resumption of fluid intake POD1 & $53(96 \%)$ & $25(100 \%)$ & $52(95 \%)$ \\
\hline Resumption of solid intake POD2 & $31(56 \%)$ & $17(68 \%)$ & $35(63 \%)$ \\
\hline Mobilization from POD 1 & $33(60 \%)$ & $17(68 \%)$ & $35(63 \%)$ \\
\hline Drain removal on POD 4 & $26(47 \%)$ & $16(64 \%)$ & $28(51 \%)$ \\
\hline Urinary catheter removal on POD 2 & $38(69 \%)$ & $13(52 \%)$ & $33(60 \%)$ \\
\hline Removal epidural on POD3 & $44(80 \%)$ & $20(80 \%)$ & $43(78 \%)$ \\
\hline
\end{tabular}




\section{REFERENCES}

1. Centre DC (2011) National guidlines "pancreatic carcinoma” version 2.0. Utrecht

2. Kow AW, Sadayan NA, Ernest A et al (2012) Is pancreaticoduodenectomy justified in elderly patients? Surgeon 10(3):128-136

3. Ito $\mathrm{Y}$, Kenmochi $\mathrm{T}$, Irino $\mathrm{T}$ et al (2011) The impact of surgical outcome after pancreaticoduodenectomy in elderly patients. World J Surg Oncol 9:102

4. Scurtu R, Bachellier P, Oussoultzoglou E et al (2006) Outcome after pancreaticoduodenectomy for cancer in elderly patients. J Gastrointest Surg 10(6):813-822

5. Tani M, Kawai M, Hirono S et al (2009) A pancreaticoduodenectomy is acceptable for periampullary tumors in the elderly, even in patients over 80 years of age. $J$ Hepatobiliary Pancreat Surg 16(5):675-680

6. Suzuki S, Kaji S, Koike N et al (2013) Pancreaticoduodenectomy can be safely performed in the elderly. Surg Today 43(6):620-624

7. Barbieri A, Vanhaecht K, Van Herck P et al (2009) Effects of clinical pathways in the joint replacement: a meta-analysis. BMC Med 7:32

8. Podore PC, Throop EB (1999) Infrarenal aortic surgery with a 3-day hospital stay: a report on success with a clinical pathway. J Vasc Surg 29(5):787-792

9. Arsalani-Zadeh R, ElFadl D, Yassin N et al (2011) Evidencebased review of enhancing postoperative recovery after breast surgery. Br J Surg 98(2):181-196

10. Basse L, Hjort Jakobsen D, Billesbolle P et al (2000) A clinical pathway to accelerate recovery after colonic resection. Ann Surg 232(1):51-57

11. Varadhan KK, Neal KR, Dejong CH et al (2010) The enhanced recovery after surgery (ERAS) pathway for patients undergoing major elective open colorectal surgery: a meta-analysis of randomized controlled trials. Clin Nutr 29(4):434-440

12. Coolsen MMD RM, de Wilt AA, Lassen K, Slim K, Dejong CHC (2013) Systematic review and meta-analysis of enhanced recovery after pancreatic surgery with particular emphasis on pancreaticoduodenectomies. World J Surg 37(9):1909-1918. doi:10.1007/s00268-013-2044-3

13. Spelt L, Ansari D, Sturesson C et al (2011) Fast-track programmes for hepatopancreatic resections: where do we stand? HPB 13(12):833-838

14. Wind J, Polle SW, Fung Kon Jin PH et al (2006) Systematic review of enhanced recovery programmes in colonic surgery. Br J Surg 93(7):800-809 
15. Balzano G, Zerbi A, Braga $M$ et al (2008) Fast-track recovery programme after pancreaticoduodenectomy reduces delayed gastric emptying. Br J Surg 95(11):1387-1393

16. Porter GA, Pisters PW, Mansyur C et al (2000) Cost and utilization impact of a clinical pathway for patients undergoing pancreaticoduodenectomy. Ann Surg Oncol 7(7):484-489

17. di Sebastiano P, Festa L, De Bonis A et al (2011) A modified fasttrack program for pancreatic surgery: a prospective single-center experience. Langenbecks Arch Surg 396(3):345-351

18. Lassen K, Coolsen MM, Slim K et al (2012) Guidelines for perioperative care for pancreaticoduodenectomy: Enhanced Recovery After Surgery (ERAS(R)) Society recommendations. Clin Nutr 31(6):817-830

19. Hamel MB, Henderson WG, Khuri SF et al (2005) Surgical outcomes for patients aged 80 and older: morbidity and mortality from major noncardiac surgery. J Am Geriatr Soc 53(3):424429

20. Gouvas N, Tan E, Windsor A et al (2009) Fast-track versus standard care in colorectal surgery: a meta-analysis update. Int J Colorectal Dis 24(10):1119-1131

21. Mangram AJ, Horan TC, Pearson ML et al (1999) Guideline for prevention of surgical site Infection, 1999. Centers for Disease Control and Prevention (CDC) Hospital Infection Control Practices Advisory Committee. Am J Infect Control 27(2):97-132

22. Bassi C, Dervenis C, Butturini G et al (2005) Postoperative pancreatic fistula: an international study group (ISGPF) definition. Surgery 138(1):8-13

23. Wente MN, Bassi C, Dervenis C et al (2007) Delayed gastric emptying (DGE) after pancreatic surgery: a suggested definition by the International Study Group of Pancreatic Surgery (ISGPS). Surgery 142(5):761-768

24. Levy MM, Fink MP, Marshall JC et al (2003) 2001 SCCM/ESICM/ACCP/ATS/SIS International Sepsis Definitions Conference. Intensiv Care Med 29(4):530-538

25. Welsch T, Eisele H, Zschabitz S et al (2011) Critical appraisal of the International Study Group of Pancreatic Surgery (ISGPS) consensus definition of postoperative hemorrhage after pancreatoduodenectomy. Langenbecks Arch Surg 396(6):783-791

26. Maher JW, Bakhos W, Nahmias N et al (2009) Drain amylase levels are an adjunct in detection of gastrojejunostomy leaks after Roux-en-Y gastric bypass. J Am Coll Surg 208(5):881-884

27. Dindo D, Demartines N, Clavien PA (2004) Classification of surgical complications: a new proposal with evaluation in a cohort of 6336 patients and results of a survey. Ann Surg 240(2):205-213 
28. Sukharamwala P, Thoens J, Szuchmacher M et al (2012) Advanced age is a risk factor for postoperative complications and mortality after a pancreaticoduodenectomy: a meta-analysis and systematic review. HPB 14(10):649-657

29. Makary MA, Winter JM, Cameron JL et al (2006) Pancreaticoduodenectomy in the very elderly. J Gastrointest Surg 10(3):347-356

30. Sohn TA, Yeo CJ, Cameron JL et al (1998) Should pancreaticoduodenectomy be performed in octogenarians? J Gastrointest Surg 2(3):207-216

31. Bathe OF, Levi D, Caldera $\mathrm{H}$ et al (2000) Radical resection of periampullary tumors in the elderly: evaluation of long-term results. World J Surg 24(3):353-358. doi:10.1007/ s002689910056

32. Brozzetti S, Mazzoni G, Miccini M et al (2006) Surgical treatment of pancreatic head carcinoma in elderly patients. Arch Surg 141(2):137-142

33. Hodul P, Tansey J, Golts E et al (2001) Age is not a contraindication to pancreaticoduodenectomy. Am Surg 67(3):270-275

34. Finlayson E, Fan Z, Birkmeyer JD (2007) Outcomes in octogenarians undergoing high-risk cancer operation: a national study. J Am Coll Surg 205(6):729-734

35. Riall TS, Reddy DM, Nealon WH et al (2008) The effect of age on short-term outcomes after pancreatic resection: a populationbased study. Ann Surg 248(3):459-467

36. de Wilde RF, Besselink MG, van der Tweel I et al (2012) Impact of nationwide centralization of pancreaticoduodenectomy on hospital mortality. Br J Surg 99(3):404-410

37. Fiore JF Jr, Faragher IG, Bialocerkowski A et al (2013) Time to readiness for discharge is a valid and reliable measure of shortterm recovery after colorectal surgery. World J Surg 37(12):2927-2934. doi:10.1007/s00268-013-2208-1

38. Maessen JM, Dejong CH, Kessels AG et al (2008) Length of stay: an inappropriate readout of the success of enhanced recovery programs. World J Surg 32(6):971-975. doi:10.1007/s00268007-9404-9

39. Riall TS (2009) What is the effect of age on pancreatic resection? Adv Surg 43:233-249

40. Ahmed J, Khan S, Gatt M et al (2010) Compliance with enhanced recovery programmes in elective colorectal surgery. Br J Surg 97(5):754-758

41. Nicholson A, Lowe MC, Parker J et al (2014) Systematic review and meta-analysis of enhanced recovery programmes in surgical patients. Br J Surg 101(3):172-188 
42. Bassi C, Molinari E, Malleo G et al (2010) Early versus late drain removal after standard pancreatic resections: results of a prospective randomized trial. Ann Surg 252(2):207-214

43. Kawai M, Tani M, Terasawa $\mathrm{H}$ et al (2006) Early removal of prophylactic drains reduces the risk of intra-abdominal infections in patients with pancreatic head resection: prospective study for 104 consecutive patients. Ann Surg 244(1):1-7

44. Conlon KC, Labow D, Leung D et al (2001) Prospective randomized clinical trial of the value of intraperitoneal drainage after pancreatic resection. Ann Surg 234(4):487-493

45. Van Buren G 2nd, Bloomston M, Hughes SJ et al (2014) A randomized prospective multicenter trial of pancreaticoduodenectomy with and without routine intraperitoneal drainage. Ann Surg 259(4):605-612

46. Al-Sharaf K, Andren-Sandberg A, Ihse I (1999) Subtotal pancreatectomy for cancer can be safe in the elderly. Eur J Surg (Acta chirurgica) 165(3):230-235

47. Fong Y, Blumgart LH, Fortner JG et al (1995) Pancreatic or liver resection for malignancy is safe and effective for the elderly. Ann Surg 222(4):426-434

48. Bottger TC, Engelmann R, Junginger T (1999) Is age a risk factor for major pancreatic surgery? An analysis of 300 resections. Hepatogastroenterology 46(28):2589-2598

49. Kurian AA, Wang L, Grunkemeier G et al (2013) Defining "the elderly" undergoing major gastrointestinal resections: receiver operating characteristic analysis of a large ACS-NSQIP cohort. Ann Surg 258(3):483-489

50. Junejo MA, Mason JM, Sheen AJ et al (2012) Cardiopulmonary exercise testing for preoperative risk assessment before hepatic resection. Br J Surg 99(8):1097-1104

51. Gouma DJ, van Geenen RC, van Gulik TM et al (2000) Rates of complications and death after pancreaticoduodenectomy: risk factors and the impact of hospital volume. Ann Surg 232(6):786-795

52. Balzano G, Zerbi A, Capretti G et al (2008) Effect of hospital volume on outcome of pancreaticoduodenectomy in Italy. Br J Surg 95(3):357-362 
Q 810

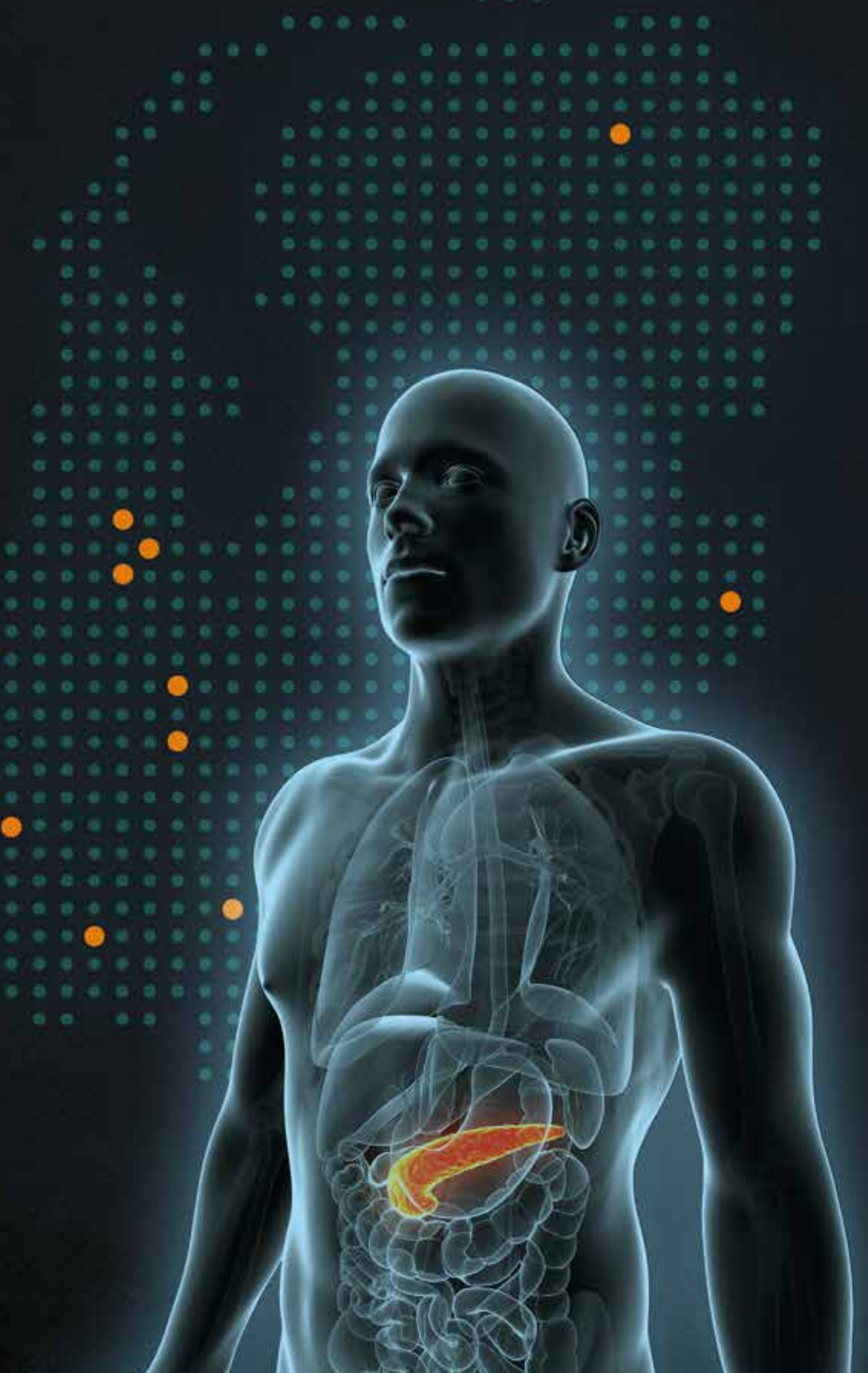

00080000000000000

0.00000000000000

0.000 .00 .0

0.0000000

$\ldots$

0000000000

Q

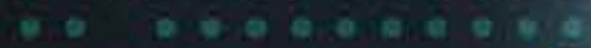

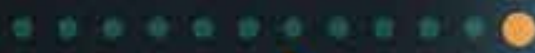

0.0000000008

0.000 .0 .00

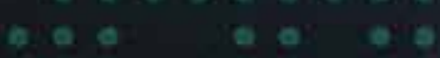

$\ldots$

a: 


\title{
LOW SKELETAL MUSCLE RADIATION ATTENUATION AND VISCERAL ADIPOSITY ARE ASSOCIATED WITH OVERALL SURVIVAL AND SURGICAL SITE INFECTIONS IN PATIENTS WITH PANCREATIC CANCER
}

\author{
D.P.J. van Dijk ${ }^{1,2} \mid$ M.J.A.M. Bakens ${ }^{1} \mid$ M.M.E. Coolsen ${ }^{1}$ | S.S. Rensen ${ }^{1,2}$ \\ R.M. van Dam¹ | M.J.L. Bours ${ }^{3,4}$ | M.P. Weijenberg ${ }^{3,4}$ | C.H.C. Dejong ${ }^{1,2,4}$ \\ S.W.M. Olde Damink1,2,5
}

J Cachexia Sarcopenia Muscle. 2017 Apr;8(2):317-326.

1 Department of Surgery, Maastricht University Medical Centre, Maastricht, The Netherlands

2 NUTRIM School of Nutrition and Translational Research in Metabolism, Maastricht University, Maastricht, The Netherlands

${ }^{3}$ Department of Epidemiology, Maastricht University, Maastricht, The Netherlands

${ }^{4}$ GROW School for Oncology and Developmental Biology, Maastricht University, Maastricht, The Netherlands

5 Institute for Liver and Digestive Health, University College London, London, UK 


\section{ABSTRACT}

Background Cancer cachexia and skeletal muscle wasting are related to poor survival. In this study, quantitative body composition measurements using computed tomography (CT) were investigated in relation to survival, post-operative complications, and surgical site infections in surgical patients with cancer of the head of the pancreas.

Methods A prospective cohort of 199 patients with cancer of the head of the pancreas was analyzed by CT imaging at the L3 level to determine;muscle radiation attenuation (average Hounsfield units of total L3 skeletal muscle); visceral adipose tissue area; subcutaneous adipose tissue area; intermuscular adipose tissue area; and skeletal muscle area. Sex-specific cut-offs were determined at the lower tertile for muscle radiation attenuation and skeletal muscle area and the higher tertile for adipose tissues. These variables of body composition were related to overall survival, severe post-operative complications (Dindo-Clavien $\geq 3$ ), and surgical site infections (wounds inspected daily by an independent trial nurse) using Cox regression analysis and multivariable logistic regression analysis, respectively.

Results Low muscle radiation attenuation was associated with shorter survival in comparison with moderate and high muscle radiation attenuation [median survival 10.8 (95\% CI: 8.8-12.8) vs. 17.4 (95\% CI: 14.7-20.1), and 18.5 (95\% CI: 9.2-27.8) months, respectively; $\mathrm{P}<0.008]$. Patient subgroups with high muscle radiation attenuation combined with either low visceral adipose tissue or age $<70$ years had longer survival than other subgroups $(\mathrm{P}=0.011$ and $\mathrm{P}=0.001$, respectively). Muscle radiation attenuation was inversely correlated with intermuscular adipose tissue $\left(\mathrm{r}_{\mathrm{p}}=0.697, \mathrm{P}<0.001\right)$. High visceral adipose tissue was associated with an increased surgical site infection rate, OR: 2.4 (95\% CI: $1.1-5.3 ; \mathrm{P}=0.027)$.

Conclusion Low muscle radiation attenuation was associated with reduced survival, and high visceral adiposity was associated with an increase in surgical site infections. The strong correlation between muscle radiation attenuation and intermuscular adipose tissue suggests the presence of ectopic fat in muscle, warranting further investigation. CT image analysis could be implemented in pre-operative risk assessment to assist in treatment decision-making. 


\section{INTRODUCTION}

Cancer of the head of the pancreas (HOP) has a poor prognosis with 1 year and 5 years survival rates of $24 \%$ and $7 \%$, respectively. ${ }^{1}$ The poor prognosis is partly attributable to cancer cachexia, a syndrome of severe weight loss and muscle wasting, which occurs in the vast majority of patients with pancreatic cancer and other cancers in the head region of the pancreas (e.g. ampullary carcinoma and distal cholangiocarcinoma). ${ }^{2,3}$ Currently, surgery is the only available treatment for HOP cancer to achieve curation, usually by performing a classical pancreaticoduodenectomy (Whipple) or pylorus-preserving pancreaticoduodenectomy. This type of surgery is very invasive and has a high risk of serious complications that considerably reduce survival, such as pancreatic fistula, gastrojejunostomy leakage, and surgical site infection (SSI). ${ }^{4,5}$ Therefore, pre-operative selection of patients who are less vulnerable to complications is important.

For pre-operative risk assessment in HOP cancer, determining the degree of cachexia is particularly relevant. While weight loss usually is patient reported and therefore partly subjective, muscle and adipose tissue area can be objectively measured using the standard abdominal computer tomography (CT) scan that is routinely performed prior to surgery. Indeed, the total skeletal muscle area on a single CT slice at the third lumbar vertebra (L3) is strongly correlated with total body skeletal muscle area. ${ }^{6}$ The area of visceral adipose tissue (VAT), subcutaneous adipose tissue (SAT), and intermuscular adipose tissue (IMAT) can also be accurately estimated using this approach. Although a low skeletal muscle area has been associated with poor outcome in various cancer types, ${ }^{7}$ including pancreatic cancer, ${ }^{8,9}$ the amount of (visceral) adipose tissue seems to have more impact on outcome in patients with pancreatic cancer. Several studies found a strong association between increased VAT and post-operative pancreatic fistula in patients with pancreatic cancer, ${ }^{8,10,11}$ while other studies found associations with increased major post-operative complications ${ }^{12}$ and pulmonary complications. ${ }^{13}$ Increased fat content in muscle tissue (myosteatosis) also seems to impact clinical outcome in pancreatic cancer. In fact, there are indications that increased muscle fat content rather than low muscle mass is associated with shorter survival in patients with unresectable pancreatic cancer. ${ }^{14} \mathrm{CT}$ scans contain information about the radio density of a specific tissue type in Hounsfield units (HUs), which is referred to as radiation attenuation. A recent review showed that 
muscle radiation attenuation is highly variable among patients with cancer. ${ }^{15}$ Low muscle radiation attenuation could be a reflection of increased intramyocellular triglycerides (i.e. myosteatosis) or increased water content (i.e. muscle oedema). Goodplaster et al. ${ }^{16}$ showed an inverse association between muscle radiation attenuation and triglyceride content in muscle phantoms and muscle biopsies from healthy adults. Myosteatosis has also been associated with insulin resistance and decreased muscle activity. ${ }^{17-19}$ These changes in the composition of muscle tissue may result in diminished muscle function and strength, which, in turn, is associated with poor surgical outcome. ${ }^{20}$ We therefore aimed to assess the association of radiation attenuation, adipose tissue, and other characteristics of body composition with postoperative survival, post-operative complications, and SSIs in patients with HOP cancer.

\section{METHODS}

\section{SUBJECTS}

This study was a chart review of a prospective cohort of 199 patients undergoing pancreatic surgery between 2008-2013 at the Maastricht University Medical Centre (MUMC), the Netherlands. Patients were included for analysis if they had pathologyproven or radiology-proven cancer of the pancreatic head, ampulla, distal common bile duct, or duodenum. Exclusion criteria were the presence of a neuro-endocrine tumor, benign or pre-malignant disease, metastatic disease on radiology examination (e.g. liver or lung metastases), intraductal papillary mucinous neoplasm, and missing abdominal CT scan or abdominal CT scan of poor quality.

\section{DATA COLLECTION}

The primary outcome parameter of this study was overall survival, measured in months from the day of surgery. Secondary outcomes included major post-operative complications and SSIs. The pancreaticoduodenectomy composite endpoint (CEP $)^{21}$ was used as outcome parameter for major post-operative complications (Dindo-Clavien grade $\geq 3$ ). ${ }^{22}$ The eight most important complications after a pancreaticoduodenectomy are compiled into a single variable, the CEP. The CEP is a binary variable that is given a score of 1 if a patient 
has experienced one or more of the eight complications; a score of 0 is given if a patient has none of the eight complications. The eight endpoints included in the CEP were intraabdominal abscess, sepsis, gastrojejunostomy leakage, post-pancreaticoduodenectomy haemorrhage, bile leakage/hepaticojejunostomy leakage, pancreatic fistula /pancreatic anastomosis leakage, delayed gastric emptying, and operative mortality. Intra-abdominal abscess was defined as any quantity of purulent fluid leaking via the abdominal drain that is culture positive or a walled-off collection of pus in the abdominal cavity at the time of radiological imaging, reoperation, or percutaneous drainage; gastrojejunostomy leakage was defined as anastomotic incompetence documented either by confirmatory upper gastrointestinal contrast X-rays, CT scans, or reoperation; operative mortality was defined as death within 90 days from surgery. ${ }^{21}$ Sepsis was defined as the presence of both infection and a systemic inflammatory response. ${ }^{23}$ Postpancreaticoduodenectomy haemorrhage, bile leakage, pancreatic fistula, and delayed gastric emptying were scored according to the International Study Group of Liver Surgery ${ }^{24}$ or International Study Group of Pancreatic Surgery criteria as applicable. ${ }^{25-27}$ Post-operative SSIs were scored by an independent trial nurse both in-hospital and at the outpatient department during a 90 days period after surgery. Wounds were inspected daily during hospital stay and at every visit to the outpatient department. Infections were scored as incisional or organ/space SSIs according to the Centers for Disease Control and Prevention definitions. ${ }^{28}$ Patientreported weight, height, and weight loss in the 6 months prior to surgery as well as age and sex were recorded at the outpatient department. Comorbidities (diabetes mellitus, cardiac, pulmonal, and renal) were retrieved from the patient's medical file. C-reactive protein (CRP) and albumin levels at diagnosis (maximum of 1 month before surgery) were recorded from the patient's medical file (if available) as markers of inflammation, but these were not routinely measured in all patients. Measurements were performed as part of standard care by the Department of Clinical Chemistry of the MUMC. Definitive diagnosis and tumor staging were performed post-operatively by the pathologist. In case of signs of incurable disease during surgery (e.g. peritoneal metastasis), no resection was performed, resulting in missing pathology data. These patients were included in the analysis because they are a substantial part of the surgical patient population and therefore potentially could benefit from additional pre-operative work-up including CTbased body composition analysis. The study protocol was approved by the medical ethical committee of the MUMC that waived the requirement to obtain informed consent. 


\section{COMPUTED TOMOGRAPHY SCAN ANALYSIS}

Pre-operative CT scans were performed maximally 6 weeks before surgery. Abdominal CT scans were analyzed in anonymized format by one blinded independent researcher trained in radiologic anatomy and body composition analysis. Firstly, a single slice of each patient's CT scan was selected at the level of the L3. CT scans with large radiation artefacts or with missing parts of muscle tissue on the ventral, dorsal, or both lateral edges of the scan were excluded. Muscles included into the analysis were the internal and external obliques, transversus abdominus, rectus abdominus, psoas, quadratus lumborum, and erector spinae muscles. CT scans were analyzed using sliceOmatic 5.0 (TomoVision, Magog, Canada) software for Microsoft Windows ${ }^{\oplus}$ Using predefined HU ranges, the total cross-sectional area $(\mathrm{cm} 2)$ of skeletal muscle tissue (29 to $150 \mathrm{HU}$ ), VAT (150 to $50 \mathrm{HU}$ ), SAT (190 to $30 \mathrm{HU}$ ), and IMAT (190 to $30 \mathrm{HU}$ ) was determined. In addition, the radiation attenuation for skeletal muscle was assessed by calculating the average $\mathrm{HU}$ value of the total muscle area within the specified range of 29 to $150 \mathrm{HU}$ (i.e. this is calculated from the muscle tissue only excluding the IMAT). The total areas of skeletal muscle, VAT,and SAT were corrected for stature to calculate the L3-muscle index, L3-VAT index, and L3-SAT index in $\mathrm{cm}^{2} / \mathrm{m}^{2}$, providing good estimates of total body skeletal muscle, VAT, and SAT mass. ${ }^{6}$

\section{STATISTICAL ANALYSIS}

Prado et al. ${ }^{29}$ and Martin et al. ${ }^{7}$ previously published cut-off values for L3-muscle index and radiation attenuation, found by using optimal stratification. However, these cut-offs were found in a Canadian cohort of patients with respiratory tract and gastro-intestinal cancer and might not be comparable with the present Dutch cohort of patients with HOP cancer. Body composition varies greatly among regions and ethnicities as illustrated by the large Japanese cohort study of Fujiwara et al., which found highly different cut-offs compared with the study of Martin (e.g. female cut-off for L3-muscle index at 29.6 in the Japanese cohort versus 41 in the Canadian cohort). ${ }^{7,30}$ Therefore, we decided to set our own cut-offs as performed by other studies with similar population sizes. ${ }^{31-34}$ Optimum stratification works well for large cohorts in which the lowest P-value will be used to set the cut-off. ${ }^{35}$ However, in smaller cohorts, the P-value is too unstable to use optimum stratification to find a reliable cutoff. Because we considered our cohort was too small 
for cut-point analysis by optimal stratification, we determined cut-off values for our cohort based on tertiles. Determining the cut-off at a tertile enables comparison between groups with a relative low/high value to be compared with the rest of the group while not forcing subjects with a value around the cut-off value in a low or high category. Cutoff values were set at the lowest tertile for radiation attenuation and L3-muscle index, and at the highest tertile for L3-VAT index, L3-SAT index, and IMAT. Because IMAT is not uniformly distributed throughout the muscle, it was not added to the regression analysis. Body composition is highly influenced by sex; therefore, separate cut-off values were determined for men and women. Data were analyzed using IBM SPSS 23 for Microsoft Windows ${ }^{\oplus}$. Differences in patient characteristics were analyzed using the independent T-test or Pearson $\chi 2$ test. The Kaplan-Meier estimate and Cox regression analysis were used to assess the association of each individual body composition measurement with survival. Multiple logistic regression was used to assess the association of body composition with major complications and SSIs. For both Cox regression and multiple logistic regression analyses, two models were used. Model 1 was the unadjusted univariable analysis. Model 2 was a multivariable analysis adjusted for sex, age, and body mass index (BMI) because these are known important confounders of body composition and survival. ${ }^{7}$ In addition, any variable that generated a P-value of $<0.1$ in univariable analysis was added to the multivariable analysis. For correlations, Pearson's correlation coefficient $\left(\mathrm{r}_{\mathrm{p}}\right)$ was used. Only correlations with a value of $\geq 0.5$ or $\leq-0.5$ are reported. A $\mathrm{P}$-value of $<0.05$ was considered significant.

\section{RESULTS}

\section{PATIENT COHORT}

From all 199 patients of the prospective cohort, 186 were included in the present analysis. Eight patients were excluded because of benign disease, three because of intraductal papillary mucinous neoplasm, and two because of poor quality CT scans. Two patients had incomplete data on post-operative complications and infections but were included in the survival analysis. The median follow-up was 57.7 months. Patient characteristics are shown in Table 1. 
Table 1. General characteristics of patients with cancer of the head of the pancreas according to low and high muscle radiation attenuation

\begin{tabular}{|c|c|c|c|c|}
\hline & $\begin{array}{c}\text { Total } \\
(n=186)\end{array}$ & $\begin{array}{l}\text { Low muscle } \\
\text { radiation } \\
\text { attenuation } \\
\quad(n=62) \\
\end{array}$ & $\begin{array}{l}\text { Moderate-high } \\
\text { muscle radiation } \\
\text { attenuation } \\
(n=124)\end{array}$ & $P$-value \\
\hline Male (n, \%) & $102(54.8 \%)$ & $34(54.8 \%)$ & $68(54.8 \%)$ & 1.000 \\
\hline Age (years) & 66.5 & $69.8 \pm 8.7$ & $64.8 \pm 9.8$ & 0.001 \\
\hline Body mass index $\left(\mathrm{kg} / \mathrm{m}^{2}\right)$ & 25.2 & $26.8 \pm 5.2$ & $24.4 \pm 3.9$ & $<0.001$ \\
\hline Weight loss (\%) ${ }^{\mathrm{a}}$ & 9.4 & $11.0 \pm 8.4$ & $8.7 \pm 7.0$ & 0.124 \\
\hline \multicolumn{5}{|l|}{ Comorbidity (n, \%) } \\
\hline Diabetes mellitus & $42(22.6 \%)$ & $16(25.8 \%)$ & $26(21.0 \%)$ & 0.492 \\
\hline Cardiac & $78(41.9 \%)$ & $32(51.6 \%)$ & $46(37.1 \%)$ & 0.071 \\
\hline Pulmonary & $19(10.2 \%)$ & $7(11.3 \%)$ & $12(9.7 \%)$ & 0.759 \\
\hline Renal & $9(4.8 \%)$ & $4(6.5 \%)$ & $5(4.0 \%)$ & 0.488 \\
\hline \multicolumn{5}{|l|}{ Pathology (n, \%) } \\
\hline Pancreatic & $73(39.2 \%)$ & $21(33.9 \%)$ & $52(41.9 \%)$ & 0.288 \\
\hline Ampullary & $28(15.1 \%)$ & $9(14.5 \%)$ & $19(15.3 \%)$ & 0.885 \\
\hline Cholangiocarcinoma & $10(5.4 \%)$ & $1(1.6 \%)$ & $9(7.3 \%)$ & 0.169 \\
\hline Duodenal carcinoma & $8(4.3 \%)$ & $3(4.8 \%)$ & $5(4.0 \%)$ & 1.000 \\
\hline Other $^{b}$ & $5(2.7 \%)$ & $1(1.6 \%)$ & $4(3.2 \%)$ & 0.666 \\
\hline None available/palliative surgeryc & $62(33.3 \%)$ & $27(42.5 \%)$ & $35(28.2 \%)$ & 0.037 \\
\hline Composite endpoint ( $n, \%)^{a}$ & $88(47.3 \%)$ & $34(55.8 \%)$ & $54(43.5 \%)$ & 0.130 \\
\hline Intra-abdominal abscess & $35(18.8 \%)$ & $14(22.6 \%)$ & $21(16.9 \%)$ & 0.339 \\
\hline Sepsis & $23(12.4 \%)$ & $6(9.7 \%)$ & $17(13.7 \%)$ & 0.453 \\
\hline Gastrojejunostomy leakage & $7(3.8 \%)$ & $2(3.2 \%)$ & $5(4.0 \%)$ & 1.000 \\
\hline $\begin{array}{l}\text { Post-pancreaticoduodenectomy } \\
\text { haemorrhage }\end{array}$ & $22(11.8 \%)$ & $7(11.3 \%)$ & $15(12.1 \%)$ & 0.872 \\
\hline Bile leakage & $16(8.6 \%)$ & $6(9.7 \%)$ & $10(8.1 \%)$ & 0.724 \\
\hline Pancreatic fistula & $26(14.0 \%)$ & $10(16.1 \%)$ & $16(12.9 \%)$ & 0.550 \\
\hline Delayed gastric emptying & $44(23.7 \%)$ & $17(27.4 \%)$ & $27(21.8 \%)$ & 0.356 \\
\hline Operative mortality & $26(14.0 \%)$ & $9(14.5 \%)$ & $15(12.1 \%)$ & 0.643 \\
\hline Surgical site infections ( $\mathrm{n}, \%$ ) & $101(54.3 \%)$ & $34(54.8 \%)$ & $67(54.0 \%)$ & 0.917 \\
\hline Incisional & $73(39.2 \%)$ & $26(41.9 \%)$ & $47(37.9 \%)$ & 0.595 \\
\hline Organ/space & $49(26.3 \%)$ & $18(29.0 \%)$ & 31 (25.0\%) & 0.556 \\
\hline
\end{tabular}


Laboratory results (pre-operative)

$\begin{array}{lcccr}\text { C-reactive protein }(\mathrm{mg} / \mathrm{L})^{\mathrm{a}} & 37.0 & 37.9 \pm 50.6 & 36.5 \pm 60.2 & 0.913 \\ \text { Albumin }(\mathrm{g} / \mathrm{L})^{\mathrm{a}} & 34.4 & 31.0 \pm 6.2 & 35.8 \pm 6.3 & 0.006\end{array}$

Muscle radiation attenuation was measured as the average Hounsfield units of the total skeletal muscle area on a single cross-sectional computer tomography image at the level of the third lumbar vertebra. Sex-specific cut-offs for muscle radiation attenuation were determent at the lower tertile (male: $33.9 \mathrm{HU}$, female: $30.9 \mathrm{HU}$ ).

HU, Hounsfield units.

aMissing data were excluded: weight loss $n=67$, comorbidity $n=2$, composite endpoint $n=2, C$-reactive protein $n=97$, and albumin $n=122$.

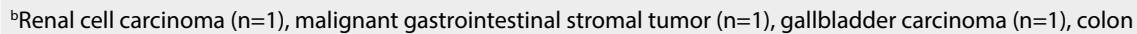
carcinoma $(n=1)$, and leiomyosarcoma $(n=1)$.

cPathology was not available in cases where the surgeon decided to convert to palliative surgery because of an incurable disease (e.g. peritoneal metastases).

Table 2. Means and sex-specific cut-off values for all CT-scan measurements at the third lumbar vertebra of patients with cancer of the head of the pancreas at diagnosis

\begin{tabular}{llcccc}
\hline & \multicolumn{2}{c}{$\begin{array}{c}\text { Male } \\
(\mathbf{n = 1 0 2})\end{array}$} & \multicolumn{2}{c}{$\begin{array}{c}\text { Female } \\
\text { (n=84) }\end{array}$} & $\begin{array}{c}\text { Total } \\
\text { (n=186) }\end{array}$ \\
\cline { 2 - 6 } & \multicolumn{1}{c}{ Mean (SD) } & Cut-off & Mean (SD) & Cut-off & Mean (SD) \\
\hline Radiation attenuation $(\mathrm{HU})$ & $36.38(7.73)$ & 33.9 & $33.84(9.85)$ & 30.9 & $35.24(8.82)$ \\
\hline L3-muscle index $\left(\mathrm{cm}^{2} / \mathrm{m}^{2}\right)$ & $49.13(7.27)$ & 45.1 & $39.98(6.38)$ & 36.9 & $45.00(8.25)$ \\
\hline L3-visceral adipose tissue index $\left(\mathrm{cm}^{2} / \mathrm{m}^{2}\right)$ & $55.42(31.28)$ & 68.2 & $33.76(23.51)$ & 39.2 & $45.64(29.98)$ \\
\hline L3-subcutaneous adipose tissue index $\left(\mathrm{cm}^{2} / \mathrm{m}^{2}\right)$ & $44.86(22.76)$ & 49.8 & $63.41(30.29)$ & 72.6 & $52.85(27.74)$ \\
\hline L3-intermuscular adipose tissue $\left(\mathrm{cm}^{2}\right)$ & $15.54(13.38)$ & 16.6 & $14.81(11.07)$ & 15.4 & $15.21(12.37)$ \\
\hline
\end{tabular}

Muscle radiation attenuation was measured as the average Hounsfield units ( $\mathrm{HU}$ ) of the total skeletal muscle area on a single cross-sectional computer tomography (CT) image at the level of the third lumbar vertebra (L3). The L3-muscle index, L3-visceral adipose tissue index, and L3-subcutaneous adipose tissue index were measured as total area at L3 level, corrected for stature. L3-intermuscular adipose tissue was measured as total area at L3 level. Sex-specific cut-offs were determent at the lower tertile for muscle radiation attenuation and L3-muscle index, and at the higher tertile for L3-visceral adipose tissue index, L3-subcutaneous adipose tissue index, and L3- intermuscular adipose tissue.

$\mathrm{SD}$, standard deviation.

CT scan analysis was performed on all 186 patients for muscle radiation attenuation, L3muscle-index, and L3-VAT-index. Because the tissues of some patients were outside of the CT scan range, IMAT and L3-SAT index could be measured in 183 and 144 patients, respectively. Mean and sex-specific cut-off values for all CT derived body composition parameters are shown in Table 2. 


\section{SURVIVAL ANALYSIS}

Initial survival analysis was performed using the unadjusted Kaplan-Meier estimate for all CT scan measurements. Patients with a low muscle radiation attenuation had a significantly lower survival than patients with a moderate or high radiation attenuation, median survival of 10.8 (95\% CI: 8.8-12.8) vs. 17.4 (95\% CI: 14.7-20.1), and 18.5 months (95\% CI:9.2-27.8), respectively ( $\mathrm{P}=0.008$, Figure 1A). There were no significant differences in survival between patients within the different categories of L3-muscle index, L3-VAT index, and L3-SAT index. Patients with both high muscle radiation attenuation and a low L3-VAT index $(n=93,50.0 \%)$ had significantly higher survival than patients with other combinations (Figure $1 \mathrm{~B}, \mathrm{P}=0.011$ ). Patients with both a high muscle radiation attenuation and age $<70(\mathrm{n}=81,43.5 \%)$ had a higher survival compared with other combinations, while both a low muscle radiation attenuation and age $\geq 70$ ( $\mathrm{n}$ $=33,17.7 \%$ ) were associated with significantly lower survival (Figure $1 \mathrm{C}, \mathrm{P}=0.001$ ). Results of the Cox-regression analysis are shown in Figure 2. There was a significantly shorter survival in patients with a low muscle radiation attenuation (HR 1.57, 95\% CI $1.08-2.29, \mathrm{P}=0.020$ ) compared with patients with a moderate or high muscle radiation attenuation.

L3-muscle index, L3-VAT index, and L3-SAT index were not significantly associated with survival. 


\section{Survival}

A

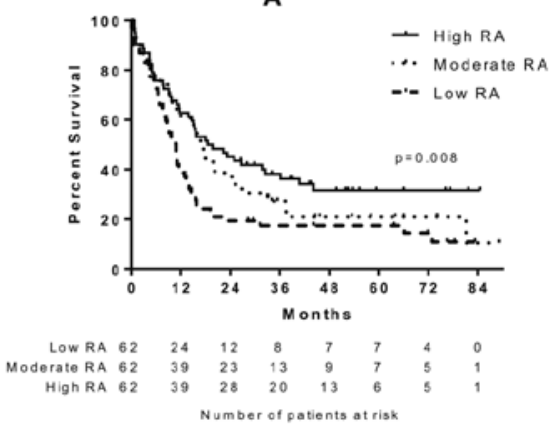

C

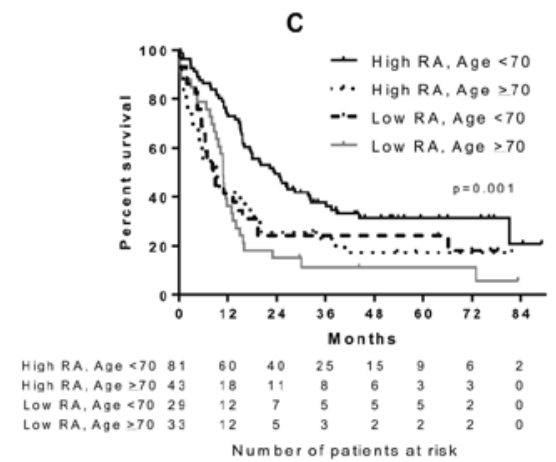

B

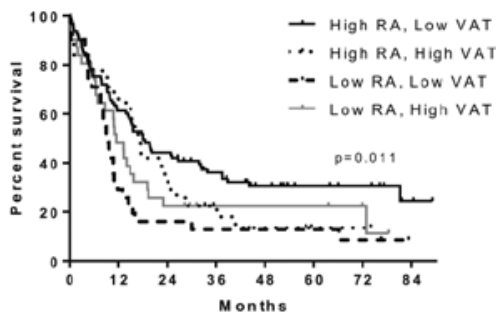

FIGURE 1. Survival is related to different risk categories in patients with cancer of the head of the pancreas. (A) Kaplan-Meier estimate (univariable analysis): patients with low muscle radiation attenuation had a significantly lower survival than patients with moderate or high radiation attenuation (log-rank test, $\mathrm{P}=0.002$ ). (B) Kaplan-Meier estimate (univariable analysis): patients with both high muscle radiation attenuation and low visceral adipose tissue index had significantly higher survival than other categories (log-rank test, $\mathrm{P}=0.011$ ). (C) Kaplan-Meier estimate (univariable analysis): patients with both high muscle radiation attenuation and low age had a significantly higher survival than other categories, while patients with low muscle radiation attenuation and high age had significantly lower survival (log-rank test, $\mathrm{P}=0.001)$. RA, radiation attenuation; VAT, visceral adipose tissue index. 


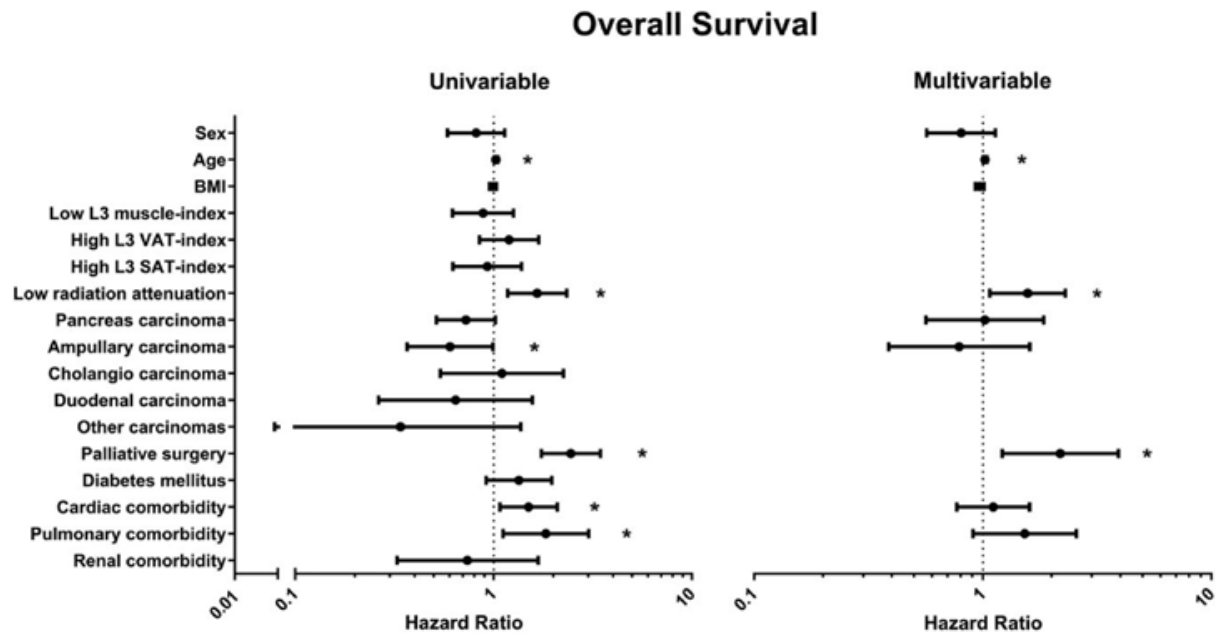

FIGURE 2. Association between computed tomography scan measurements at the third lumbar vertebra and potential confounders of patients with cancer of the head of the pancreas at diagnosis with survival using Cox-regression analysis. Values are displayed as hazard ratio and 95\% confidence interval. Sex, age, body mass index $(\mathrm{BMI})$, and variables that generated a $P$-value of $<0.1$ in univariable analysis were entered in the multivariable analysis. $C$-statistic $=0.66$ for multivariable analysis. SAT, subcutaneous adipose tissue; VAT, visceral adipose tissue. ${ }^{*} P<0.05$.

\section{POST-OPERATIVE COMPLICATIONS AND SURGICAL SITE INFECTIONS.}

In total, 88 patients had one or more pancreatic surgery specific post-operative complications, leading to a positive CEP: sepsis $(n=23)$, gastrojejunostomy leakage $(n=$ $7)$, post-pancreatectomy haemorrhage $(n=22)$, bile leakage $(n=16)$, delayed gastric emptying $(\mathrm{n}=44)$, operative mortality $(\mathrm{n}=24)$, intra-abdominal abscess $(\mathrm{n}=35)$, and pancreatic fistula $(n=26)$. Low L3-muscle index was significantly associated with less post-operative complications [adjusted OR: 0.48, (95\% CI 0.24-0.96), P = 0.038; Figure 3]. One hundred and one patients developed an SSI (52 incisional, 28 organ/space SSIs, and 21 had both types). High L3-VAT index was significantly associated with an increased incidence of SSIs [adjusted OR: 2.42, (95\% CI 1.10-5.28), P = 0.027; Figure 4]. 


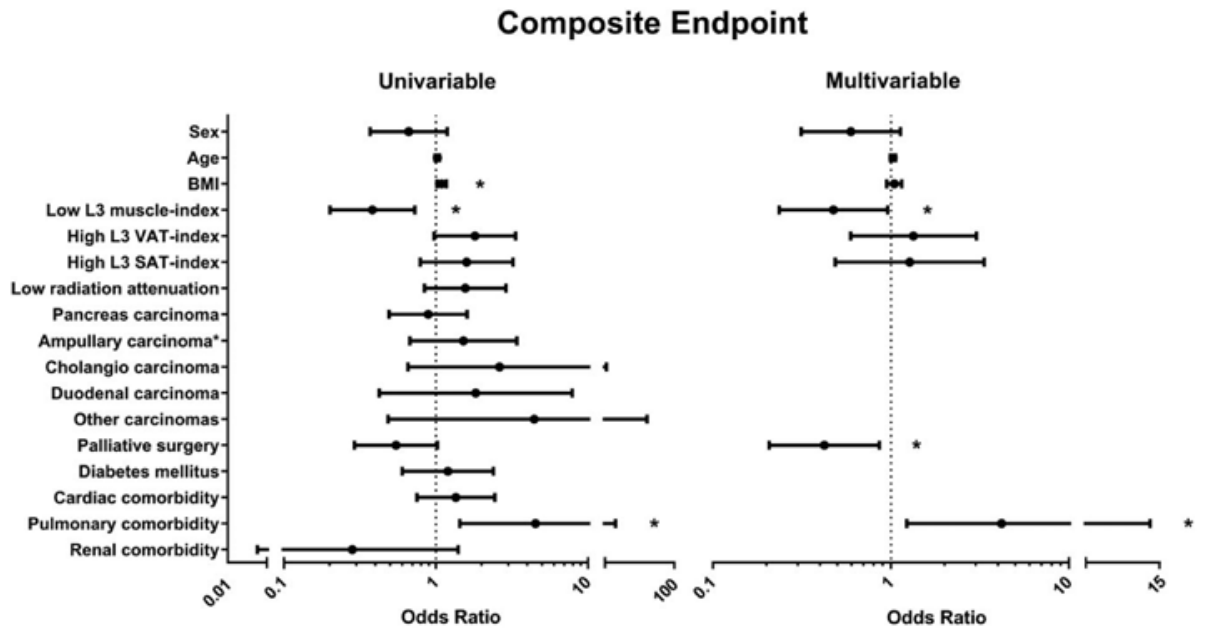

FIGURE 3. Association between computed tomography scan measurements and potential confounders with post-operative complications using logistic regression analysis. Values are displayed as odds ratio and 95\% confidence interval. Sex, age, body mass index (BMI), and variables that generated a $P$-value of $<0.1$ in a univariable analysis were entered in the multivariable analysis. $C$-statistic $=0.72$ for multivariable analysis. SAT, subcutaneous adipose tissue; VAT, visceral adipose tissue. ${ }^{*} P<0.05$.

\section{COMORBIDITIES AND CORRELATIONS}

Comorbidities for all patients are shown in Table 1. Patients with low muscle radiation attenuation did not have a higher prevalence of diabetes or cardiac, pulmonary, and renal comorbidities. Patients with low muscle radiation attenuation had significantly lower preoperative albumin levels compared with patients with moderate-high muscle radiation attenuation. There was no difference in pre-operative CRP levels. Patients with an age $>70$ years had a significantly lower muscle radiation attenuation and L3-muscle index than patients with an age $<70$ years (radiation attenuation: $32.4 \pm 8.5$ vs. $37.2 \pm 8.5$; L3-muscle index: $43.3 \pm 7.9$ vs. $46.2 \pm 8.3$, respectively). Muscle radiation attenuation correlated inversely with IMAT area $\left(r_{p}=0.697, \mathrm{P}<0.001\right)$. As expected, BMI correlated positively with both L3-VAT index $\left(\mathrm{r}_{\mathrm{p}}=0.583, \mathrm{P}<0.001\right)$ and SAT $\left(\mathrm{r}_{\mathrm{p}}=0.681, \mathrm{P}<0.001\right)$. 


\section{Surgical Site Infections}

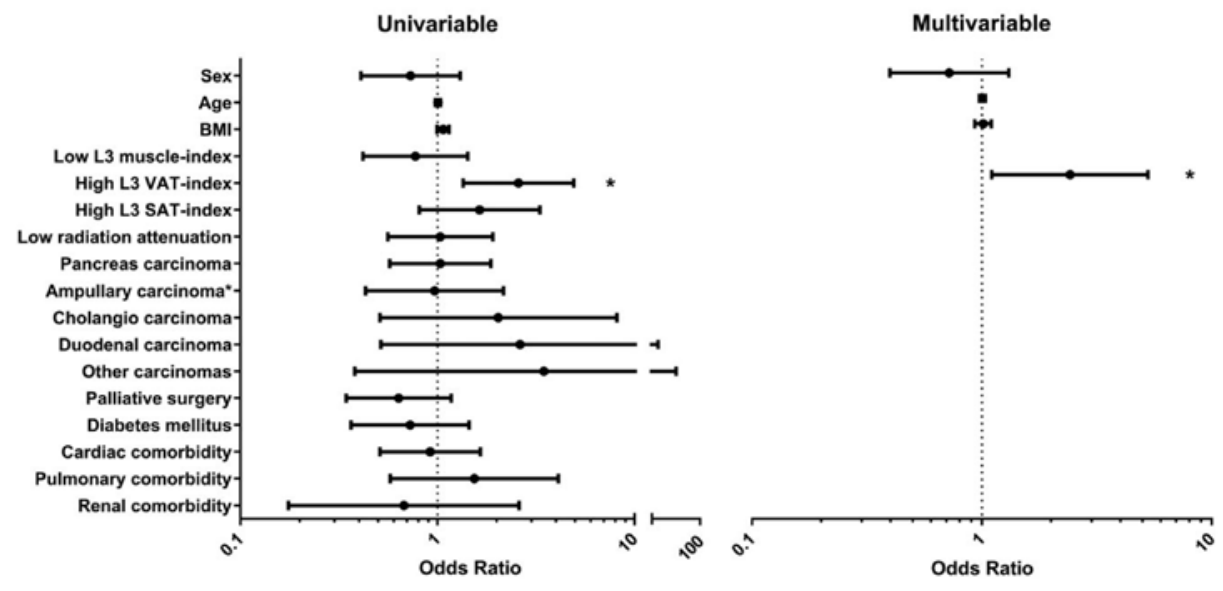

FIGURE 4. Association between computed tomography scan measurements and potential confounders with surgical site infections using logistic regression analysis. Values are displayed as odds ratio and $95 \%$ confidence interval. Sex, age, body mass index (BMI), and variables that generated a $P$-value of $<0.1$ in univariable analysis were entered in the multivariable analysis. C-statistic $=0.62$ for multivariable analysis. SAT, subcutaneous adipose tissue; VAT, visceral adipose tissue. ${ }^{*} P<0.05$.

\section{DISCUSSION}

In this study, low skeletal muscle radiation attenuation was observed to be associated with worse overall survival in patients with HOP cancer. Additionally, high L3-VAT index was related to increased incidence of SSIs.

Okumura et al. previously observed decreased overall survival and shorter recurrencefree survival in patients with pancreatic cancer and high intramuscular adipose tissue content (in this study, this was measured as muscle radiation attenuation divided by SAT radiation attenuation) but did not investigate post-operative complications. ${ }^{36}$ Although their results are in line with the present study, they used a different approach to define muscle quality. Firstly, we analyzed all muscles at the L3-level instead of only the psoas muscle, as was performed by Okumura et al. We evaluated all muscles at L3 because this 
better represents the total body skeletal muscle mass ${ }^{6}$ and has the benefit of being less susceptible to measurement errors (which will be averaged out). Secondly, we separated IMAT from skeletal muscle tissue, while Okumura et al. included IMAT in the calculation of the average psoas muscle HUs. Including the IMAT (which has a much lower HU value than muscle tissue) greatly influences the measured radiation attenuation. Because the distribution of intermuscular tissue is not uniform within muscles, the measured radiation attenuation might differ depending on which muscle or CT slice is chosen for analysis.

Joglekar et al. observed more post-operative complications in patients with pancreatic cancer and a low radiation attenuation or low psoas muscle area but did not observe a significant association of these factors with overall survival. ${ }^{37}$ Unfortunately, patients with low radiation attenuation and low psoas muscle area were pooled for analysis in that study, making it difficult to compare the results with the present study and potentially explaining the absence of an association with survival.

To our knowledge, no studies have been reported that use similar methodology to investigate muscle radiation attenuation in patients with pancreatic cancer. When looking at studies in other malignancies with similar methodology as the present study, low muscle radiation attenuation has consistently been associated with poor survival in hepatocellular carcinoma, ${ }^{30,38,39}$ respiratory and colorectal cancer, ${ }^{7}$ and follicular lymphoma. ${ }^{40}$ Skeletal muscle area was not associated with outcomes in the present study, which agrees with previous findings in pancreatic cancer patients. ${ }^{14,37,41}$ It should be noted that the frequently reported L3-muscle index or any other single time-point skeletal muscle area measurement might not accurately indicate muscle wasting. Normal muscle area can be highly variable among individuals and is dependent on sex, race, age, physical fitness, and build. Moreover, a large muscle area does not necessarily mean better muscle function. ${ }^{42}$ Furthermore, given that weight loss is a much better predictor of survival than baseline weight in cachectic patients, ${ }^{43}$ information on muscle loss is likely to be important to assess the relation between sarcopenia and survival. A study by Stene et al. using CT scans before and after chemotherapy showed that muscle loss but not low muscularity at baseline was predictive for time to death in patients undergoing palliative treatment for non-small cell lung cancer. ${ }^{44}$ Because it is impossible to assess muscle loss from the single CT scan usually available for a patient, other muscle-related parameters 
should be explored as proxies for muscle loss and muscle function. In the present study, we found that muscle radiation attenuation was predictive of poor outcome. The main issue to be resolved now is to identify what (patho)physiological processes are reflected by a low radiation attenuation, and if these are related to on muscle function. Many studies have suggested that low radiation attenuation is a sign of triglyceride accumulation in muscle cells. ${ }^{15,38,39,45}$ However, so far, only one study actually demonstrated a weak negative correlation between low muscle radiation attenuation and increased muscle fiber lipid content in patients with type 2 diabetes mellitus. ${ }^{16}$ The correlation between muscle radiation attenuation and IMAT that we observed supports an association between low radiation attenuation and ectopic fat in the muscle tissue (radiation attenuation is calculated from the total skeletal muscle tissue area only and does not include the IMAT area). Importantly, IMAT is independently associated with insulin resistance in healthy elderly men without diabetes. ${ }^{46}$ Hence, decreased radiation attenuation in cachectic patients might reflect insulin resistance, a frequently observed condition in this patient population. ${ }^{47}$ Low radiation attenuation has also been shown to be associated with systemic inflammation, a hallmark of cachexia. ${ }^{45}$ We also found that patients with low muscle radiation attenuation had lower albumin levels, which is associated with systemic inflammation. CRP levels were not significantly higher in patients with low radiation attenuation. However, these finding should be interpreted with caution because we had many missing data on systemic inflammation in our cohort. All in all, to identify the determinants of the reduced radiation attenuation, studies combining detailed CT image analysis with histological evaluation of the imaged muscle are required.

The rate of SSIs strongly associated with high L3-VAT index but was not related to muscle radiation attenuation or other CT measurements in our cohort. This is in contrast to the study of Lieffers et al., which found an increase in postoperative infections in sarcopenic patients after colorectal surgery. ${ }^{48}$ In addition, the observed relation between SSIs and high L3-VAT index area was not observed by Lieffers et al. These discrepancies may be attributable to the fact that the type of surgery differs (pancreas vs. colorectal), and we included infections up to 90 days after surgery (which is common in pancreatic surgery because of the late occurrence of complications) instead of 30 days as performed by Lieffers et al. Furthermore, we only recorded SSIs instead of all infections. 
We focused on SSIs because these are among the most relevant and most frequent infections in (pancreatic) surgery. They are usually poorly recorded making retrospective and even prospective studies a difficult task. In the present study, a trial nurse inspected the wound and medical file daily for signs of SSI, which in our opinion is the optimal way to prevent underdetection of SSIs. The increased risk of SSIs in patients with high L3-VAT index could be related to impaired wound healing secondary to oxygenation problems, which is a common finding in large depots of adipose tissue. ${ }^{49}$ This is even more pronounced in obese individuals in whom VAT arteriolar function and angiogenesis have been shown to be impaired. ${ }^{50,51}$ In addition, high leptin levels (as a reflection of increased adipose tissue) have been associated with an increased risk of SSIs in colorectal cancer. ${ }^{52}$ These mechanisms remain speculative and should be explored in future studies.

Surprisingly, we found that patients with a low L3-muscle index had a reduced risk of post-operative complications. Although many studies did not show a benefit for high muscularity with respect to complication risk, ${ }^{37,41,53,54}$ the apparent benefit of low muscularity is unexpected and contrary to what was found in the vast majority of studies published in the field. The low risk of post-operative complications was not reflected by a better survival of these patients. Therefore, this finding should be interpreted with caution because it may have been the result of uncontrolled bias or statistical error.

None of the assessed body composition measurements stand on their own, and combinations of unfavorable phenotypes can increase the impact on patient outcome. This has been indicated previously for combinations of myosteatosis with BMI, ${ }^{7}$ obesity, ${ }^{55}$ and sarcopenia. ${ }^{14}$ Although our cohort is rather small for such subgroup analyses, our survival analyses indicate that combinations of muscle radiation attenuation with visceral adiposity or age can have additional effects on survival. Exploration of patient phenotypes defined by clusters of different characteristics would provide very useful data for risk assessment in the clinical setting.

In conclusion, we showed that muscle radiation attenuation is a predictor of survival after pancreatic surgery, whereas a high L3-VAT index is associated with the risk of SSIs. Our data therefore indicate that simple and fast analysis of a single CT image can be valuable for pre-operative risk assessment in patients with HOP cancer. Future intervention studies are needed to investigate whether increasing muscle radiation 
attenuation through diet and/or exercise before surgery can improve prognosis of patients with HOP cancer.

\section{ACKNOWLEDGEMENTS}

David van Dijk is supported as a PhD candidate by the Netherlands Organization for Scientific Research (NWO Grant 022.003.011). Martijn Bours is partly supported by grants from the Alpe d'HuZes Foundation of the Dutch Cancer Society (grant no. UM2012-5633), and from the Kankeronderzoekfonds Limburg' as part of Health Foundation Limburg (grant no. 00005739).

We would like to thank Magriet Rouflart for her commitment and hard work in scoring and recording the surgical site infections and Professor Vicky Baracos for her friendly help in analyzing and interpreting the results of this study. The authors certify that they comply with the ethical guidelines for authorship and publishing of the Journal of Cachexia, Sarcopenia and Muscle. ${ }^{56}$

\section{CONFLICT OF INTEREST}

All authors declare that they have no conflict of interest. 


\section{REFERENCES}

1. Nederlandse Kankerregistratie [database on the Internet]1989. Available from: http:// cijfersoverkanker.nl/. Accessed: February 1, 2012

2. Fearon K, Strasser F, Anker SD, Bosaeus I, Bruera E, Fainsinger RL, et al. Definition and classification of cancer cachexia: an international consensus. Lancet Oncol 2011;12:489-95.

3. Dewys W, Begg C, Lavin P, Band P, Bennett J, Bertino J, et al. Prognostic effect of weight loss prior to chemotherapy in cancer patients. Eastern Cooperative Oncology Group. Am J Med 1980;69:491-7.

4. van der Gaag NA, Harmsen K, Eshuis WJ, Busch OR, van Gulik TM, Gouma DJ. Pancreatoduodenectomy associated complications influence cancer recurrence and time interval to death. Eur J Surg Oncol 2014;40:551-8.

5. Sugiura T, Uesaka K, Ohmagari N, Kanemoto H, Mizuno T. Risk factor of surgical site infection after pancreaticoduodenectomy. World J Surg 2012;36:2888-94.

6. Mourtzakis M, Prado CMM, Lieffers JR, Reiman T, McCargar LJ, Baracos VE. A practical and precise approach to quantification of body composition in cancer patients using computed tomography images acquired during routine care. Appl Physiol Nutr Metab 2008;33:997-1006.

7. Martin L, Birdsell L, Macdonald N, Reiman T, Clandinin MT, McCargar LJ, et al. Cancer cachexia in the age of obesity: skeletal muscle depletion is a powerful prognostic factor, independent of body mass index. J Clin Oncol 2013;31:1539-47.

8. Kirihara Y, Takahashi N, Hashimoto Y, Sclabas GM, Khan S, Moriya T, et al. Prediction of pancreatic anastomotic failure after pancreatoduodenectomy: the use of preoperative, quantitative computed tomography to measure remnant pancreatic volume and body composition. Ann Surg 2013;257:512-9.

9. Nishida Y, Kato Y, Kudo M, Aizawa H, Okubo S, Takahashi D, et al. Preoperative sarcopenia strongly influences the risk of postoperative pancreatic fistula formation after pancreaticoduodenectomy. J Gastrointest Surg 2016;20:1586-94.

10. Tranchart H, Gaujoux S, Rebours V, Vullierme M-PP, Dokmak S, Levy P, et al. Preoperative CT scan helps to predict the occurrence of severe pancreatic fistula after pancreaticoduodenectomy. Ann Surg 2012;256:139-45.

11. Park CM, Park JS, Cho ES, Kim JK, Yu JS, Yoon DS. The effect of visceral fat mass on pancreatic fistula after pancreaticoduodenectomy. J Invest Surg 2012;25:169-73. 
12. Sandini M, Bernasconi DP, Fior D, Molinelli M, Ippolito D, Nespoli L, et al. A high visceral adipose tissue-to-skeletal muscle ratio as a determinant of major complications after pancreatoduodenectomy for cancer. Nutrition (Burbank, Los Angeles County, Calif). 2016.

13. Shimizu A, Tani M, Kawai M, Hirono S, Miyazawa M, Uchiyama K, et al. Influence of visceral obesity for postoperative pulmonary complications after pancreaticoduodenectomy. J Gastrointest Surg 2011;15:1401-10.

14. Rollins KE, Tewari N, Ackner A, Awwad A, Madhusudan S, Macdonald IA, et al. The impact of sarcopenia and myosteatosis on outcomes of unresectable pancreatic cancer or distal cholangiocarcinoma. Clin Nutr (Edinburgh, Scotland). 2015.

15. Aubrey J, Esfandiari N, Baracos VE, Buteau FA, Frenette J, Putman CT, et al. Measurement of skeletal muscle radiation attenuation and basis of its biological variation. Acta Physiol (Oxf) 2014;210:489-97.

16. Goodpaster BH, Kelley DE, Thaete FL, He J, Ross R. Skeletal muscle attenuation determined by computed tomography is associated with skeletal muscle lipid content. J Appl Physiol (1985). 2000;89:104-10.

17. Lee S, Kuk JL, Davidson LE, Hudson R, Kilpatrick K, Graham TE, et al. Exercise without weight loss is an effective strategy for obesity reduction in obese individuals with and without Type 2 diabetes. J Appl Physiol (1985). 2005;99:1220-5.

18. Taaffe DR, Henwood TR, Nalls MA, Walker DG, Lang TF, Harris TB. Alterations in muscle attenuation following detraining and retraining in resistance-trained older adults. Gerontology 2009;55:217-23.

19. MacDonald AJ, Greig CA, Baracos V. The advantages and limitations of crosssectional body composition analysis. Curr Opin Support Palliat Care 2011;5:342-9.

20. Friedman J, Lussiez A, Sullivan J, Wang S, Englesbe M. Implications of sarcopenia in major surgery. Nutr Clin Pract 2015;30:175-9.

21. Coolsen MM, Clermonts SH, van Dam RM, Winkens B, Malagó M, Fusai GK, et al. Development of a composite endpoint for randomized controlled trials in pancreaticoduodenectomy. World J Surg 2013;38:1468-75.

22. Dindo D, Demartines N, Clavien P-AA. Classification of surgical complications: a new proposal with evaluation in a cohort of 6336 patients and results of a survey. Ann Surg 2004;240:205-13.

23. Levy MM, Fink MP, Marshall JC, Abraham E, Angus D, Cook D, et al. 2001 SCCM/ESICM/ ACCP/ATS/SIS International Sepsis Definitions Conference. Intensive Care Med 2003;29:5308. 
24. Koch M, Garden OJ, Padbury R, Rahbari NN, Adam R, Capussotti L, et al. Bile leakage after hepatobiliary and pancreatic surgery: a definition and grading of severity by the International Study Group of Liver Surgery. Surgery 2011;149:680-8.

25. Wente MN, Veit JA, Bassi C, Dervenis C, Fingerhut A, Gouma DJ, et al. Postpancreatectomy hemorrhage (PPH): an International Study Group of Pancreatic Surgery (ISGPS) definition. Surgery 2007;142:20-5.

26. Bassi C, Dervenis C, Butturini G, Fingerhut A, Yeo C, Izbicki J, et al. Postoperative pancreatic fistula: an international study group (ISGPF) definition. Surgery 2005;138:8-13.

27. Wente MN, Bassi C, Dervenis C, Fingerhut A, Gouma DJ, Izbicki JR, et al. Delayed gastric emptying (DGE) after pancreatic surgery: a suggested definition by the International Study Group of Pancreatic Surgery (ISGPS). Surgery 2007;142:761-8.

28. Mangram AJ, Horan TC, Pearson ML, Silver LC, Jarvis WR. Guideline for Prevention of Surgical Site Infection, 1999. Centers for Disease Control and Prevention (CDC) Hospital Infection Control Practices Advisory Committee. Am J Infect Control 1999;27:97-132.

29. Prado CM, Lieffers J, McCargar L, Reiman T, Sawyer M, Martin L, et al. Prevalence and clinical implications of sarcopenic obesity in patients with solid tumors of the respiratory and gastrointestinal tracts: a population-based study. Lancet Oncol 2008;9:629-35.

30. Fujiwara N, Nakagawa H, Kudo Y, Tateishi R, Taguri M, Watadani T, et al. Sarcopenia, intramuscular fat deposition, and visceral adiposity independently predict the outcomes of hepatocellular carcinoma. J Hepatol 2015;63:131-40.

31. Sabel MS, Lee J, Cai S, Englesbe MJ, Holcombe S, Wang S. Sarcopenia as a prognostic factor among patients with stage III melanoma. Ann Surg Oncol 2011;18:3579-85.

32. Antoun S, Lanoy E, Iacovelli R, Albiges- Sauvin L, Loriot Y, Merad-Taoufik M, et al. Skeletal muscle density predicts prognosis in patients with metastatic renal cell carcinoma treated with targeted therapies. Cancer 2013;119:3377-84.

33. Kazemi-Bajestani S, Mazurak VC, Baracos V. Computed tomography-defined muscle and fat wasting are associated with cancer clinical outcomes. Semin Cell Dev Biol 2016;54:2-10.

34. Martin L. Diagnostic criteria for cancer cachexia: data versus dogma. Curr Opin Clin Nutr Metab Care 2016;19:188-98.

35. Williams BA, Mandrekar JN, Mandrekar SJ, Cha SS, Furth AF. Finding optimal cutpoints for continuous covariates with binary and time-to-event outcomes. Rochester, MN, Mayo Foundation, Technical Report Series \#79, 2006. 
36. Okumura S, Kaido T, Hamaguchi Y, Fujimoto Y, Masui T, Mizumoto M, et al. Impact of preoperative quality as well as quantity of skeletal muscle on survival after resection of pancreatic cancer. Surgery 2015;157:1088-98.

37. Joglekar S, Asghar A, Mott SL, Johnson BE, Button AM, Clark E, et al. Sarcopenia is an independent predictor of complications following pancreatectomy for adenocarcinoma. J Surg Oncol 2014;111:771-5.

38. Kaibori M, Ishizaki M, Iida H, Matsui K, Sakaguchi T, Inoue K, et al. Effect of intramuscular adipose tissue content on prognosis in patients undergoing hepatocellular carcinoma resection. J Gastrointest Surg 2015;19:1315-23.

39. Hamaguchi Y, Kaido T, Okumura S, Ito T, Fujimoto Y, Ogawa K, et al. Preoperative intramuscular adipose tissue content is a novel prognostic predictor after hepatectomy for hepatocellular carcinoma. J Hepatobiliary Pancreat Sci 2015;22:475-85.

40. Chu MP, Lieffers J, Ghosh S, Belch AR, Chua NS, Fontaine A, et al. Skeletal muscle radiodensity is an independent predictor of response and outcomes in follicular lymphoma treated with chemoimmunotherapy. PLoS One 2015;10.

41. Peng PD, van Vledder MG, Tsai S, de Jong MC, Makary M, Ng J, et al. Sarcopenia negatively impacts short-term outcomes in patients undergoing hepatic resection for colorectal liver metastasis. HPB (Oxford). 2011;13:439-46.

42. Delmonico MJ, Harris TB, Visser M, Park SW, Conroy MB, Velasquez-Mieyer P, et al. Longitudinal study of muscle strength, quality, and adipose tissue infiltration. Am J Clin Nutr 2009;90:1579-85.

43. Fearon K, Arends J, Baracos V. Understanding the mechanisms and treatment options in cancer cachexia. Nat Rev Clin Oncol 2013;10:90-9.

44. Stene GB, Helbostad JL, Amundsen T, Sørhaug S, Hjelde H, Kaasa S, et al. Changes in skeletal muscle mass during palliative chemotherapy in patients with advanced lung cancer. Acta Oncol 2014;1-9.

45. Malietzis G, Johns N, Al-Hassi HO, Knight SC, Kennedy RH, Fearon KC, et al. Low muscularity and myosteatosis is related to the host systemic inflammatory response in patients undergoing surgery for colorectal cancer. Ann Surg 2015;263:320-5.

46. Miljkovic I, Cauley JA, Wang PY, Holton KF, Lee CG, Sheu Y, et al. Abdominal myosteatosis is independently associated with hyperinsulinemia and insulin resistance among older men without diabetes. Obesity (Silver Spring). 2013;21:2118-25. 
47. Tisdale M. Mechanisms of cancer cachexia. Physiol Rev 2009;89:381-410.

48. Lieffers JR, Bathe OF, Fassbender K, Winget M, Baracos VE. Sarcopenia is associated with postoperative infection and delayed recovery from colorectal cancer resection surgery. Br J Cancer 2012;107:931-6.

49. Goossens GH, Blaak EE. Adipose tissue dysfunction and impaired metabolic health in human obesity: a matter of oxygen? Front Endocrinol (Lausanne) 2015;6:55.

50. Farb MG, Ganley-Leal L, Mott M, Liang Y, Ercan B, Widlansky ME, et al. Arteriolar function in visceral adipose tissue is impaired in human obesity. Arterioscler Thromb Vasc Biol 2012;32:467-73.

51. Gealekman O, Guseva N, Hartigan C, Apotheker S, Gorgoglione M, Gurav K, et al. Depotspecific differences and insufficient subcutaneous adipose tissue angiogenesis in human obesity. Circulation 2011;123:186-94.

52. Ortega-Deballon P, Ménégaut L, Fournel I, Orry D, Masson D, Binquet C, et al. Are adiponectin and leptin good predictors of surgical infection after colorectal surgery? A prospective study. Surg Infect (Larchmt) 2015.

53. Jones KI, Doleman B, Scott S, Lund JN, Williams JP. Simple psoas cross-sectional area measurement is a quick and easy method to assess sarcopenia and predicts major surgical complications. Colorectal Dis 2015;17:6.

54. Kuroki LM, Mangano M, Allsworth JE, Menias CO, Massad LS, Powell MA, et al. Pre-operative assessment of muscle mass to predict surgical complications and prognosis in patients with endometrial cancer. Ann Surg Oncol 2015;22:972-9.

55. Tan B, Birdsell L, Martin L, Baracos V, Fearon K. Sarcopenia in an overweight or obese patient is an adverse prognostic factor in pancreatic cancer. Clin Cancer Res 2009;15:6973-9.

56. von Haehling S, Morley JE, Coats AJS, Anker SD. Ethical guidelines for publishing in the Journal of Cachexia, Sarcopenia and Muscle: update 2015. J Cachexia Sarcopenia Muscle 2015;6:315-6. 
Q 810

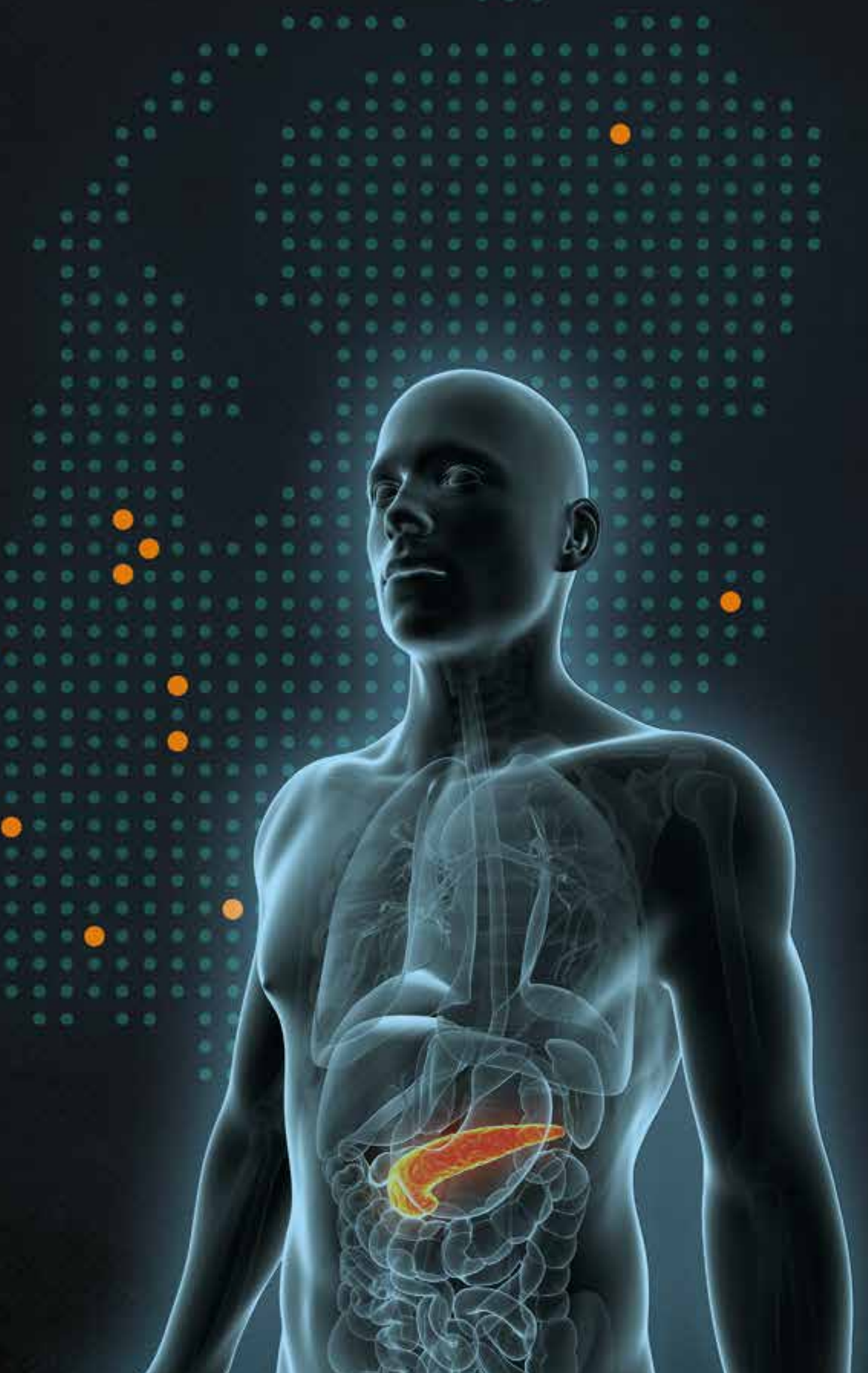

00080000000000000

0.00000000000000

0.000 .00 .0

0.0000000

$\ldots$

0000000000

Q

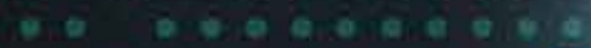

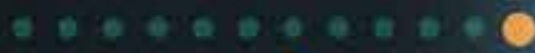

0.0000000008

0.000 .0 .00

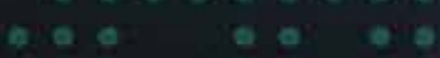

$\ldots$

a: 


\section{SUMMARY AND GENERAL DISCUSSION}




\section{SUMMARY AND GENERAL DISCUSSION}

Survival in pancreatic cancer is poor and surgical resection is currently the only treatment with curative intent. ${ }^{1,2}$ Ideally, surgery is followed by adjuvant chemotherapy. ${ }^{2,3}$

The goal of this thesis was to identify variation in preoperative, operative and postoperative treatment in non-metastasized pancreatic cancer patients in the Netherlands. Furthermore, possible reasons for variation in pancreatic cancer care were investigated. By doing so, the results can lead to suggestions for further improvements in pancreatic cancer care. The main findings of this thesis are discussed in this chapter. It concludes with its limitations.

The study in Chapter 2 showed that the likelihood for surgical treatment for pancreatic cancer in patients without metastatic disease is higher if patients are diagnosed in a highvolume pancreatic center compared to centers without the involvement of a specialized pancreatic surgeon. These results show considerable variation in defining resectability between centers. Tumor staging and defining resectability is complex and up-to-date knowledge is needed. ${ }^{4}$ Not only patients diagnosed in a non-specialized center but also elderly patients above 70 years were less likely to undergo surgical treatment. This might be caused by a combination of patient preferences and a nihilistic approach of physicians to pancreatic surgery in elderly patients. Nevertheless, elderly patients strongly benefit from centralization and also showed an improved survival after tumor resection. ${ }^{5-9}$

As patients with pancreatic cancer often present with obstructive jaundice, preoperative biliary drainage to lower bilirubin levels can be considered. On the other hand, preoperative drainage increases the number of complications. Surprisingly, the study presented in Chapter 3 showed that a majority of jaundiced patients still undergo preoperative biliary drainage prior to surgery. In the majority of patients no medical reason justifying preoperative biliary drainage could be retrieved. Interestingly, most patients underwent preoperative biliary drainage prior to referral for surgery to a specialized center. Proportions of preoperative biliary drainage also varied considerably between pancreatic centers. There is a considerable practice variation in the Netherlands, which may be due to logistic problems to offer early surgery in specialized centers. Addressing these logistic 
problems may be a way to reduce drainage-related complications and thus improve the care for pancreatic cancer patients.

The study presented in Chapter 4 shows that also the likelihood of adjuvant chemotherapy treatment varies considerably between pancreatic centers in the Netherlands. This might be caused by varying attitudes of the multidisciplinary tumor boards in pancreatic centers, or by medical oncologists from referring hospitals who may choose to react differently on the advice of the multidisciplinary tumor board.

The presented study also examined characteristics determining the likelihood of receiving adjuvant chemotherapy. In the Netherlands only $54 \%$ of the patients received adjuvant chemotherapy after pancreatoduodenectomy. The patients undergoing adjuvant chemotherapy treatment had a prolonged survival compared to patients not receiving chemotherapy. It was shown that elderly patients were less likely to undergo adjuvant chemotherapy. Interestingly, it has been demonstrated that adjuvant chemotherapy in elderly patients was associated with an improved survival to at least a similar degree as for younger patients. ${ }^{10}$ So physicians might need to be less reluctant in treating elderly patients with adjuvant chemotherapy. Aside from elderly patients also patients with stage I disease were less likely to receive chemotherapy, despite the fact that also in low-staged tumors the beneficial results of adjuvant chemotherapy can be expected. ${ }^{3}$ Clinicians should be aware of the potential underuse of adjuvant chemotherapy, which should be standard of care. Survival in pancreatic cancer can be further improved after resection and postoperative recovery. An additional benefit on disease-free and overall survival regardless of age can be achieved by treating patients with adjuvant chemotherapy. ${ }^{2,3} \mathrm{~A}$ modified Folfirinox regimen might even lead to better survival compared to gemcitabine as adjuvant chemotherapy. ${ }^{11}$

The decision whether or not to treat a patient with systemic therapy and / or radiotherapy is even getting more complex in the near future with emerging multimodality strategies in neoadjuvant and adjuvant therapies. The potential benefits of neoadjuvant therapy in pancreatic cancer are currently studied in a randomized controlled trial. ${ }^{12,13}$ Preliminary data suggest a further improvement in outcome in patients treated with neo-adjuvant chemoradiotherapy compared to surgery alone. ${ }^{14}$ 
In Chapter 5 the influence of socio-economic status on the likelihood for surgical treatment in the Netherlands is studied. In the USA, differences in treatment for pancreatic cancer based on the effect of socio-economic status were mostly caused by the nature of the health care system that is not equally accessible to all patients. ${ }^{15,16}$ In the Netherlands health care is covered equally for all residents regardless of income or social status. The results of this study showed that even in the Netherlands with its equally accessible health care system, patients with a lower socio-economic status had a lower likelihood of receiving surgical treatment. The difference in likelihood for surgical treatment between socio-economic status groups might be caused by life-style related factors related to a low socio-economic status, making patients less suitable for a pancreatoduodenectomy. ${ }^{17}$ Furthermore the study showed that patients with high socio-economic status were more likely to be referred to a center with surgical expertise. This might be explained by a higher educational level resulting in better-informed patients seeking for the best treatment options. ${ }^{18}$ The inequalities lead to a variation in care and probably have multifactorial causes being both patient-related as well as physician-related. ${ }^{19}{ }^{20}$ Physicians should be aware of this phenomenon to reduce differences in health care within the population.

Chapter 6 focuses on how to optimize pancreatic cancer care in elderly patients. An enhanced recovery after surgery (ERAS) pathway has been implemented in most pancreatic centers in the Netherlands and has been proven to accelerate recovery and reduce hospital costs. ${ }^{21}$ Typical elements of this pathway are avoidance of preand postoperative fasting, optimized analgesia and early mobilization. The study in chapter 6 describes that an ERAS protocol is also feasible in patients $\geq 70$ years of age. Compliance with the different elements was similar to that in younger patients, and its safety seemed to be confirmed since readmission, morbidity and mortality rates did not differ between groups. Also in elderly patients the survival benefit after resection should not be diminished and using an ERAS protocol can safely accelerate recovery. ${ }^{5-7}$ Improved recovery after surgery in elderly patients might lead to an increase in resections and thereby reduce the current variation in pancreatic cancer treatment. Furthermore, an accelerated recovery might lead to a higher number of elderly patients being treated postoperatively with chemotherapy. This might reduce the current variation in patients treated with adjuvant chemotherapy. 
Preoperative risk assessment can be helpful in selecting patients fit for surgery. It might be useful to predict postoperative outcomes in deciding whether or not to refer patients to a specialized center. In Chapter 7 the influence of several body composing components on postoperative outcome is studied. Pre-operative computed tomography scans were used for body composition analysis at the level of lumbar vertebra 3 (L3). ${ }^{22}$ Components analyzed were skeletal muscle tissue, intermuscular adipose tissue, visceral adipose tissue and subcutaneous adipose tissue. The radiation attenuation for skeletal muscle was calculated by excluding the intermuscular adipose tissue of the muscle tissue. The study showed that low skeletal muscle radiation attenuation was associated with worse overall survival in patients with pancreatic cancer. The muscle radiation attenuation is easy to analyze on a single CT image and can be useful in pre-operative risk assessment in patients with pancreatic cancer. So, assessing cachexia can be useful in determining the eligibility for surgical treatment. Furthermore, physical fitness can be improved if patients are preoperatively identified as high-risk patients. In the Netherlands the Betterin-Better-out strategy focuses on "pre-habilitation" to better withstand the impact of major surgery. ${ }^{23,24}$

\section{LIMITATIONS}

The current thesis is mainly based on findings of large observational studies, with mainly prospectively collected data. For most studies of this thesis, data of the Dutch Cancer Registry (NCR) were used. The study design has some limitations as some factors that might influence the choice of treatment in pancreatic cancer are missing. Lifestyle related factors such as smoking, alcohol and obesity might have had an influence on the choice of treatment. Furthermore patients' treatment preference would be an interesting factor to analyze but this is usually not recorded in the patient files. With regard to the use of adjuvant chemotherapy it would be of interest to have more information about resection status, postoperative complications and performance status. This can provide insights in whether or not a patient is fit enough for adjuvant treatment.

\section{FUTURE PERSPECTIVES}

Centralizing surgical procedures in pancreatic cancer improved morbidity and mortality and thereby survival of pancreatic cancer in the Netherlands. Nevertheless, the current 
thesis showed that there is still a variation in pancreatic cancer treatment between centers. Diagnostics and staging by an experienced multidisciplinary tumor board might be helpful to increase the likelihood for non-metastasized patients to undergo surgery and adjuvant chemotherapy. The overall outcome can also be improved by reducing the proportion of patients undergoing preoperative biliary drainage by early referral to a pancreatic center and optimizing logistics to provide early surgery. The ability to offer more patients the optimal treatment for pancreatic cancer might be achieved by optimizing selection of patients fit for surgery. Since low muscle radiation on CT-scan was related to a lower overall survival, preoperatively determining low muscle radiation might be helpful in selecting patients for referral to a specialized center. Optimizing the surgical procedure itself by performing minimally invasive surgery is subject of current research and might further improve surgical outcomes in the future. ${ }^{25}$

This thesis revealed a variation in the quality of care for pancreatic cancer in the Netherlands and identified some of the reasons for it. Future research will focus on ways to reduce variation (e.g. by standardized preoperative and postoperative pathways and regional cancer networks) and hopefully further increase the quality of care. 


\section{REFERENCES}

1. Vincent A, Herman J, Schulick R, Hruban RH, Goggins M. Pancreatic cancer. Lancet. 2011;378(9791):607-20.

2. Oncoline. Pancreascarcinoom: Netherlands Comprehensive Cancer Organisation (IKNL); 2011 [updated 2011-08-22. Available from: http://www.oncoline.nl/pancreascarcinoom.

3. Oettle H, Neuhaus P, Hochhaus A, Hartmann JT, Gellert K, Ridwelski K, et al. Adjuvant chemotherapy with gemcitabine and long-term outcomes among patients with resected pancreatic cancer: the CONKO-001 randomized trial. JAMA. 2013;310(14):1473-81.

4. Walters DM, Lapar DJ, de Lange EE, Sarti M, Stokes JB, Adams RB, et al. Pancreas-protocol imaging at a high-volume center leads to improved preoperative staging of pancreatic ductal adenocarcinoma. Ann Surg Oncol. 2011;18(10):2764-71.

5. Oguro S, Shimada K, Kishi Y, Nara S, Esaki M, Kosuge T. Perioperative and long-term outcomes after pancreaticoduodenectomy in elderly patients 80 years of age and older. Langenbecks Arch Surg. 2013;398(4):531-8.

6. Adham M, Bredt LC, Robert M, Perinel J, Lombard-Bohas C, Ponchon T, et al. Pancreatic resection in elderly patients: should it be denied? Langenbecks Arch Surg. 2014;399(4):449-59.

7. Finlayson E, Fan Z, Birkmeyer JD. Outcomes in octogenarians undergoing high-risk cancer operation: a national study. J Am Coll Surg. 2007;205(6):729-34.

8. van der Geest LG, Besselink MG, van Gestel YR, Busch OR, de Hingh IH, de Jong KP, et al. Pancreatic cancer surgery in elderly patients: Balancing between short-term harm and longterm benefit. A population-based study in the Netherlands. Acta Oncol. 2016;55(3):278-85.

9. van der Geest LG, Besselink MG, Busch OR, de Hingh IH, van Eijck CH, Dejong CH, et al. Elderly Patients Strongly Benefit from Centralization of Pancreatic Cancer Surgery: A Population-Based Study. Ann Surg Oncol. 2016;23(6):2002-9.

10. Nagrial AM, Chang DK, Nguyen NQ, Johns AL, Chantrill LA, Humphris JL, et al. Adjuvant chemotherapy in elderly patients with pancreatic cancer. Br J Cancer. 2014;110(2):313-9.

11. T. Conroy PH, M. Hebbar, M.B. Abdelghani, A. Chia-chi Wei, J. Raoul, L. Chone, E. Francois, P. Artru, J.J. Biagi, T. Lecomte, E. Assenat, R. Faroux, M. Ychou, J. Volet, A. Sauvanet, C. Jouffroy-Zeller, P. RAT, F. Castan, J. Bachet. Unicancer GI PRODIGE 24/CCTG PA.6 trial: A multicenter international randomized phase III trial of adjuvant mFOLFIRINOX versus gemcitabine (gem) in patients with resected pancreatic ductal adenocarcinomas. J Clin Oncol. 2018;36:suppl; abstr LBA4001. 
12. Versteijne E, van Eijck CH, Punt CJ, Suker M, Zwinderman AH, Dohmen MA, et al. Preoperative radiochemotherapy versus immediate surgery for resectable and borderline resectable pancreatic cancer (PREOPANC trial): study protocol for a multicentre randomized controlled trial. Trials. 2016;17(1):127.

13. O’Reilly D, Fou L, Hasler E, Hawkins J, O’Connell S, Pelone F, et al. Diagnosis and management of pancreatic cancer in adults: A summary of guidelines from the UK National Institute for Health and Care Excellence. Pancreatology. 2018.

14. Tienhoven GV, Versteijne E, Suker M, Groothuis KBC, Busch OR, Bonsing BA, et al. Preoperative chemoradiotherapy versus immediate surgery for resectable and borderline resectable pancreatic cancer (PREOPANC-1): A randomized, controlled, multicenter phase III trial. Journal of Clinical Oncology. 2018;36(18_suppl):LBA4002-LBA.

15. Sun $\mathrm{H}, \mathrm{Ma} \mathrm{H}$, Hong G, Sun $\mathrm{H}$, Wang J. Survival improvement in patients with pancreatic cancer by decade: a period analysis of the SEER database, 1981-2010. Sci Rep. 2014;4:6747.

16. Seyedin S, Luu C, Stabile BE, Lee B. Effect of socioeconomic status on surgery for pancreatic adenocarcinoma. Am Surg. 2012;78(10):1128-31.

17. Cheung MC, Yang R, Byrne MM, Solorzano CC, Nakeeb A, Koniaris LG. Are patients of low socioeconomic status receiving suboptimal management for pancreatic adenocarcinoma? Cancer. 2010;116(3):723-33.

18. Batty GD, Der G, Macintyre S, Deary IJ. Does IQ explain socioeconomic inequalities in health? Evidence from a population based cohort study in the west of Scotland. BMJ. 2006;332(7541):580-4.

19. Bernheim SM, Ross JS, Krumholz HM, Bradley EH. Influence of patients' socioeconomic status on clinical management decisions: a qualitative study. Ann Fam Med. 2008;6(1):53-9.

20. Williams RL, Romney C, Kano M, Wright R, Skipper B, Getrich CM, et al. Racial, gender, and socioeconomic status bias in senior medical student clinical decision-making: a national survey. J Gen Intern Med. 2015;30(6):758-67.

21. Coolsen MM, van Dam RM, van der Wilt AA, Slim K, Lassen K, Dejong CH. Systematic review and meta-analysis of enhanced recovery after pancreatic surgery with particular emphasis on pancreaticoduodenectomies. World J Surg. 2013;37(8):1909-18.

22. Mourtzakis M, Prado CM, Lieffers JR, Reiman T, McCargar LJ, Baracos VE. A practical and precise approach to quantification of body composition in cancer patients using computed tomography images acquired during routine care. Appl Physiol Nutr Metab. 2008;33(5):9971006. 
23. Berkel AEM, Bongers BC, van Kamp MS, Kotte H, Weltevreden P, de Jongh FHC, et al. The effects of prehabilitation versus usual care to reduce postoperative complications in high-risk patients with colorectal cancer or dysplasia scheduled for elective colorectal resection: study protocol of a randomized controlled trial. BMC Gastroenterol. 2018;18(1):29.

24. Punt IM, van der Most R, Bongers BC, Didden A, Hulzebos EHJ, Dronkers JJ, et al. [Improving pre- and perioperative hospital care : Major elective surgery]. Bundesgesundheitsblatt Gesundheitsforschung Gesundheitsschutz. 2017;60(4):410-8.

25. Klompmaker S, van Hilst J, Wellner UF, Busch OR, Coratti A, D’Hondt M, et al. Outcomes After Minimally-invasive Versus Open Pancreatoduodenectomy: A Pan-European Propensity Score Matched Study. Annals of Surgery. 2018;Publish Ahead of Print. 
Q 810

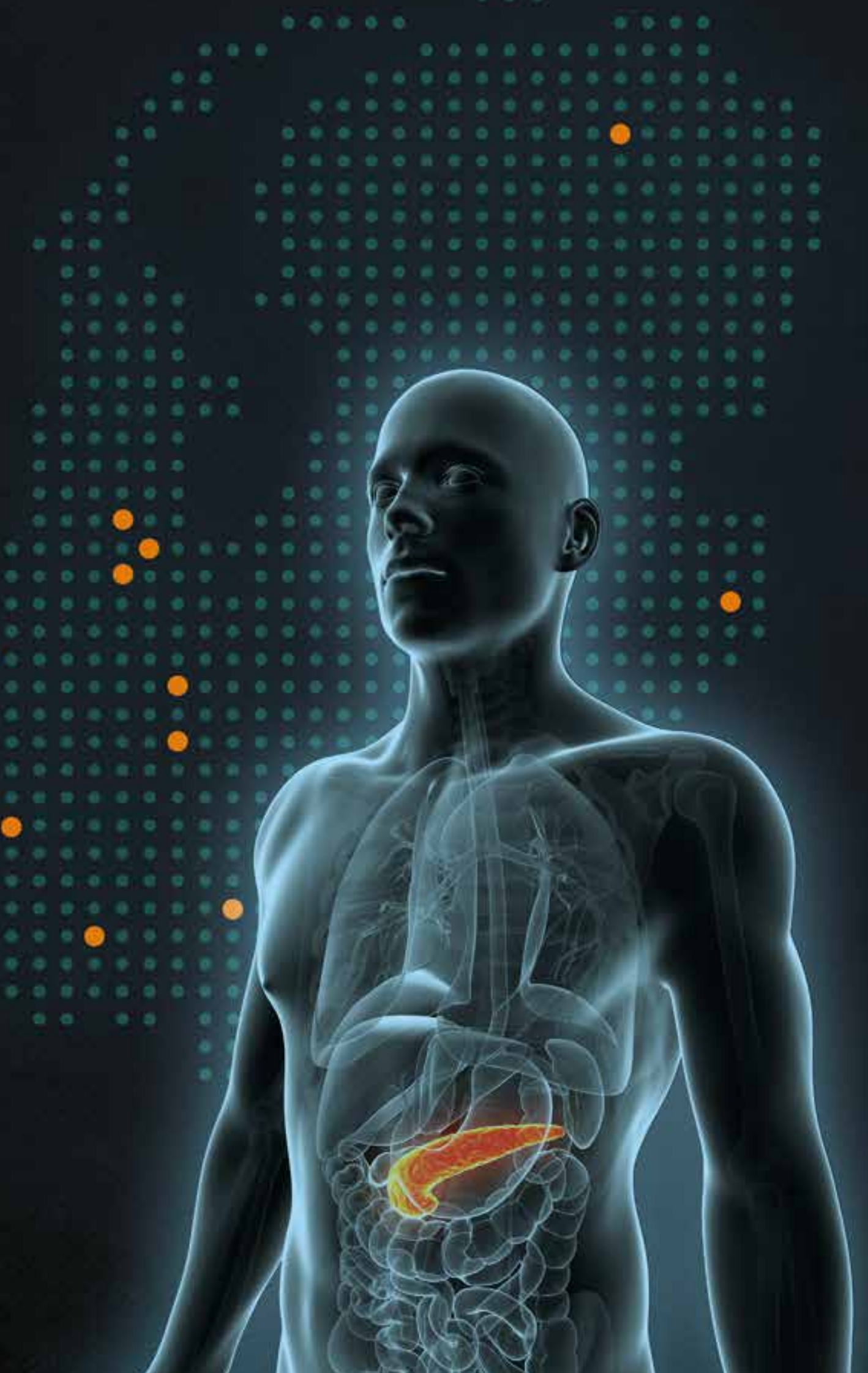

00080000000000000

0.00000000000000

0.000 .00 .0

0.0000000

$\ldots$

0000000000

Q

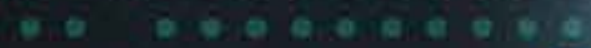

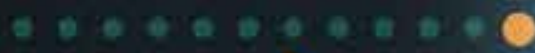

0.0000000008

0.000 .0 .00

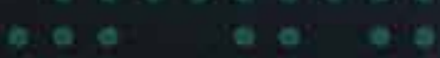

$\ldots$

a: 


\section{VALORIZATION}




\section{VALORIZATION}

\section{INTRODUCTION}

This thesis describes several aspects of the surgical treatment of pancreatic cancer in the Netherlands. The aim was to identify variation and possible reasons for variation in preoperative, operative and postoperative treatment of non-metastasized pancreatic cancer in the Netherlands. By addressing these reasons for variation, and thereby reducing variation between centers, pancreatic cancer care may be improved.

\section{SOCIAL AND ECONOMIC RELEVANCE OF SCIENTIFIC RESULTS}

Pancreatic cancer is known for its poor survival. Optimal treatment consists of surgical resection with adjuvant chemotherapy. ${ }^{1}$ Survival is likely to increase by combining these therapies. ${ }^{2}$ The current thesis provides insights in treatment variations between centers in the Netherlands and answers the question which factors influence the likelihood for surgical treatment and adjuvant chemotherapy treatment in patients without metastatic disease. By knowing these influences, clinicians can optimize the selection process for pancreatoduodenectomy and possibly reduce the variation in treatment. Subsequently, the number of patients treated with curative intention may be increased.

A pancreatoduodenectomy, the surgical treatment for most types of pancreatic cancer, is known as a procedure with a relatively high morbidity rate. ${ }^{1}$ Preoperatively identifying high-risk patients might result in the ability to improve the selection of patients fit for surgery. This thesis suggests that muscle radiation attenuation assessment at preoperative CT scans may be a useful tool to detect cachexia prior to surgery. Furthermore, the current thesis shows that a relatively high percentage of patients still undergo preoperative biliary drainage, resulting in a higher rate of complications compared to early surgery. ${ }^{3}$ These insights provide arguments for clinicians to optimize the current care pathways.

The costs of a pancreatoduodenectomy are substantial, with a median of around $€ 17.500$ if no complication occurs. The total hospital costs will increase with $34 \%$ up to $71 \%$ if complications occur. ${ }^{4}$ This can be an additional argument for optimizing perioperative care. Improving pancreatic cancer care for elderly patients might lead to more elderly patients being selected for surgical treatment and thereby may reduce variation in care. ${ }^{5,6}$ This thesis showed that an enhanced recovery pathway is feasible in elderly patients. 
If postoperative recovery in elderly patients is improved, it might lead to more patients being treated with adjuvant chemotherapy following the Dutch guidelines. ${ }^{7}$ In this thesis it is shown that the ERAS principles can be safely applied to the elderly population.

\section{TARGET POPULATION}

Results of this thesis are relevant for patients and clinicians involved in the treatment of pancreatic cancer. It provides insights in the current variation in care and gives suggestions on how to reduce this variation in patients with non-metastasized pancreatic-cancer.

\section{INNOVATION AND FUTURE}

Pancreatic centers in the Netherlands collaborate in the Dutch Pancreatic Cancer Group (DPCG). Research in pancreatic cancer, such as the Dutch Pancreatic Cancer Project (PACAP), is initiated and coordinated by this national panel of experts consisting of oncological surgeons, oncologists, gastroenterologists, radiologists, radiation therapists, pathologists, specialized nurses and dieticians. PACAP includes prospective data registration, a pancreatic biobank, and clinical studies.

This thesis showed that patients diagnosed in a specialized pancreatic center had a twofold higher likelihood for undergoing surgical resection, which suggests that an upto-date level of knowledge is necessary to provide an optimal diagnostic and treatment procedure. ${ }^{8}$ Ideally, each patient receives the best of care independent of hospital of diagnosis or hospital of treatment. Also quality-of-life should be addressed in pancreatic cancer patients. ${ }^{9}$ Psychological and social support may improve postoperative quality-oflife and optimize fitness of a patient to undergo treatment. ${ }^{9,10}$

Non-specialized centers and specialized centers should be able to share patient data and discuss the best treatment options for each patient. This might be achieved in regional multidisciplinary tumor boards with easy access to expert opinions. It can reduce the number of patients undergoing preoperative biliary drainage and it will most probably increase the number of patients undergoing surgical resection and adjuvant chemotherapy. Examples of regional expert teams in the Netherlands are Oncozon, EMBRAZE and GIOCA. ${ }^{11,12}$ 


\section{REFERENCES}

1. Vincent A, Herman J, Schulick R, Hruban RH, Goggins M. Pancreatic cancer. Lancet. 2011;378(9791):607-20.

2. Oettle H, Neuhaus P, Hochhaus A, Hartmann JT, Gellert K, Ridwelski K, et al. Adjuvant chemotherapy with gemcitabine and long-term outcomes among patients with resected pancreatic cancer: the CONKO-001 randomized trial. JAMA. 2013;310(14):1473-81.

3. van der Gaag NA, Rauws EA, van Eijck CH, Bruno MJ, van der Harst E, Kubben FJ, et al. Preoperative biliary drainage for cancer of the head of the pancreas. $N$ Engl J Med. 2010;362(2):129-37.

4. Santema TB, Visser A, Busch OR, Dijkgraaf MG, Goslings JC, Gouma DJ, et al. Hospital costs of complications after a pancreatoduodenectomy. HPB (Oxford). 2015;17(8):723-31.

5. van der Geest LG, Besselink MG, Busch OR, de Hingh IH, van Eijck CH, Dejong CH, et al. Elderly Patients Strongly Benefit from Centralization of Pancreatic Cancer Surgery: A Population-Based Study. Ann Surg Oncol. 2016;23(6):2002-9.

6. van der Geest LG, Besselink MG, van Gestel YR, Busch OR, de Hingh IH, de Jong KP, et al. Pancreatic cancer surgery in elderly patients: Balancing between short-term harm and longterm benefit. A population-based study in the Netherlands. Acta Oncol. 2016;55(3):278-85.

7. Oncoline. Pancreascarcinoom: Netherlands Comprehensive Cancer Organisation (IKNL); 2011 [updated 2011-08-22. Available from: http://www.oncoline.nl/pancreascarcinoom.

8. Walters DM, Lapar DJ, de Lange EE, Sarti M, Stokes JB, Adams RB, et al. Pancreas-protocol imaging at a high-volume center leads to improved preoperative staging of pancreatic ductal adenocarcinoma. Ann Surg Oncol. 2011;18(10):2764-71.

9. Lewis AR, Pihlak R, McNamara MG. The importance of quality-of-life management in patients with advanced pancreatic ductal adenocarcinoma. Curr Probl Cancer. 2018;42(1):26-39.

10. Arvaniti M, Danias N, Igoumenidis M, Smyrniotis V, Tsounis A, Sarafis P. Comparison of Quality of Life before and after pancreaticoduodenectomy: a prospective study. Electronic physician. 2018;10(7):7054-62.

11. GIOCA. [Available from: https://www.amc.nl/web/specialismen/kankerzorg-oncologischcentrum/gastro-intestinaal-oncologisch-centrum-amsterdam-gioca.htm.

12. OncoZON. [Available from: https://www.oncozon.nl. 
Q 810

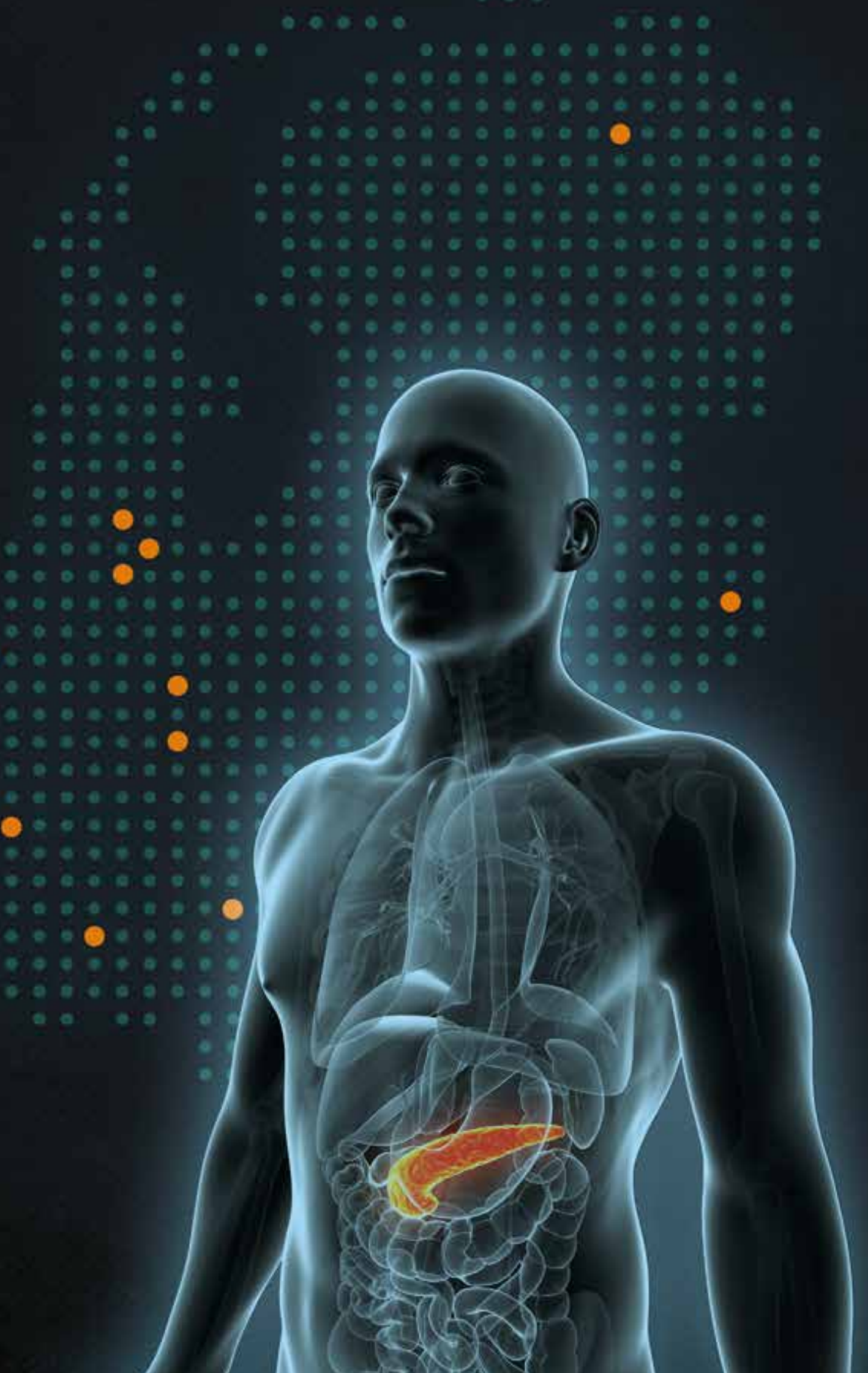

00080000000000000

0.00000000000000

0.000 .00 .0

0.0000000

$\ldots$

0000000000

Q

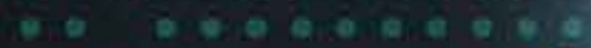

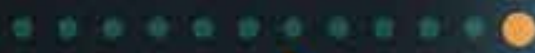

0.0000000008

0.000 .0 .00

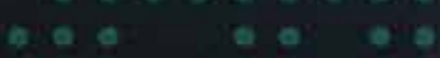

$\ldots$

a: 


\section{NEDERLANDSE SAMENVATTING}




\section{NEDERLANDSE SAMENVATTING}

Kanker van de alvleesklier kent een erg slechte prognose. De vijf jaar overleving is maar zo'n $7 \%$. Chirurgische resectie biedt de enige kans op genezing of op zijn minst langdurige overleving, en is alleen mogelijk als een patiënt geen uitgezaaide ziekte heeft. Bij voorkeur wordt een operatie gevolgd door een behandeling met systemische chemotherapie.

Dit proefschrift heeft als doel om de variatie binnen Nederlandse ziekenhuizen in de behandeling van patiënten met alvleesklierkanker te onderzoeken. Verder wordt onderzocht welke factoren mogelijk invloed hebben op een variatie in zorg.

In hoofdstuk 2 hebben we aangetoond dat patiënten met niet uitgezaaide alvleesklierkanker een grotere kans hebben op een chirurgische behandeling als ze worden gediagnostiseerd in een ziekenhuis waar ook chirurgische behandeling mogelijk is. Bij diagnose in een ziekenhuis waar geen alvleesklier chirurgie mogelijk is, is de kans op een chirurgische behandeling in een van de alvleesklier centra dus significant kleiner. Wellicht speelt de ervaring in behandeling van alvleesklierkanker van het volledige multidisciplinaire team hierbij een rol. Het lijkt van belang om elke patiënt reeds in een vroeg stadium te bespreken in een multidisciplinair team dat voldoende ervaring heeft met de stadiering en behandeling van alvleesklierkanker. Op die manier kan de zorg voor deze patiënten verder verbeterd worden. In hoofdstuk 2 zien we tevens dat patiënten boven de 70 jaar een kleinere kans hadden om geopereerd te worden.

Geelzucht is een van de klachten waar patiënten met alvleesklierkanker zich mee kunnen presenteren. Die geelzucht wordt meestal veroorzaakt door obstructie van de galwegen door de alvleeskliertumor. Door een stent in de galwegen te plaatsen, kan de geelzucht verminderd worden, men noemt dit biliaire drainage. Het was lange tijd gebruikelijk om bij geelzucht de galwegen te draineren voorafgaand aan een operatie en daarmee de geelzucht te verminderen. Een gerandomiseerd onderzoek heeft echter aangetoond dat dit leidt tot meer complicaties vergeleken met geen drainage en op korte termijn opereren. In hoofdstuk 3 hebben we onderzocht bij hoeveel procent van de alvleesklierkanker patiënten met geelzucht de galwegen nog gedraineerd worden voorafgaand aan een operatie. Daarbij is tevens gekeken naar wat de reden hiervoor was. We zagen dat het 
merendeel van de patiënten nog gedraineerd werd in plaats van spoedig te opereren zonder drainage. Hiervoor was meestal geen duidelijke medische reden. Wellicht dat het niet altijd haalbaar was om op korte termijn een operatie in te plannen. De meeste patiënten werden gedraineerd voor verwijzing naar een alvleeskliercentrum, in een ziekenhuis waar geen alvleesklierchirurgie mogelijk is. Maar ook tussen de ziekenhuizen waar alvleesklierchirurgie wel mogelijk is, was er een significant verschil in het toepassen van galwegdrainage.

Hoofdstuk 4 laat zien dat er ook na een operatie variatie is in de behandeling van patiënten met alvleesklierkanker. Postoperatief wordt behandeling met chemotherapie geadviseerd voor een betere overleving, men noemt dit adjuvant chemotherapie. We zagen dat het percentage patiënten dat behandeld werd met chemotherapie na een alvleesklieroperatie verschilt tussen de alvleeskliercentra in Nederland. Vooral oudere patiënten hadden een lagere kans op adjuvant chemotherapie, net als patiënten met een laag tumorstadium. Echter, ook bij deze patiënten kan adjuvant chemotherapie leiden tot een betere overleving. Artsen dienen dus niet te terughoudend te zijn met het voorschrijven van adjuvant chemotherapie.

In hoofdstuk 5 wordt onderzocht wat de invloed is van de sociaal economische status op de kans voor een chirurgische behandeling bij alvleesklierkanker in Nederland. We weten dat in de Verenigde Staten patiënten met een laag sociaal economische status een lagere kans hebben op een chirurgische behandeling. Het blijkt dat dit ook geldt voor patiënten in Nederland. Patiënten met een laag sociaal economische status hadden een lagere kans op een chirurgische behandeling. Dit is opvallend bij een Nederlands zorgstelsel waarin geen verschil gemaakt wordt in sociaal economische status en de zorg voor iedereen gelijk toegankelijk is. Mogelijk wordt het verklaard door verschillen in leefstijl die patiënten met een laag sociaal economische status minder geschikt makt voor een uitgebreide chirurgische ingreep. Artsen dienen zich bewust te zijn van deze verschillen.

Om na een operatie het herstel te bevorderen, is er een protocol samengesteld, het zogenaamde ERAS (Enhanced Recovery After Surgery) protocol. Patiënten die sneller hersteld zijn van een operatie komen wellicht ook eerder in aanmerking voor aanvullende 
behandelingen. Het ERAS protocol is al effectief gebleken bij patiënten onder de 70 jaar oud. In hoofdstuk 6 tonen we aan dat het ERAS protocol ook effectief en veilig is bij patiënten boven de 70 jaar oud. Ook oudere patiënten hebben overlevingsvoordeel van een operatie bij alvleesklierkanker en een spoedig herstel middels het ERAS protocol. Een verbetering in het postoperatieve herstel van oudere patiënten leidt wellicht tot minder terughoudendheid om deze patiëntengroep te opereren en tot meer patiënten die behandeld kunnen worden met adjuvant chemotherapie.

De besluitvorming om al dan niet te opereren, kan wellicht verbeterd worden als we de kans op complicaties na een operatie beter kunnen voorspellen. In hoofdstuk 7 hebben we verschillende lichaamseigenschappen bekeken door het verrichten van metingen op de CT-scan die verricht zijn voor de operatie en beoordeelt of deze van invloed is op de uitkomsten na chirurgie. Deze studie laat zien dat verminderde inkleuring van de skeletspieren op een CT-scan (mogelijk op basis van vervetting) geassocieerd is met een slechtere overleving bij alvleesklierkanker. Patiënten met alvleesklierkanker kunnen in een slechte voedingstoestand zijn, we noemen dit cachexie. Het preoperatief beoordelen van de mate van cachexie kan nuttig zijn in de overweging om al dan niet chirurgisch te behandelen of om de voedingstoestand eerst te verbeteren.

In dit proefschrift zijn verschillende aspecten belicht die leiden tot een variatie in de zorg van alvleesklierkanker in Nederland. Tijdige bespreking van patiënten in een multidisciplinair expert team en verdere optimalisatie van preoperatieve en postoperatieve zorgpaden leidt in de toekomst hopelijk tot minder variatie en een optimalisatie van de zorg van alvleesklierkanker in Nederland. 
Q 810

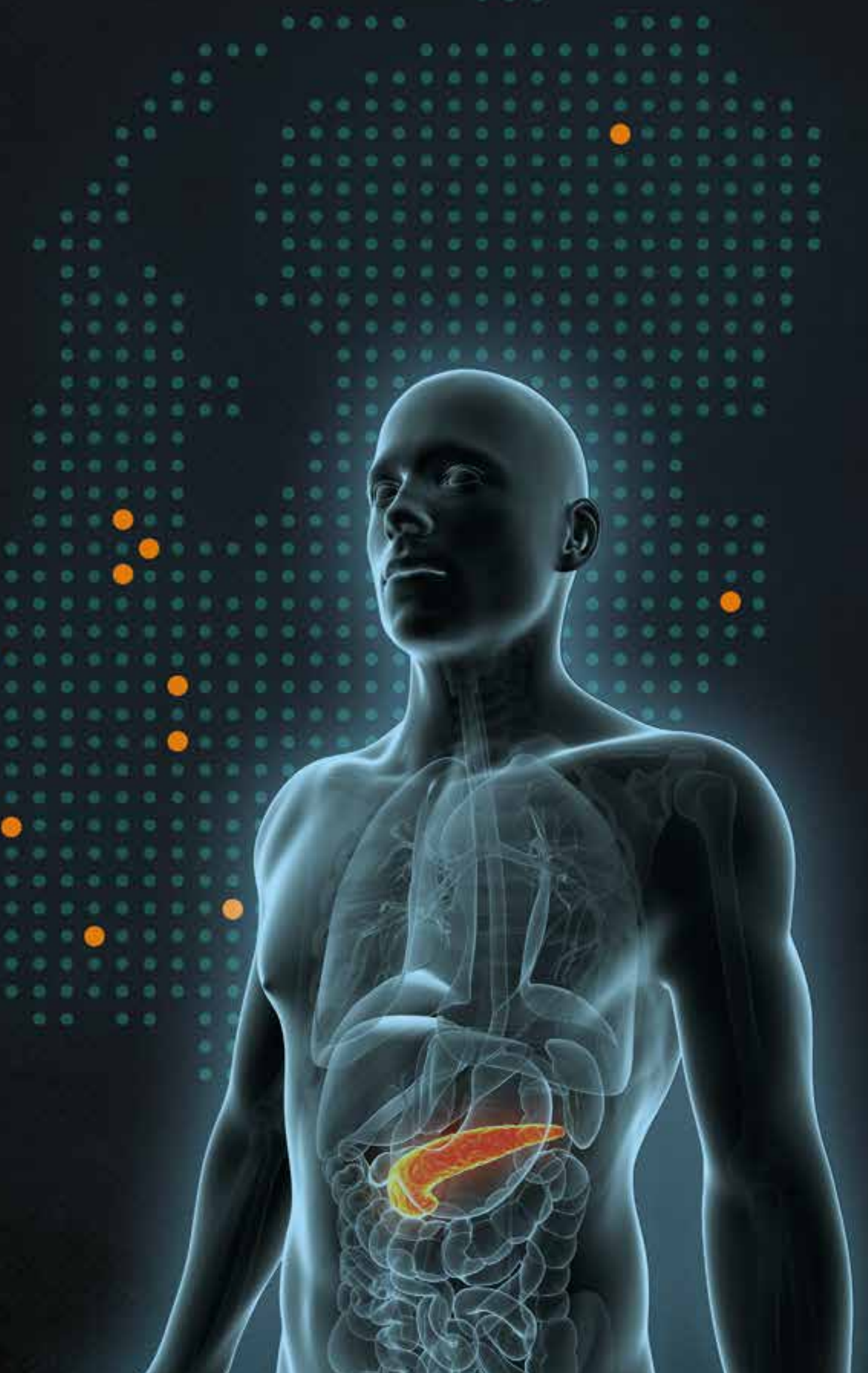

00080000000000000

0.00000000000000

0.000 .00 .0

0.0000000

$\ldots$

0000000000

Q

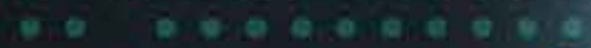

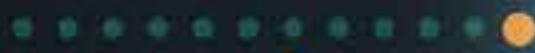

0.0000000008

0.000 .0 .00

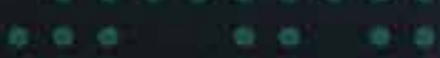

$\ldots$

a: 


\title{
APPENDICES
}

\author{
PUBLICATIONS \\ CURRICULUM VITAE \\ DANKWOORD
}




\section{PUBLICATIONS}

\section{PUBLICATIONS INCLUDED IN THIS THESIS}

M.J.A.M. Bakens, L.B. van Rijsen, V. van Woerden, M.H.C. Besselink, D. Boerma, O.R. Busch, C.H.C. Dejong, M.F. Gerhards, Y. Keulemans, J.M. Klaase, M.D. Luyer, I.Q. Molenaar, W. Steen, D.S. Tseng, D.J. Gouma, I.H.J.T. de Hingh.

Evaluation of preoperativebiliarydrainage in patients undergoing pancreatoduodenectomy for suspected pancreatic or periampullary cancer. (2018) JOP; 2018 Jan 29; 19(1):1-6

M.J.A.M. Bakens, VEPP Lemmens, IHJT de Hingh.

Socio-economic status influences the likelihood of undergoing surgical treatment for pancreatic cancer in the Netherlands. (2017) HPB; DOI: 10.1016/j.hpb.2017.01.010

D.P.J. van Dijk, M.J.A.M. Bakens, M.M.E. Coolsen, S.S. Rensen, R.M. van Dam, M.J.L. Bours, M.P. Weijenberg, C.H.C. Dejong, S.W.M. Olde Damink.

Low skeletal muscle radiation attenuation and visceral adiposity are associated with overall survival and surgical site infections in patients with pancreatic cancer. (2016) Journal of Cachexia, Sarcopenia and Muscle; DOI: 10.1002/jcsm.12155

M.J.A.M. Bakens, L.G. van der Geest, M. van Putten, HW van Laarhoven, GJ Creemers, MG Besselink, VE Lemmens, IH de Hingh. Dutch Pancreatic Cancer Group.

The use of adjuvant chemotherapy for pancreatic cancer varies widely between hospitals: a nationwide population-based analysis. (2016) Cancer Med; DOI: 10.1002/cam4.921

M.J.A.M. Bakens, Y.R.B.M. van Gestel, M. Bongers, M.G.H. Besselink, C.H.C. Dejong, I.Q. Molenaar, O.R.C. Busch, V.E.P.P. Lemmens, I.H.J.T. de Hingh; On behalf of the Dutch Pancreatic Cancer Group (DPCG). Hospital of diagnosis and likelihood of surgical treatment for pancreatic cancer. (2015) British Journal of Surgery DOI: 10.1002/bjs.9951 
M.M.E. Coolsen, M. Bakens, R.M. van Dam, S.W.M. Olde Damink, C.H.C. Dejong. Implementing an enhanced recovery programme after pancreaticoduodenectomy in elderly patients - is it feasible? (2014) World J Surg DOI: 10.1007/s00268-014-2782-x

\section{OTHER PUBLICATIONS}

K. de Mooij, M.J.A.M. Bakens, E. De Loos, J. Stoot.

A common procedure with a rare anatomical finding: a case report on a true left-sided galbladder. (2018) J Vis Surg; DOI: 10.21037/jovs.2018.08.07 


\section{CURRICULUM VITAE}

Maikel Bakens was born with his twin sister Steffanie in Weert, the Netherlands on the 16th of November 1989. In 2008 he graduated from Bisschoppelijk College secondary school and started studying medicine at Maastricht University.

During his studies he did an internship in Tygerberg hospital in Cape Town, South-Africa and he started doing research at

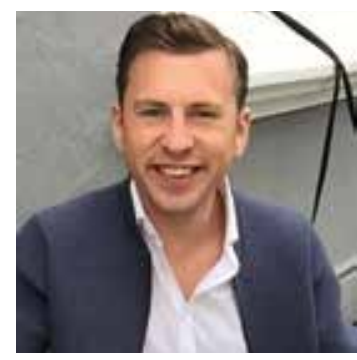
the department of Surgery, Maastricht University Medical Center, under supervision of Prof. dr. CHC Dejong, Dr. RM van Dam and Dr. MME Coolsen.

In 2014 he obtained his medical degree after which he started working as a researcher in hepato-pancreato-biliary surgery under supervision of Prof. dr. IHJT de Hingh at the Catharina Hospital in Eindhoven and Prof. dr. VEPP Lemmens at the Netherlands Comprehensive Cancer Organisation (IKNL). His research mainly focused on variation in care of pancreatic cancer in the Netherlands and lead to several (inter)national conference contributions including oral presentations at the Grassi prize session at the World Congress of Surgery (2015, Bangkok, Thailand), the ESMO World Congress on Gastrointestinal Cancer (2015, Barcelona, Spain), the European-African Hepato Pancreato Biliary Association (2015, Manchester, UK) and the Dutch society for Surgery ( $\mathrm{NVvH}, 2015$, Veldhoven). This research including a number of publications formed the basis of this thesis.

From July 2015 until February 2016 Maikel worked as a resident at the intensive care department at the Catherina Hospital in Eindhoven. In March 2016 he started as a resident not in training in surgery at the Zuyderland Medical Center in Heerlen and Sittard-Geleen. In January 2018 he started his surgical training in the same hospital under the supervision of Dr. M. Sosef. 


\section{DANKWOORD}

Het is zover! Mijn boekje is af! Het was niet altijd makkelijk om de kliniek te combineren met het onderzoek, maar wat ben ik blij dat het nu af is.

Zonder de onuitputtelijke steun van mijn promotoren, medeauteurs, collega's, vrienden en familie was dit nooit gelukt.

Allen ontzettend bedankt!

Prof. dr. I.H.J.T. De Hingh, beste Ignace, na mijn afstuderen kreeg ik de kans om onder jouw leiding onderzoek te doen in het Catharina ziekenhuis en bij IKNL. Naast de drukke kliniek wist je altijd tijd vrij te maken voor je onderzoekers. Samen namen we mijn manuscripten met de 'Bakens'-taal kritisch door. Maar ook als het om persoonlijke dingen ging, had je altijd een luisterend oor.

We maakten wel eens geintjes over of en wanneer je professor zou worden, ik was ervan overtuigd dat het je zou lukken en hier staan we dan. Ik ben ontzettend trots dat ik als eerste promovendus bij jou als professor mijn verdediging mag houden en ben ervan overtuigd dat er nog vele zullen volgen. Ignace, ontzettend bedankt.

Prof. dr. V.E.P.P. Lemmens, beste Valery, ik denk met veel plezier terug aan onze samenwerking. De manier waarop jij met veel positiviteit leiding geeft aan het onderzoek binnen IKNL kan ik erg waarderen. Bedankt!

Prof. dr. C.H.C. Dejong, beste Kees, tijdens mijn studie ben ik begonnen met mijn onderzoek onder jouw supervisie. Maar ook bij het vinden van mijn eerste baan en de sollicitatie voor de opleiding heelkunde ben je altijd van grote steun geweest. Ontzettend bedankt voor al je inspanningen, je bent een groot voorbeeld voor me.

Dr. R. van Dam, Ronald en Dr. M.M.E. Coolsen, Mariëlle, jullie staan aan de basis van mijn proefschrift. Als student ben ik bij jullie begonnen met het doen van onderzoek. Ik denk met veel plezier terug aan onze samenwerking en de congressen (en kroegen) die we samen bezocht hebben, met Seoul als hoogtepunt! 
Medeauteurs bedankt voor jullie inzet bij mijn publicaties. In het bijzonder Prof. dr. M.G.H. Besselink, Marc, ik heb veel respect voor hoe je vol enthousiasme je onderzoektaken uitvoert. Je reageert altijd vliegensvlug met inhoudelijk goede feedback op de manuscripten. Bedankt!

De leden van de beoordelingscommissie, voorzitter Prof. dr. N.D. Bouvy, Prof. dr. N.L.U. van Meeteren, Prof. dr. S. Siesling en Dr. J.H.M.B. Stoot bedankt voor jullie inzet om mijn proefschrift kritisch te beoordelen.

Erik, fantastisch dat jij mijn paranimf bent! We kunnen uren praten over de fratsen die we hebben uitgehaald, maar ook bij minder leuke dingen zijn we er voor elkaar. Onze reizen naar Noorwegen, Istanbul en Marokko waren hoogtepunten. Crossend op een quad door de woestijn en onze levendige gesprekken met de Turske agenten tijdens oud en nieuw, ik denk er vaak lachend aan terug. Bedankt voor de mooie tijden en op naar nieuwe herinneringen!

Pieter, aka Kempie! Ze noemden ons wel eens Peppi en Kokki. Ik ben ontzettend blij met jou als paranimf. In 2008 leerden we elkaar kennen tijdens onze allereerste onderwijsgroep aan de universiteit. Van samen studeren, het snijzaal practicum tot de rode kruisjes, met jou is het altijd feest. Onze humor begrijpt lang niet iedereen maar gelukkig kunnen we er zelf het hardst om lachen. Tijdens onze vakanties in Cuba en Thailand/Cambodja maakten we de gekste situaties mee, met vooral erg bijzondere types. Dat er nog vele feestjes en vakanties, beginnend in rij 23 met een gin tonic, mogen volgen!

Collega's van IKNL, bedankt voor de gezellige momenten. Zonder de inzet van de datamanagers die alle data registreren, was dit proefschrift niet mogelijk geweest. Jullie doen ontzettend goed werk!

Collega's van de Dutch Pancreatic Cancer Group (DPCG), jullie zijn een prachtig voorbeeld van hoe samenwerking op landelijk niveau een verschil kan maken. Collega onderzoekers bedankt voor de leuke sfeer tijdens de congressen! Rio en Sao Paulo waren voor mij een hoogtepunt! 
De maatschap chirurgie, arts-assistenten, mede-onderzoekers en collega's van de intensive care van het Catharina ziekenhuis in Eindhoven. Bedankt voor de mooie tijd die ik bij jullie gewerkt heb!

Graag wil ik ook de chirurgen werkzaam bij de maatschap chirurgie in het Zuyderland Medisch Centrum bedanken. Alfred, Annette, Atilla, Berry, Clarissa, Els, Eric, Erik, Evert-Jan, James, Jan, Jan Willem, Karel, Kees-Jan, Lee, Meindert, Paul, Raoul, Rob, Sofie, Ton en Yvonne, ik vind het geweldig dat ik onder jullie supervisie mijn opleiding kan volgen. Ik heb ontzettend veel plezier in mijn werk mede dankzij jullie inzet.

Semi-artsen, PA's, Arts-assistenten, en CHIVO's van de afdeling chirurgie van het Zuyderland Medisch Centrum, wat ben ik blij dat ik met jullie mag werken! Mede dankzij jullie ga ik elke dag met een grote lach naar mijn werk. Bedankt voor de collegialiteit en vooral ook de gezelligheid. Dat er nog vele borrels in ST, feestjes en winterbijscholingen mogen volgen. Eén voor allen en allen voor één!

Floor, of zoals ik je vaak noem Florentyna! We hebben elkaar leren kennen in het Zuyderland en sindsdien zijn we onafscheidelijk. Na een weekend zitten we allebei weer vol met verhalen die gedeeld moeten worden. Ik hoop dat we nog lang samen mogen werken en wijntjes kunnen drinken. Je bent een topper!

Mannen van Capitargos! We wonen inmiddels allemaal ver uit elkaar, maar ik ben blij dat we zo nu en dan weer een avond als vanouds kunnen beleven. Jullie hebben mijn studententijd tot een waanzinnig mooie tijd gemaakt, bedankt.

Jorien, jij bent mijn partner in crime. Ik kan me niet voorstellen hoe een feestje zonder jou is. Wat hebben we veel meegemaakt en gelachen. Wachtend op een slotenmaker die de verkeerde postcode gekregen had of brak in de trein naar huis, het maakte allemaal niet uit, want wij waren samen. Ik hoop dat we nog veel mooie momenten gaan meemaken.

Mijn sportmaatje Philippe! Zonder jou zou mijn weg naar de sportschool een stuk lastiger en saaier zijn. Als ik zeg 'dit is écht de laatste oefening' weet jij me toch weer te 
motiveren om er nog een bij te doen. Gelukkig kunnen we daarna snel het terras op voor onze welverdiende lunch. Thanks voor je doorzettingsvermogen en gezelligheid!

Naomi! Kemp en ik hebben je leren kennen tijdens onze reis in Cuba en ik ben onwijs blij met de mooie band die we hebben opgebouwd. Ik heb veel respect voor hoe jij je gevoel volgt. De feestjes in Amsterdam en onze reünie in Parijs waren onvergetelijk, er komen vast nog veel mooie herinneringen bij!

Lieke, Emilie en Malou bedankt voor de hilarische momenten die we samen hebben meegemaakt. De blik op het gezicht van de brandweermannen die mijn wc-deur moesten openbreken na een avond stappen, zal ik nooit vergeten.

Maar ook de weekendjes weg met Lieke waren onvergetelijk, wat hebben we gelachen. Ik wil nog veel van dit soort avonden met jullie beleven dames!

Bart, Johnny, Pim, Stijn, Luuk, Pieter, Sanne, Eva, Maud, Oana en Jorien, zonder jullie zou de zomer er heel anders uit zien! Wat een feest om met jullie te partyen. Ho even, er moeten nog veel van dit soort dagen volgen. Absoluut!

Stephan en Benjamin, mooi hoe we elkaar hebben leren kennen en regelmatig de beest uit hangen! Stephan, je bent voor mij een extra drijfveer geweest om dit boekje af te ronden. Thanks voor alle mooie tijden!

De kruisjes, Feline, Eline, Marleen, Pieter en Joris. Wat begon als een studentenbestuur, werd al snel een groep hechte vrienden. Wat hebben we gelachen met de pisco's bij de bruiloft van Feline en onze reis door Peru. Recent de bruiloft van Eline, wat was het geweldig om weer met zijn allen samen te zijn. Dat er nog veel feestjes mogen volgen want ik mis ons geblaf. Woef woef!

Bedankt aan mijn vrienden in Amsterdam, Robbert en Olivier, Bram, Maarten, Marc en Eric, onze vriendschap is me erg dierbaar. Het is geweldig om met jullie Amsterdam te verkennen. Robbert, we kennen elkaar sinds onze studies in Maastricht en het is altijd als vanouds als we elkaar weer zien. Of dat nou in Amsterdam is of tijdens de carnaval in Mestreech. Bedankt! 
Ook mijn vrienden in Rotterdam, onwijs bedankt voor jullie steun. Jeroen en Jeroen, ik heb erg genoten van onze hardloopsessies met daarna meestal een goed glas wijn. Berlijn vormde een hoogtepunt! Marc en Niels, Pieter en Kari, Koen en Pieter Jan, Robert, Femke, en John en Taco, ik ben ontzettend blij dat ik nu al een aantal jaren de kerstavond met jullie mag doorbrengen. Wat een gezelligheid! John en Taco, wat zijn jullie warme mensen! Ik ben ontzettend blij met onze vriendschap, dat er nog veel gezellige avonden mogen volgen.

Familie Bakens en familie Schonkeren, bedankt voor jullie interesse en steun. In het bijzonder mijn peettante Mieke, ik kan onze etentjes erg waarderen. Laten we dit erin houden!

Jan en Mirande, John en Ryan, ik ben blij dat we zo'n goede band hebben en ondanks dat we niet bij elkaar om de hoek wonen, toch regelmatig met zijn allen bij elkaar komen. Jan en Mirande, het mag misschien halfbroer en halfzus heten, het voelt als broer en zus!

Nog geen vijf minuten nadat ik voet op deze aarde had gezet was jij daar, mijn tweelingzusje Steffanie! Wat ben ik ontzettend blij met jou. Samen hebben we tot en met zes VWO bij elkaar in de klas gezeten en konden we alles aan. Het verbaasde niemand dat we na ons middelbaar dezelfde opleiding gingen doen, geneeskunde. Niet meer in dezelfde stad, maar desondanks blijven we elkaar regelmatig zien. Ik ben ontzettend trots op je.

Pap en mam, mijn trotse ouders! Wat heb ik een ontzettend fijne jeugd gehad. En dankzij jullie onvoorwaardelijke steun heb ik dit boekje tot een goed einde kunnen brengen. Ik heb jullie meermaals verbaasd en enigszins bezorgd zien kijken als ik weer iets nieuws bedacht had. 'Je motor rijbewijs?!', of recent 'de Kilimanjaro beklimmen? Hoe kom je daar nou weer bij?!' Maar al snel kunnen we er om lachen en kan ik altijd op jullie steun rekenen. Jullie zijn toppers, ik hou van jullie. 
2. $8 \sin ^{2}$

0.18

a. 8

c.

8

Q 18

0.0

a 2

a) 0

$\cos \theta \mathrm{ge}$

a a sing

9. 0 gira 0

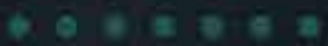

4. 0 ang ard a

a a o:a:s, a

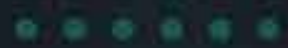

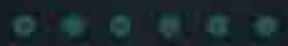

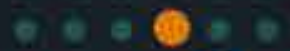

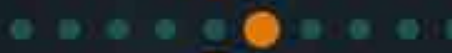

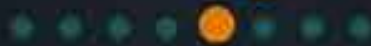

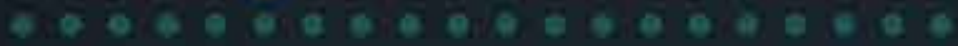

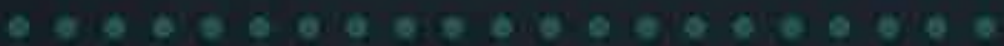

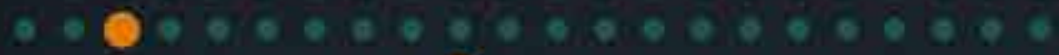

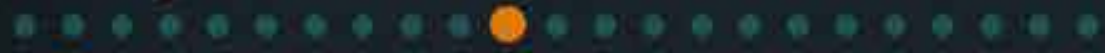

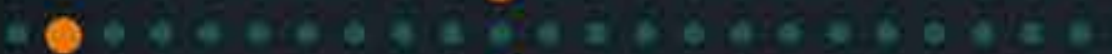

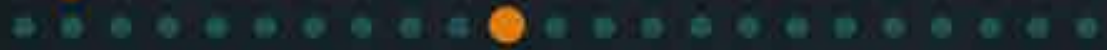

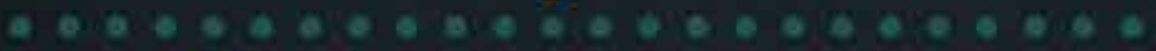

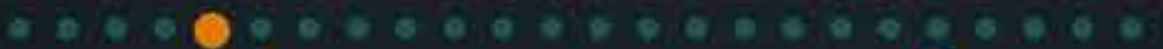

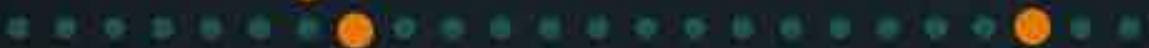

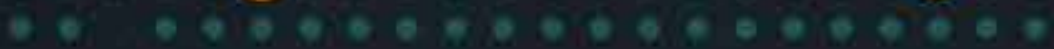
a

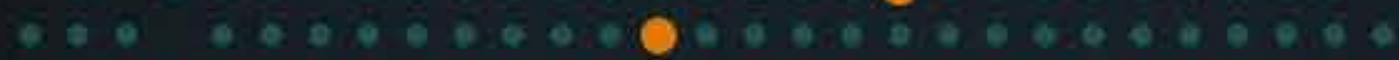

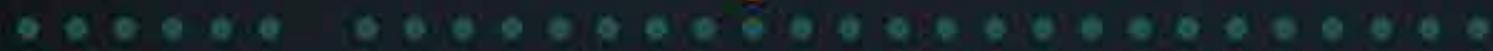

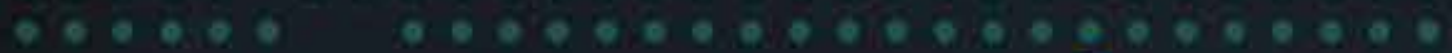
a a ra
D. 010

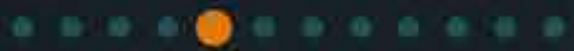

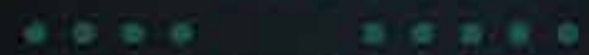

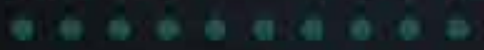

a

gin a 8

aire 2

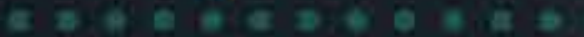

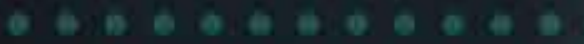

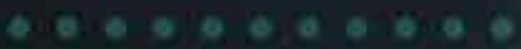

Q. 8,0 , a n

Q a d a d a

$\cos 2 \mathrm{se}$

a $\mathrm{a}$.

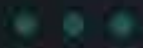

(4. 0.9 .0

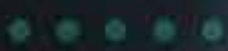

C) 0.016 